JOSÉ CARLOS GONÇALVES PERES

\title{
ANÁLISE DE UM REATOR FOTOQUÍMICO ANULAR USANDO A FLUIDODINÂMICA COMPUTACIONAL
}




\section{JOSÉ CARLOS GONÇALVES PERES}

\section{ANÁLISE DE UM REATOR FOTOQUÍMICO ANULAR USANDO A FLUIDODINÂMICA COMPUTACIONAL}

Dissertação apresentada à Escola Politécnica da Universidade de São Paulo para obtenção do Título de Mestre em Ciências. 


\section{JOSÉ CARLOS GONÇALVES PERES}

\section{ANÁLISE DE UM REATOR FOTOQUÍMICO ANULAR USANDO A FLUIDODINÂMICA COMPUTACIONAL}

Dissertação apresentada à Escola Politécnica da Universidade de São Paulo para obtenção do Título de Mestre em Ciências.

Área de Concentração:

Engenharia Química

Orientador:

Prof. Dr. Ardson dos Santos Vianna Jr. 
Este exemplar foi revisado e corrigido em relação à versão original, sob responsabilidade única do autor e com a anuência de seu orientador.

São Paulo, 13 de maio de 2013.

Assinatura do autor

Assinatura do orientador

\section{FICHA CATALOGRÁFICA}

Peres, José Carlos Gonçalves

Análise de um reator fotoquímico anular usando a fluidodinâmica computacional / J.C.G. Peres. -- versão corr. -- São Paulo, 2013.

$125 \mathrm{p}$.

Dissertação (Mestrado) - Escola Politécnica da Universidade de São Paulo. Departamento de Engenharia Química.

1. Simulação 2. Mecânica dos fluidos computacional 3. Turbulência 4. Radiação ultravioleta I. Universidade de São Paulo. Escola Politécnica. Departamento de Engenharia Química II. t. 
Para minhas três avós: Vó Júlia, Vó Luzia e Tia Maria 


\section{AGRADECIMENTOS}

Aos meus pais, que sempre me estimulam a seguir meus sonhos e não poupam esforços para que eles se concretizem;

Ao meu orientador, Prof. Dr. Ardson dos Santos Vianna Jr. Em sua primeira orientação pela Universidade de São Paulo, este carioca me mostrou o o que é orientar um aluno efetivamente. Com sua ajuda, contornamos os percalços que surgiram ao longo do trabalho sem jamais duvidar de seu êxito. A amizade e o respeito que cultivamos um pelo outro foram fundamentais para conseguirmos cumprir todas as metas propostas para o projeto.

Aos Prof. Drs. Roberto Guardani, Antonio Carlos Silva Costa Teixeira e José Luís de Paiva, por terem acompanhado a evolução do trabalho e me ajudado a explorar ferramentas avançadas para simulação de equipamentos, contribuindo com as pesquisas do Centro de Engenharia de Sistemas Químicos da Escola Politécnica da USP;

Aos Profs. Drs. Reinaldo Giudici e Marcelo Martins Seckler, pelas valiosas sugestões e comentários no exame de qualificação, diretrizes para elevar a qualidade do trabalho;

À minhas amigas Kátia Ribeiro e Débora Pereira Coutinho da Silva. Sempre fui prestigiado com suas presenças em meus seminários, em muitos dos quais elas foram protagonistas ao me ajudar a fazer os famosos "aviõezinhos". Recebi muito apoio também durante as disciplinas de pós-graduação e na pesquisa sobre sistemas fotoquímicos;

À Silvia Martins Baeder, sempre solicita e carinhosa ao me atender quando necessário com as questões de TI e de manutenção dos softwares utilizados no trabalho;

Ao pessoal da Secretaria do Departamento de Engenharia Química, em particular a Alexandre Oliveira, Maria Elisete Alves Monteiro e Maria das Graças Alves de Sousa, pela ajuda com a documentação interna e organização para os congressos;

Ao CNPq, pelo apoio financeiro ao projeto. 


\section{RESUMO}

Os processos oxidativos avançados são promissores para a degradação de compostos orgânicos resistentes aos tratamentos convencionais, como o fenol. A fluidodinâmica computacional (CFD) tornou-se uma poderosa ferramenta para analisar processos fotoquímicos por resolver os balanços acoplados de quantidade de movimento, de massa e de radiação. $\mathrm{O}$ objetivo deste trabalho é investigar o processo $\mathrm{UV} / \mathrm{H}_{2} \mathrm{O}_{2}$ num reator fotoquímico anular usando CFD e um modelo cinético mais realista.

$\mathrm{O}$ modelo em CFD foi criado de forma progressiva. Inicialmente, foram determinados os campos de velocidade para três vazões $\left(30,60\right.$ e $\left.100 \mathrm{~L} \mathrm{~h}^{-1}\right)$. Considerou-se dois diâmetros de lâmpada para reproduzir a configuração experimental do sistema. A discretização foi feita com malhas tetraédricas variando entre 270000 e 1200000 elementos. Quatro modelos de turbulência RANS foram analisados: $k-\epsilon, k-\omega$, o Shear Stress Transport (SST) e o modelo de tensões de Reynolds (RSM). O campo de velocidades foi validado comparando a DTR com seu levantamento experimental.

A próxima etapa foi incluir o mecanismo de degradação de fenol proposto por Edalatmanesh, Dhib e Mehrvar (2008) no modelo em CFD. Trata-se de um modelo cinético baseado em equações dinâmicas para todas as espécies. O campo de radiação foi calculado pelo modelo radial e pela solução da equação de transporte de radiação através do método discrete transfer. As simulações reproduziram dados experimentais abrangendo uma larga gama de concentrações iniciais de fenol, razões molares $\mathrm{H}_{2} \mathrm{O}_{2}$ /fenol e três potências de emissão das lâmpadas.

O campo de velocidades obtido era dependente da vazão: o fluido pode manter movimento helicoidal sobre toda a extensão do reator ou se desenvolver como um escoamento pistonado. O modelo $k-\epsilon$ não reproduziu bem o escoamento por não ser adequado para escoamentos rotativos. Os outros modelos geraram curvas de DTR com bom ajuste aos dados experimentais, especialmente o modelo $k-\omega$.

O desvio médio entre as simulações de degradação de fenol e os dados experimentais é inferior a $8 \%$. Verificou-se que, devido ao escoamento rotativo, os reagentes ficavam concentrados próximos à parede externa e migravam para a região da lâmpada ao longo do reator. A elevada intensidade de radiação na superfície da lâmpada criou uma camada ao seu redor na qual a fotólise do $\mathrm{H}_{2} \mathrm{O}_{2}$ ocorreu com grande taxa. Os radicais ${ }^{\bullet} \mathrm{OH}$ gerados nessa camada eram transportados para a região das paredes por convecção. Isso fez com que a maior parte do fenol fosse atacada na segunda metade do reator e gerou acúmulo do radical próximo à lâmpada na seção de saída do reator, já que o poluente já fora oxidado nessa área. O método discrete transfer previu intensidades de radiação maiores que o modelo radial, e, consequentemente, maior concentração de radicais ${ }^{\bullet} \mathrm{OH}$. Os resultados satisfatórios indicam que CFD foi uma ferramenta adequada para analisar este escoamento reativo.

Palavras-chave: Escoamento reativo. Processo $\mathrm{UV} / \mathrm{H}_{2} \mathrm{O}_{2}$. Simulação. Modelos de turbulência. Distribuição de tempos de residência. Campo de radiação. 


\section{ABSTRACT}

Advanced oxidation processes are a promising technology for degradation of organic compounds resistant to conventional treatments such as phenol. Computational fluid dynamics (CFD) has recently emerged as a powerful tool that allows a deeper understanding of photochemical processes in reactor engineering by solving the coupled momentum, mass and radiation balances. This work aimed to investigate the $\mathrm{UV} / \mathrm{H}_{2} \mathrm{O}_{2}$ process in an annular photoreactor using CFD and a more realistic kinetic model.

A progressive approach was used to develop the CFD reactor model. First, the velocity fields were determined for three volumetric flow rates $\left(30,60\right.$ and $100 \mathrm{~L} \mathrm{~h}^{-1}$ ). Two lamp diameters were considered to reflect the experimental configuration of the system. Tetrahedral meshes varying form 270,000 to 1,200,000 elements were analyzed to achieve grid independence. For accounting turbulence effects, four RANS models were tested: $k-\epsilon, k-\omega$, the Shear Stress Transport (SST) and the Reynolds Stress models (RSM). The velocity field was validated through comparison to RTD experimental data.

Next step was introducing the mechanism of phenol degradation proposed by Edalatmanesh, Dhib and Mehrvar (2008) into the CFD model. This kinetic model is based on dynamic equations for all species. The fluence rate field was calculated by the radial model and by solving the radiation transport equation with the discrete transfer method. Simulations reproduced experimental data spanning a wide range of initial phenol concentrations, $\mathrm{H}_{2} \mathrm{O}_{2} /$ phenol molar ratios and three values for lamp power.

It was found that the velocity field depends on the volumetric flow rate: either it maintains a swirling motion through the whole reactor or might develop like a plug flow. The $k-\epsilon$ model did not represent the RTD data accurately, and the velocity field therefore, since it is not appropriate for swirling flows. The other turbulence models showed good match of RTD, especially the $k-\omega$ model.

Simulations of phenol degradation deviated less than $8 \%$ from experimental data. It was possible verified that, due to the swirling inlet effects, reactants got concentrated close to the outer wall and migrated on the lamp direction along the reactor path. High radiation intensities close to the lamp surface created a layer around it where photolysis of $\mathrm{H}_{2} \mathrm{O}_{2}$ took place with higher rates. ${ }^{\circ} \mathrm{OH}$ radicals were generated in that layer and transported towards the outer wall by convection. This caused most of phenol to be consumed in the second half of the reactor and accumulation of the radical near the lamp and the reactor outlet, since the pollutant in this area was already oxidized. The discrete transfer method predicted higher incident radiation intensity than the radial model, and higher concentrations of ${ }^{\bullet} \mathrm{OH}$ radicals as a consequence. Satisfactory results indicated that CFD was an appropriate tool for analyzing this reactive flow.

Keywords: Reactive flow. UV/ $\mathrm{H}_{2} \mathrm{O}_{2}$ process. Simulation. Turbulence models. Residence time distribution. Fluence rate distribution. 


\section{LISTA DE ILUSTRAÇÕES}

1 Discretização do domínio e definição dos raios para solução da RTE pelo método discrete transfer (FELDHEIM; LYBAERT, 2004). . . . . . . 49

2 O reator fotoquímico modelado neste trabalho. . . . . . . . 55

3 Detalhe da entrada tangente ao corpo do reator. . . . . . . . . 56

4 Fluxograma da unidade de degradação analisada. . . . . . . . . . . . 57

5 Curvas de degradação de fenol levantadas por Tambani (2011). . . . . 59

6 Demonstração do comportamento numericamente stiff das espécies envolvidas no mecanismo de degradação de fenol proposto por Edalatmanesh, Dhib e Mehrvar (2008). . . . . . . . . . . . . 60

7 Sequência de atividades realizadas neste trabalho. . . . . . . . . . 62

8 Dimensões do reator analisado. . . . . . . . . . . . . . . 63

9 Domínio computacional do reator e seções selecionadas para avaliação de variáveis. . . . . . . . . . . . . . . . . . 65

10 Espectro de emissão das lâmpadas empregadas no reator fotoquímico

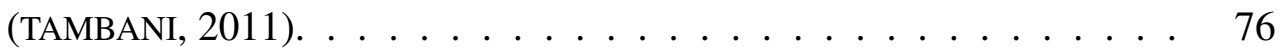

11 Vistas lateral e frontal das malhas $(a)$ A e (b) C desenvolvidas para o reator anular. . . . . . . . . . . . . . . 78

12 Análise de independência de malhas do modelo computacional do reator através dos perfis de velocidade em $z=20 \mathrm{~cm}$, para as configurações A e vazão de $30 \mathrm{Lh}^{-1} \ldots$. . . . . . . . . . . . . . . . . . 79 
13 Análise de independência de malhas do modelo computacional do reator através dos perfis de velocidade em $z=80 \mathrm{~cm}$, para as configurações A e vazão de $30 \mathrm{Lh}^{-1} \ldots$. . . . . . . . . . . . . . . .

14 Análise de independência de malhas do modelo computacional do reator através dos perfis de velocidade em $z=20 \mathrm{~cm}$, para a configuração B e vazão de $30 \mathrm{Lh}^{-1} \ldots \ldots \ldots \ldots \ldots$

15 Análise de independência de malhas do modelo computacional do reator através dos perfis de velocidade em $z=80 \mathrm{~cm}$, para a configuração B e vazão de $30 \mathrm{Lh}^{-1} \ldots \ldots \ldots \ldots \ldots \ldots \ldots$

16 Padrão de escoamento ao longo da extensão do reator para as configurações A e vazão de $30 \mathrm{Lh}^{-1} \ldots$. . . . . . . . . . . . . . . .

17 Padrão de escoamento ao longo da extensão do reator para as configurações A e vazão de $60 \mathrm{Lh}^{-1} \ldots \ldots \ldots \ldots$. . . . . . . . . . . .

18 Componentes axial $\left(v_{z}\right)$ e tangencial $\left(v_{y}\right)$ da velocidade na seção transversal em $z=20 \mathrm{~cm}$, para as configurações A1/A2. . . . . . . .

19 Componentes axial $\left(v_{z}\right)$ e tangencial $\left(v_{y}\right)$ da velocidade na seção transversal em $z=60 \mathrm{~cm}$, para as configurações A1/A2. . . . . . .

20 Componentes axial $\left(v_{z}\right)$ e tangencial $\left(v_{y}\right)$ da velocidade na seção transversal em $z=100 \mathrm{~cm}$, para as configurações A1/A2. . . . . . . .

21 Comparação do efeito de entrada causado pela (a) geometria em U analisada por Sozzi e Taghipour (2006a) e (b) pela configuração tangencial proposta pelo CESQ. . . . . . . . . . . . . .

22 Validação do modelo computacional do escoamento no reator por meio da sua distribuição de tempos de residência, para as configurações A e vazão de $30 \mathrm{Lh}^{-1} \ldots \ldots \ldots \ldots \ldots \ldots$ 
23 Validação do modelo computacional do escoamento no reator por meio da sua distribuição de tempos de residência, para as configurações A e vazão de $100 \mathrm{Lh}^{-1} \ldots \ldots \ldots \ldots$

24 Validação do modelo computacional do escoamento no reator por meio da sua distribuição de tempos de residência, para a configuração B e vazão de $30 \mathrm{Lh}^{-1} \ldots \ldots \ldots \ldots \ldots \ldots$

25 Reator analisado por Liu et al. (2007) . . . . . . . . . . . . .

26 Mapa da distância adimensional até a parede $\left(y^{+}\right)$para a configuração B e vazão de $30 \mathrm{Lh}^{-1} \ldots \ldots \ldots \ldots \ldots$. . . . . . . . . . . . .

27 Mapa da distância adimensional até a parede $\left(y^{+}\right)$para as configurações A1/A2 e vazão de $100 \mathrm{Lh}^{-1} \ldots \ldots \ldots \ldots$

28 Avaliação da influência da intensidade de turbulência na entrada sobre o campo de velocidades na seção transversal em $z=20 \mathrm{~cm}$, com vazões de (a) 30 e (b) $100 \mathrm{~L} \mathrm{~h}^{-1}$ para as configurações A1/A2. . . . . . . . .

29 Perfil de concentração de fenol para o caso de reação 1 considerando

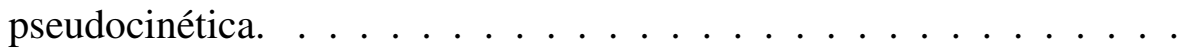

30 Comportamento dos balanços de massa da parte térmica do mecanismo de degradação do fenol com coeficientes do termo fonte inadequados.

31 O impacto de coeficiente de termo fonte de $10^{15} \mathrm{~kg} \cdot \mathrm{m}^{-3} \cdot \mathrm{s}^{-1}$ sobre os balanços de massa da parte térmica do mecanismo de degradação do fenol (Inicialização em modo automático e passo de $1 \times 10^{-5} \mathrm{~s}$ ). . . .

32 O impacto do coeficiente de termo fonte de $10^{15} \mathrm{~kg} \mathrm{~m}^{-3} \mathrm{~s}^{-1}$ sobre os balanços de massa do mecanismo de degradação do fenol (Inicialização em modo automático e passo de $\left.1 \times 10^{-5} \mathrm{~s}\right) \ldots \ldots \ldots \ldots$ 
33 O impacto do coeficiente de termo fonte de $10^{15} \mathrm{~kg} \mathrm{~m}^{-3} \mathrm{~s}^{-1}$ sobre os balanços de massa do mecanismo de degradação do fenol (Inicialização em modo automático e passo de $\left.1 \times 10^{-5} \mathrm{~s}\right) \ldots \ldots \ldots$

34 Perfil do campo de radiação na seção transversal $z=60 \mathrm{~cm}$ para o caso de reação 1, com o modelo de campo de radiação radial. . . . . . . . 99

35 Campo de radiação típico para a configuração A1 determinado pelo modelo radial. . . . . . . . . . . . . . . . . . . . 100

36 Distribuição de fenol no caso 1 simulado pelo modelo de campo radial e vista através de isosuperfícies de concentração molar. . . . . . . . . 101

37 Perfil de concentração de fenol, para o caso de reação 1, com campo de radiação radial. . . . . . . . . . . . . . . . . . . . . . . . . 102

38 Perfil de concentração de $\mathrm{H}_{2} \mathrm{O}_{2}$ para o caso de reação 1, com campo de radiação radial. . . . . . . . . . . . . . . . . . . . . . . 103

39 Perfil de concentração do radical hidroxila para o caso de reação 1 , com campo de radiação radial. . . . . . . . . . . . . . . . . . . . . . 104

40 Perfil do campo de radiação na seção transversal $z=60 \mathrm{~cm}$ para o caso de reação 1, determinado pelo método discrete transfer. . . . . . . . . 107

41 Perfil radial do campo determinado por Qi et al. (2011) na degradação de poluentes orgânicos pelo processo $\mathrm{TiO}_{2} / \mathrm{UV}$ e usando o método discrete transfer. . . . . . . . . . . . . . . . . . 107

42 Campo de radiação típico da configuração A1 para solução da RTE pelo método discrete transfer. . . . . . . . . . . . . . . . . . . . 108

43 Perfil de concentração de fenol, para o caso de reação 1, com campo de radiação resolvido pelo método discrete transfer. . . . . . . . . . . 110 
44 Perfil de concentração de $\mathrm{H}_{2} \mathrm{O}_{2}$ para o caso de reação 1, com campo de radiação resolvido pelo método discrete transfer. . . . . . . . . . . 111

45 Perfil de concentração do radical hidroxila para o caso de reação 1, com campo de radiação resolvido pelo método discrete transfer. . . . 112

46 Comparação entre os três modelos cinéticos para degradação de fenol pelo processo $\mathrm{UV} / \mathrm{H}_{2} \mathrm{O}_{2}$, para o caso de reação $1 . \ldots . \ldots . .113$

47 Comparação entre os três modelos cinéticos para degradação de fenol pelo processo $\mathrm{UV} / \mathrm{H}_{2} \mathrm{O}_{2}$, para o caso de reação $6 . \ldots . . . .114$

48 Comparação entre os três modelos cinéticos para degradação de fenol pelo processo $\mathrm{UV} / \mathrm{H}_{2} \mathrm{O}_{2}$, para o caso de reação 7. . . . . . . . . . . . 114

49 A função pulso retangular implementada para a injeção de traçador. 126

50 Validação do modelo computacional do escoamento no reator por meio da sua distribuição de tempos de residência, para as configurações A e vazão de $60 \mathrm{Lh}^{-1} \ldots \ldots \ldots$. . . . . . . . . . . . . . . . 127

51 Validação do modelo computacional do escoamento no reator por meio da sua distribuição de tempos de residência, para a configuração B e vazão de $60 \mathrm{Lh}^{-1} \ldots \ldots \ldots$. . . . . . . . . . . . . . . . 127

52 Validação do modelo computacional do escoamento no reator por meio da sua distribuição de tempos de residência, para a configuração B e vazão de $100 \mathrm{Lh}^{-1}$. . . . . . . . . . . . . . . . . . . 128 


\section{LISTA DE TABELAS}

1 Exemplos de tecnologias oxidativas para tratamento de águas e efluentes industriais [adaptado de Oppenlander (2003) e Esplugas et al. (2002)]. . . . . . . . . . . . . . . . . . .

2 Mecanismo de reação da fotólise do peróxido de hidrogênio por radiação UV e na ausência de espécies competidoras pelo radical $\bullet^{\circ} \mathrm{OH}$ (CRITTENDEN et al., 1999). . . . . . . . . . . . . . . . . 28

3 Parâmetros da fotólise de fenol pelo processo $\mathrm{UV} / \mathrm{H}_{2} \mathrm{O}_{2}$, com fonte radiante emitindo em 253,7 nm (EDALATMANESH; DHIB; MEHRVAR, 2008). 29

4 Constantes empíricas da formulação do modelo de turbulência $k-\epsilon$ (LAUNDER; SPALDING, 1974) . . . . . . . . . . . . . . . . 39

5 Constantes empíricas da formulação do modelo de turbulência $k-\omega$ (WILCOX, 1988). . . . . . . . . . . . . . 40

6 Constantes empíricas da formulação do modelo de turbulência SST (MENTER; KUNTZ; LANGTRY, 2003). . . . . . . . . . . . . . . 42

7 Constantes empíricas do modelo de turbulência RSM (SHIH et al., 1995). 45

8 Comparação do reator analisado neste trabalho com sistemas comerciais para tratamento de efluentes pelo processo $\mathrm{UV} / \mathrm{H}_{2} \mathrm{O}_{2}$ (EPA, 1998). . 56

9 Estudos sobre o reator fotoquímico deste trabalho já realizados pelo Centro de Engenharia de Sistemas Químicos. . . . . . . . . . . . 57

10 Caracterização das lâmpadas utilizadas no reator anular. . . . . . . . . 63

11 Propriedades de transporte do fluido simulado (GREEN; PERRY, 2008). 66 
12 Condições de contorno e cenários para o levantamento dos campos de velocidade do reator. . . . . . . . . . . . . . . . 66

13 Condições de contorno e cenários para o levantamento da distribuição de tempos de residência do reator. . . . . . . . . . . . . 68

14 Divisão da escala de tempo para simulação da DTR do modelo computacional do reator. . . . . . . . . . . . . . .

15 Experimentos de Tambani (2011) reproduzidos nas simulações do estudo cinético. . . . . . . . . . . . . . . . . . 7

16 Condições de contorno para a simulação de reações por pseudocinética. 72

17 Condições de contorno e cenários para o estudo de mecanismos cinéticos numericamente stiff. . . . . . . . . . . . . . . . . . 74

18 Condições de contorno e cenários para a simulação do processo de degradação de fenol pelo mecanismo de Edalatmanesh, Dhib e Mehrvar

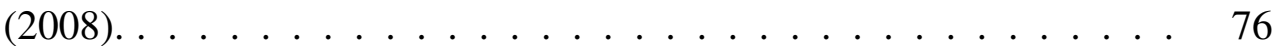

19 Descrição das malhas empregadas para discretizar o reator anular. . . 77

20 Parâmetros da distribuição de tempos de residência do modelo computacional para as configurações A do reator. . . . . . . . . . . . . . 87

21 Parâmetros da distribuição de tempos de residência do modelo computacional para a configuração B do reator. . . . . . . . . . . . . . . . . 88

22 Resultados do modelo computacional de degradação de fenol pelo processo UV/ $\mathrm{H}_{2} \mathrm{O}_{2}$ para experimentos de Tambani (2011), considerando pseudocinética de priemira ordem em relação ao fenol. 
23 Resultados do modelo computacional de degradação de fenol pelo processo UV/ $\mathrm{H}_{2} \mathrm{O}_{2}$ para experimentos de Tambani (2011), considerando o mecanismo proposto por Edalatmanesh, Dhib e Mehrvar (2008) e campo de radiação pelo modelo radial. . . . . . . . . . . . . . . . . . 98

24 Resultados do modelo computacional de degradação de fenol pelo processo UV/ $\mathrm{H}_{2} \mathrm{O}_{2}$ para experimentos de Tambani (2011), considerando o mecanismo proposto por Edalatmanesh, Dhib e Mehrvar (2008) e campo de radiação obtido pelo método discrete transfer. . . . . . . . 106 


\section{LISTA DE ABREVIATURAS E SIGLAS}

CAD Projeto assistido por computador (computer aided design)

CESQ Centro de Engenharia de Sistemas Químicos

CSTR Reator de tanque de mistura contínua (continuous stirred tank reactor)

CFD Fluidodinâmica computacional (computational fluid dynamics)

DT Método discrete transfer

DTR Distribuição de tempos de residência

EDO Equação diferencial ordinária

HEPE Hipótese do estado pseudo-estacionário

PFR Reator de escoamento pistonado (plug flow reactor)

POA Processo oxidativo avançado

RANS Equação de Navier-Stokes com a média de Reynolds (Reynolds averaged Navier-Stokes equation)

RTE Equação de transprote de radiação (radiation transport equation)

RSM Modelo de turbulência de tensões de Reynolds (Reynolds stress model)

SST Modelo de turbulência shear stress model

UV Radiação ultravioleta 


\section{LISTA DE SÍMBOLOS}

$a_{\lambda} \quad$ Coeficiente de absorção do fluido $\left(\mathrm{m}^{-1}\right)$

$b \quad$ Caminho óptico (m)

$D_{A} \quad$ Difusividade do componente A no fluido $\left(\mathrm{m}^{2} \mathrm{~s}^{-1}\right)$

$F_{1}, F_{2}$ Blending functions do modelo de turbulência SST

I Intensidade de radiação $\left(\mathrm{W} \mathrm{m}^{-2}\right)$

$j \quad$ Fluxo difusivo mássico $\left(\mathrm{kg} \mathrm{m}^{-2} \mathrm{~s}^{-1}\right)$

$k \quad$ Energia cinética de turbulência $\left(\mathrm{J} \mathrm{kg}^{-1}\right)$

$k_{\lambda} \quad$ Coeficiente de espalhamento do fluido $\left(\mathrm{m}^{-1}\right)$

$p \quad$ Pressão $(\mathrm{Pa})$

$P_{i j} \quad$ Termo de produção de tensões

$r \quad$ Taxa de reação $\left(\mathrm{mol} \mathrm{m}^{-3} \mathrm{~s}^{-1}\right)$

$R_{i j} \quad$ Correlação pressão-deformação no modelo de turbulência RSM

$R^{2} \quad$ Coeficiente de correlação linear de Pearson (adimensional)

$S \quad$ Termo fonte de uma propriedade

$S c_{t} \quad$ Número de Schmidt turbulento (adimensional)

Taxa de deformação do fluido $\left(\mathrm{s}^{-1}\right)$

$t \quad$ Tempo (s)

$t_{m} \quad$ Tempo médio de residência (s)

$U \quad$ Velocidade instantânea do fluido $\left(\mathrm{m} \mathrm{s}^{-1}\right)$ 
$\bar{U} \quad$ Velocidade média do fluido $\left(\mathrm{m} \mathrm{s}^{-1}\right)$

$u \quad$ Flutuação da velocidade instantânea em torno da média $\left(\mathrm{m} \mathrm{s}^{-1}\right)$

$x \quad$ Fração mássica de um componente (adimensional)

$x_{j} \quad$ Coordenadas espaciais $x, y, z$ na notação de Einstein

$y^{+} \quad$ Distância adimensional até a parede

\section{Símbolos gregos}

$\delta_{i j} \quad$ Delta de Kronecker

$\epsilon \quad$ Coeficiente de absorção molar $\left(\mathrm{m}^{3} \mathrm{~mol}^{-1} \mathrm{~m}^{-1}\right)$

Dissipação turbulenta $\left(\mathrm{J} \mathrm{kg}^{-1}\right)$

$\zeta_{1}, \zeta_{2}$ Argumentos das blending functions do modelo de turbulência SST

$\mu \quad$ Viscosidade dinâmica do fluido (Pa s)

$v \quad$ Viscosidade cinemática do fluido $\left(\mathrm{m}^{2} \mathrm{~s}^{-1}\right)$

$\rho \quad$ Densidade $\left(\mathrm{kg} \mathrm{m}^{-3}\right)$

$\tau \quad$ Tempo espacial (s)

$\phi \quad$ Rendimento quântico (adimensional)

$\omega \quad$ Taxa de dissipação específica $\left(\mathrm{s}^{-1}\right)$

$\Omega \quad$ Vorticidade do fluido 


\section{SUMÁRIO}

1 Introdução $\quad 19$

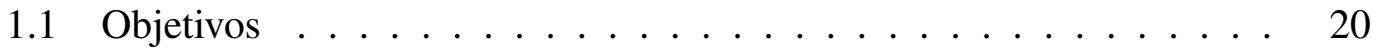

1.2 Motivação . . . . . . . . . . . . . . . . . . . . . 21

1.3 Justificativa . . . . . . . . . . . . . . . 22

1.4 Estrutura da dissertação . . . . . . . . . . . . . . . . . . 24

2 Revisão da literatura $\quad 26$

2.1 Processos oxidativos avançados . . . . . . . . . . . . . 26

$2.1 .1 \quad$ Processo $U V / \mathrm{H}_{2} \mathrm{O}_{2} \ldots \ldots \ldots \ldots 27$

2.2 Modelagem matemática de reatores . . . . . . . . . . . 32

2.2.1 Caracterização macroscópica do escoamento em reatores não-

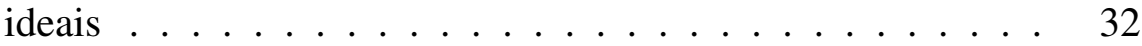

2.2.2 Caracterização microscópica da fluidodinâmica de reatores não-ideais . . . . . . . . . . . . . . . . . . . 34

2.2.2.1 Campo de velocidades . . . . . . . . . 35

2.2.2.2 Conservação de massa das espécies . . . . . . . . . 45

2.2.2.3 Campo de radiação . . . . . . . . . . . . . . 46

2.3 Aplicações de CFD a sistemas fotoquímicos . . . . . . . . . . . . . . 49 
3.1 Sistema experimental analisado e contextualização do trabalho . . . . 55

3.2 Construção dos protótipos virtuais e das malhas . . . . . . . . . . 63

3.3 Estudo fluidodinâmico . . . . . . . . . . . . . . . . . . . 64

3.3.1 Obtenção dos campos de velocidade . . . . . . . . . . . 66

3.3.2 Validação do escoamento pela distribuição de tempos de residência ........................ 67

3.4 Estudo cinético . . . . . . . . . . . . . . . . . . . 70

3.4.1 Validação das simulações de degradação do fenol . . . . . . . 70

3.4 .2 Análises iniciais . . . . . . . . . . . . 72

3.4.3 Degradação de fenol pelo processo $\mathrm{UV} / \mathrm{H}_{2} \mathrm{O}_{2} \ldots \ldots . . .73$

4 Resultados e discussões $\quad 77$

4.1 Estudo fluidodinâmico do reator . . . . . . . . . . . . . . 77

4.1.1 Avaliação de independência de malhas . . . . . . . . . . . . . 77

4.1.2 Descrição do campo de velocidades . . . . . . . . . . . 81

4.1.3 Distribuição de tempos de residência e validação do campo de velocidades .................... 86

4.2 Estudo cinético do reator . . . . . . . . . . . . . . . . . 93

$4.2 .1 \quad$ Análises iniciais . . . . . . . . . . . . . . . 93

4.2.2 Degradação de fenol pelo processo UV/ $\mathrm{H}_{2} \mathrm{O}_{2}$ com campo de radiação radial . . . . . . . . . . . . . . . . . 9 97

4.2.3 Degradação de fenol pelo processo UV/ $\mathrm{H}_{2} \mathrm{O}_{2}$ com campo resolvido pelo método discrete transfer . . . . . . . . . . 105 
5 Conclusões e recomendações

5.1 Conclusões do trabalho . . . . . . . . . . . . . . . . . 115

5.2 Recomendações para trabalhos futuros . . . . . . . . . . . . 116

Referências

Apêndice A - Distribuição de tempos de residência do modelo computacional 124

A.1 Algoritmo para levantamento da DTR . . . . . . . . . . . . 124

A.2 Curvas de DTR do modelo computacional . . . . . . . . . . 126 


\section{INTRODUÇÃO}

Os grandes centros urbanos, os polos industriais e as zonas de irrigação são regiões de intensa demanda de água, um dos recursos naturais mais explorados pela sociedade. Segundo estimativa da Agência Nacional de Águas, a retirada de água de cursos naturais brasileiros para fins industriais teve vazão aproximada de $310 \mathrm{~m}^{3} \mathrm{~s}^{-1}$ em 2009 . (ANA, 2011).

Os setores industriais de maior consumo de água e geração de efluentes são o têxtil, farmacêutico, de eletrônicos, hidrometalurgia, de papel e refinarias (HASSEMER, 2006). No setor petroquímico, p.ex., a água é empregada em processos como extração líquido-líquido, síntese de éter, craqueamento e geração de vapor de retificação. Em plantas siderúrgicas, suas principais aplicações são o resfriamento de altos fornos e lavagem de gases. As indústrias alimentícia e agrícola (usinas de açúcar, fábricas de laticínios e de bebidas) incorporam água em seus produtos, além de gerar vapor em evaporadores para concentrar soluções (BAGAJEWICZ, 2000).

A demanda por água pode superar sua oferta, seja em termos quantitativos - escassez, estiagens -, seja porque a poluição causada pelo lançamento de efluentes industriais, agrícolas, laboratoriais e humanos reduz sua qualidade, tornado-a ainda mais escassa. Esse cenário levou a um recrudescimento dos parâmetros de despejo de efluentes, com o intuito de evitar um impacto danoso aos corpos receptores.

Muitas indústrias geram substâncias orgânicas altamente tóxicas e recalcitrantes, que não são degradadas pelos microorganismos normalmente presentes em sistemas 
biológicos de tratamento. Além disso, os métodos físico-químicos tradicionais - filtração, adsorção em carvão ativado e membranas - apenas transferem os poluentes de uma fase para outra, sem destruí-los (SHARPLESS; LINDEN, 2003). Estimulou-se então o desenvolvimento de tecnologias capazes de minimizar o volume e a toxicidade dos efluentes industriais, com ênfase na mineralização de poluentes e prevenção e controle da poluição. Dentre elas estão os processos oxidativos avançados (POAs).

Os POAs podem transformar substâncias persistentes e dificilmente elimináveis em substâncias inofensivas, biologicamente degradáveis ou, pelo menos, em substâncias que possam ser mais facilmente eliminadas por processos fisico-químicos convencionais (FIGAWA, 1997). Esses processos envolvem a geração do radical hidroxila $\left({ }^{\bullet} \mathrm{OH}\right)$ pela irradiação de oxidantes como o ozônio $\left(\mathrm{O}_{3}\right)$ e o peróxido de hidrogênio $\left(\mathrm{H}_{2} \mathrm{O}_{2}\right) . \mathrm{O}^{\bullet} \mathrm{OH}$ é uma espécie extremamente reativa e pouco seletiva, oxidando substâncias tóxicas e recalcitrantes a ponto de levá-las inclusive até a mineralização completa, com taxas de 1 milhão a 1 bilhão de vezes maiores que o tratamento com ozônio (EPA, 1998). O processo UV/ $\mathrm{H}_{2} \mathrm{O}_{2}$ é um POA de interesse crescente pela facilidade de operação e eficácia no tratamento de efluentes.

\subsection{Objetivos}

O objetivo deste trabalho é aplicar a fluidodinâmica computacional (CFD) como ferramenta para simular a degradação de fenol em um reator fotoquímico anular do Centro de Engenharia de Sistemas Químicos do Departamento de Engenharia Química da Escola Politécnica da USP (CESQ-PQI/EPUSP). Os objetivos específicos são:

- caracterizar a fluidodinâmica que ocorre no reator;

- avaliar o modelo de turbulência mais apropriado para descrever sua fluidodinâmica;

- validar o campo de velocidades através de simulações da distribuição de tempos 
de residência (DTR) do reator, comparando-a com resultados experimentais;

- avaliar como o campo de velocidades obtido afeta o desenvolvimento de reações;

- avaliar o desempenho do reator para degradar fenol operando em modo contínuo;

- caracterizar a distribuição de componentes e o campo de radiação no reator;

- validar o modelo cinético e o o campo de radiação por meio de resultados experimentais.

\subsection{Motivação}

A seleção do processo de tratamento de efluentes industriais depende da qualidade desejada para a água ao final do processo e de sua aplicação (como descarte para o ambiente ou reúso). Os tratamentos oxidativos baseados em tecnologias fotoquímicas empregam energia radiante com comprimentos de onda que geram quantidades desprezíveis de calor e, consequentemente, não são conduzidos em altas temperaturas. Esta condição traz vantagens operacionais: (i) melhores condições de equilíbrio para reações exotérmicas; (ii) condições mais favoráveis para operação na fase aquosa; e (iii) minimização de produtos secundários indesejados quando o processo é bem dimensionado (CASSANO et al., 1995).

Nas últimas décadas, foram desenvolvidos processos fotoquímicos para operações em larga escala e o interesse pela fotoquímica ressurgiu (BRAUN; MAURETTE; OLIVEROS, 1991). Na Europa, mais de 3000 plantas de água potável usam tecnologia de desinfecção UV. No Estados Unidos, há mais de 500 plantas desse tipo para tratar o esgoto municipal antes de lançá-lo em cursos naturais, com capacidade operacional de 158 a $3200 \mathrm{~m}^{3} \mathrm{~h}^{-1}$; em Québec (Canadá), o tratamento é feito desde 1986 (OPPENLANDER, 2003).

Na década de 1990, houve algumas experiências bem sucedidas no uso comercial 
de POAs. Em 1992, uma unidade para tratamento de uma corrente com acetona e álcool isopropílico (ambos a $20 \mathrm{mg} \mathrm{L}^{-1}$ ) foi instalada no Kennedy Space Center, na Flórida. O sistema inicialmente foi montado em batelada com capacidade de 19000 a $23000 \mathrm{~L}$, depois adaptado para operação contínua com vazão de $19 \mathrm{~L} \mathrm{~min}^{-1}$ e com uma dose de $100 \mathrm{mg} \mathrm{L}^{-1}$ de $\mathrm{H}_{2} \mathrm{O}_{2}$; a remoção dos dois poluentes foi de $97,5 \%$. Quatro anos depois, uma planta de fabricação de borracha instalou um sistema de remoção de $N$ nitrosodimetilamina (NDMA), em concentração de $30 \mu \mathrm{g} \mathrm{L}{ }^{-1}$, também pelo processo $\mathrm{UV} / \mathrm{H}_{2} \mathrm{O}_{2}$. Nela, foi atingida remoção de mais de $98,3 \%$, com vazão de $45 \mathrm{~L} \mathrm{~min}^{-1}$ (EPA, 1998).

Resultados assim estimulam o investimento nos tratamentos fotoquímicos, dada sua capacidade de mineralizar substâncias tóxicas e recalcitrantes. Espera-se que o desenvolvimento desta área estimule engenheiros de processo a considerar a aplicabilidade industrial dos POAs na fotodegradação de compostos orgâncios em grande escala, além da possibilidade de combiná-los com os métodos tradicionais. Na indústria têxtil, p.ex., a remoção de corantes organoclorados pode ser feita com o processo $\mathrm{UV} / \mathrm{H}_{2} \mathrm{O}_{2}$, para reduzir a toxicidade do efluente e remover sua cor, seguido por um tratamento biológico convencional (HASSEMER, 2006). Outras aplicações promissoras para os POAs são a produção de água ultra pura, a oxidação de cianetos de processos de galvanoplastia, a manufatura de semicondutores, a degradação de explosivos tóxicos e reúso de água.

\subsection{Justificativa}

Apesar das vantagens discutidas na seção anterior, os processos fotoquímicos não são usados amplamente na prática industrial. Algumas razões para esse fato são:

- dificuldades de construção e operação do sistema de lâmpadas (refrigeração da parte elétrica e formação de depósitos) (CASSANO et al., 1995); 
- a falta de ferramentas adequadas para analisar o modelo completo de operação de um reator fotoquímico, i.e., considerando simultaneamente os efeitos do campo de velocidade, da cinética de degradação e do campo de radiação (MOHSENI; TAGHIPOUR, 2004).

Diversos pesquisadores descreveram as rotas de degradação de compostos orgânicos por POAs e formularam modelos cinéticos com vários níveis de complexidade (ALNAIZY; AKGERMAN, 2000; POULOPOULOS; ARVANITAKIS; PHILIPPOPOULOS, 2005; PRIMO et al., 2007; EDALATMANESH; DHIB; MEHRVAR, 2008). O projeto de sistemas de tratamento UV requer conhecimento sobre a configuração do sistema (design do reator, tubulações, quantidade de lâmpadas e sua orientação) e a cinética química (mecanismos de reação e constantes cinéticas). Sua modelagem é baseada nos princípios de conservação de quantidade de movimento e de massa de cada espécie, como em qualquer reator, com a adição do balanço de radiação (balanço fotônico) ${ }^{1}$. Os balanços de massa e de radiação estão acoplados pelos termos das taxas de reação, já que a incidência de raios UV afeta a concentração de moléculas do meio, e estas, por sua vez, interferem na absorção de radiação pelo meio reacional. Como a radiação UV não se distribui de forma uniforme, a hidrodinâmica do reator se torna crucial para o processo (MOHSENI; TAGHIPOUR, 2004).

A análise de sistemas fotoquímicos estava limitada pela falta de ferramentas numéricas robustas que tratassem o acoplamento e a complexidade dos três fenômenos discutidos acima. A partir da década de 2000, a fluidodinâmica computacional (CFD) despontou como ferramenta para contornar essas dificuldades graças ao avanço da capacidade de processamento dos computadores pessoais e da elaboração de métodos numéricos para determinar a distribuição de energia radiante nos sistemas fotoquímicos. Sua vantagem é lidar com a tridimensionalidade dos balanços de quantidade de

\footnotetext{
${ }^{1}$ A maioria das reações fotoquímicas ocorre em comprimentos de onda na faixa de $200 \leq \lambda \leq 600$ $\mathrm{nm}$. Essa faixa do espectro eletromagnético não gera calor. Além disso, os reatores fotoquímicos dificilmente atingem temperaturas elevadas, de modo que o balanço de energia térmica pode ser desacoplado do balanço de radiação.
} 
movimento, de massa e de radiação e permitir avaliar a influência da geometria do reator e de seus parâmetros operacionais (vazão de alimentação, potência da lâmpada, posição de chicanas) sobre o processo oxidativo apenas com protótipos virtuais.

\subsection{Estrutura da dissertação}

O capítulo 2 apresenta a revisão bibliográfica sobre os processos fotoquímicos e a modelagem de reatores para tal aplicação. A primeira parte introduz os processos oxidativos avançados, destacando o mecanismo de degradação de fenol pelo processo $\mathrm{UV} / \mathrm{H}_{2} \mathrm{O}_{2}$. Em seguida, discutem-se os balanços microscópicos pertinentes à operação de um reator fotoquímico e trabalhos notáveis sobre a aplicação de CFD no tratamento matemático desses reatores.

No capítulo 3, trata da descrição do sistema estudado e das simulações propostas. Indicam-se os detalhes gerais do método numérico adotado nas simulações, como seu critério de convergência, a forma de construção das malhas, o esquema de acoplamento pressão-velocidade e do tratamento do termo de advecção. A análise fluidodinâmica do reator é detalhada com a descrição das lâmpadas utilizadas, das vazões ensaiadas e dos modelos de turbulência empregados. Também é explorada a estratégia para inserir reações no modelo computacional, contemplando o estudo de reações simples para complementar o estudo fluidodinâmico, a análise de reações com constantes cinéticas de ordem de grandeza elevada e modelos para o campo de radiação e reações fotoquímicas.

O capítulo 4 traz os resultados e discussão das simulações. Apresenta-se a discussão sobre a independência de malhas, o padrão fluidodinâmico e a seleção dos modelos de turbulência mais apropriados para o reator a partir da sua distribuição de tempos de residência. Os perfis de concentração de espécies em reações simples é utilizado para comparar o reator fotoquímico a sistemas ideais e fornecer mais informações sobre 
sua fluidodinâmica. Para compreender melhor o mecanismo de degradação do fenol, discute-se a influência de parâmetros do método numérico sobre a convergência dos balanços de massa de reações com constantes cinéticas elevadas. Finalmente, comparamse três estratégias para simular a degradação de fenol pelo processo $\mathrm{UV} / \mathrm{H}_{2} \mathrm{O}_{2}$.

O capítulo 5 encerra o presente trabalho com um resumo de suas principais conclusões e recomendações para sua continuação em estudos futuros. 


\section{REVISÃO DA LITERATURA}

\subsection{Processos oxidativos avançados}

Os tratamentos de efluentes tradicionais apresentam limitações de aplicação e eficiência. Os processos físico-químicos, como precipitação, floculação, filtração, uso de membranas, air stripping, osmose e carvão ativado, transferem os poluentes de uma fase a outra, sem destruí-los. No caso do carvão ativado, p.ex., é produzido muitas vezes um resíduo sólido perigoso cuja disposição final é um problema, mesma situação dos lodos e tortas de filtração. O tratamento biológico é de baixo custo e capaz de tratar grandes volumes, porém peca pela sensibilidade às condições ambientais e às características do efluente, como a presença de materias tóxicos ou não biodegradáveis: concentrações de fenol acima de $100 \mathrm{mg} \mathrm{L}^{-1}$ desestabilizam o reator (DE; BHATTACHARJEE; DUTTA, 1997); outras desvantagens são a grande quantidade de biomassa gerada, o longo tempo envolvido para oxidação da matéria orgânica e a faixa estreita de $\mathrm{pH}$ e temperatura na qual o sistema é ativo (TEIXEIRA; JARDIM, 2004).

Os processos oxidativos fotoquímicos são tratamentos promissores para o futuro próximo (ESPLUGAS et al., 2002). Suas reações apresentam as seguintes vantagens em relacão às térmicas: $(a)$ alta seletividade; $(b)$ operação em baixas temperaturas; (c) condições mais favoráveis para operação na fase aquosa; e (d) minimização de produtos secundários indesejados quando bem dimensionadas (CASSANO et al., 1995).

Embora usem diferentes sistemas reacionais, a maioria deles recai na produção de radicais ${ }^{\bullet} \mathrm{OH}$ pela excitação de uma espécie do meio, denominada oxidante secundário. 
A cinética geralmente é de primeira ordem em relação ao ${ }^{\bullet} \mathrm{OH}$ e ao poluente, com taxas típicas de $10^{7}$ a $10^{10} \mathrm{~L} \mathrm{~mol}^{-} 1 \mathrm{~s}^{-1}$ (LAAT et al., 1999). A ordem de grandeza das constantes é reflexo do radical ser a segunda espécie mais reativa na lista de potenciais de redução $\left(E^{0}=2,80 \mathrm{~V}\right)$, abaixo apenas do flúor (OPPENLANDER, 2003). A Tabela 1 sumariza os principais tipos de POAs.

Tabela 1. Exemplos de tecnologias oxidativas para tratamento de águas e efluentes industriais [adaptado de Oppenlander (2003) e Esplugas et al. (2002)].

\begin{tabular}{|c|c|c|c|}
\hline Fase reacional & Processo & Oxidante auxiliar & Iniciação \\
\hline Homogênea & $\begin{array}{l}\mathrm{O}_{3} \\
\mathrm{O}_{3 /} \mathrm{H}_{2} \mathrm{O}_{2} \\
\mathrm{UV} / \mathrm{H}_{2} \mathrm{O}_{2} \\
\mathrm{UV} / \mathrm{O}_{3} \\
\mathrm{H}_{2} \mathrm{O} / \mathrm{VUV} \\
\text { Fenton } \\
\text { foto-Fenton }\end{array}$ & $\begin{array}{l}\mathrm{O}_{3} \\
\mathrm{O}_{3} \text { e } \mathrm{H}_{2} \mathrm{O}_{2} \\
\mathrm{H}_{2} \mathrm{O}_{2} \\
\mathrm{O}_{3} \\
\text { nenhum } \\
\mathrm{H}_{2} \mathrm{O}_{2} \\
\mathrm{H}_{2} \mathrm{O}_{2}\end{array}$ & $\begin{array}{l}\text { sem iniciação } \\
\text { sem iniciação } \\
\text { radiação no UVC } \\
\text { radiação no UVC-UVB } \\
\text { radiação VUV } \\
\text { catálise por íons } \mathrm{Fe}^{2+} \\
\text { radiação no UVA/VIS } \\
\text { e catálise por íons } \mathrm{Fe}_{2}^{+} \\
\text {e/ou } \mathrm{Fe}^{3+}\end{array}$ \\
\hline Heterogênea & $\mathrm{TiO}_{2} / \mathrm{UV}$ & $\mathrm{TiO}_{2}$ & radiação no UVA/VIS \\
\hline
\end{tabular}

\subsubsection{Processo $\mathrm{UV} / \mathrm{H}_{2} \mathrm{O}_{2}$}

A combinação de fotólise por radiação ultravioleta (UV) com o peróxido de hidrogênio $\left(\mathrm{H}_{2} \mathrm{O}_{2}\right)$ tem se mostrado eficiente no tratamento de águas contaminadas com benzeno, tolueno, fenol, tricloroetileno, 1,1-dicloroetano (DCA) e químicos da indústria de papel (HUANG; SHU, 1995). Algumas vantagens do processo $\mathrm{UV} / \mathrm{H}_{2} \mathrm{O}_{2}$ são (KIM; VOGELPOHL, 1998):

- comparado aos processos Fenton e foto-Fenton, não há geração de lodo com sais de $\mathrm{Fe}^{2+}$, facilitando o descarte do efluente;

- não exige geração do oxidante auxiliar in-situ nem equipamentos além do reator e da lâmpada, como é o caso dos processos com ozônio. 
Radiação com comprimento menor que $400 \mathrm{~nm}$ é capaz de realizar a fotólise da molécula de $\mathrm{H}_{2} \mathrm{O}_{2}$. O mecanismo aceito é a clivagem da molécula em dois radicais • OH por quantum de radiação absorvido, de acordo com a reação

$$
\mathrm{H}_{2} \mathrm{O}_{2} \stackrel{h v}{\rightarrow} 2 \cdot \mathrm{OH}
$$

A 253,7 nm e pH $<8$, o rendimento quântico da reação acima é $\phi=0$, 5; este parâmetro indica a quantidade de matéria de produtos formada (em mols) a partir da incidência de 1 mol de fótons sobre o reagente. $\mathrm{O}$ coeficiente de absorção molar do $\mathrm{H}_{2} \mathrm{O}_{2}$ nesse comprimento de onda é $\epsilon=1800 \mathrm{~L} \mathrm{~mol}^{-1} \mathrm{~m}^{-1}$. O baixo valor deste parâmetro interfere na velocidade de formação dos radicais hidroxila (HASSEMER, 2006) e é uma das desvantagens do processo.

Após sua formação, os radicais ${ }^{\bullet} \mathrm{OH}$ oxidam contaminantes por abstração de hidrogênio, transferência de elétrons ou adição radicalar (ALNAIZY; AKGERMAN, 2000). Por serem pouco seletivos, eles atacam o próprio $\mathrm{H}_{2} \mathrm{O}_{2}$ e caem num ciclo de reações radicalares conhecido como o mecanismo de Haber-Weiss (OPPENLANDER, 2003). A Tabela 2 lista as reações envolvidas, supondo que não haja scavengers do radical ${ }^{\bullet} \mathrm{OH}$, como os íons carbonato $\left(\mathrm{CO}_{3}^{2-}\right)$ e bicarbonato $\left(\mathrm{HCO}_{3}^{-}\right)$e matéria húmica. As reações são elementares, exceto a fotólise do $\mathrm{H}_{2} \mathrm{O}_{2}$.

Tabela 2. Mecanismo de reação da fotólise do peróxido de hidrogênio por radiação UV e na ausência de espécies competidoras pelo radical ${ }^{\bullet} \mathrm{OH}$ (CRITTENDEN et al., 1999).

\begin{tabular}{|c|c|c|}
\hline \multicolumn{2}{|c|}{ Reação } & \multirow{2}{*}{$\begin{array}{l}\text { Constante cinética } \\
\text { vide equação (2.1) }\end{array}$} \\
\hline (R1) & $\mathrm{H}_{2} \mathrm{O}_{2} \stackrel{h v}{\longrightarrow} 2 \cdot \mathrm{OH}$ & \\
\hline (R2) & $\cdot \mathrm{OH}+\mathrm{H}_{2} \mathrm{O}_{2} \stackrel{k_{2}}{\rightarrow} \mathrm{HO}_{2}^{\bullet}+\mathrm{H}_{2} \mathrm{O}$ & $k_{2}=2,7 \times 10^{7} \mathrm{~L} \mathrm{~mol}^{-1} \mathrm{~s}^{-1}$ \\
\hline (R3) & $\cdot \mathrm{OH}+\mathrm{HO}_{2}^{-} \stackrel{k_{3}}{\rightarrow} \mathrm{HO}_{2}^{\bullet}+\mathrm{OH}^{-}$ & $k_{3}=7,5 \times 10^{9} \mathrm{~L} \mathrm{~mol}^{-1} \mathrm{~s}^{-1}$ \\
\hline (R4) & $\mathrm{H}_{2} \mathrm{O}_{2}+\mathrm{HO}_{2}^{\cdot} \stackrel{k_{4}}{\rightarrow} \cdot \bullet \mathrm{OH}+\mathrm{H}_{2} \mathrm{O}+\mathrm{O}_{2}$ & $k_{4}=3,0 \mathrm{~L} \mathrm{~mol}^{-1} \mathrm{~s}^{-1}$ \\
\hline (R5) & $\mathrm{H}_{2} \mathrm{O}_{2}+\mathrm{O}_{2}^{--} \stackrel{k_{5}}{\rightarrow} \cdot \mathrm{OH}+\mathrm{O}_{2}+\mathrm{OH}^{-}$ & $k_{5}=0,13 \mathrm{~L} \mathrm{~mol}^{-1} \mathrm{~s}^{-1}$ \\
\hline (R6) & $\mathrm{O}_{2}^{\bullet-}+\mathrm{H}^{+} \stackrel{k_{6}}{\rightarrow} \mathrm{HO}_{2}^{\bullet}$ & $k_{6}=1,0 \times 10^{10} \mathrm{~L} \mathrm{~mol}^{-1} \mathrm{~s}^{-1}$ \\
\hline
\end{tabular}


Tabela 2. (continuação)

\begin{tabular}{lll}
\hline \multicolumn{2}{l}{ Reação } & Constante cinética \\
\hline$(\mathrm{R} 7)$ & $\mathrm{HO}_{2}^{\bullet} \stackrel{k_{7}}{\rightarrow} \mathrm{O}_{2}^{\bullet-}+\mathrm{H}^{+}$ & $k_{7}=1,58 \times 10^{5} \mathrm{~s}^{-1}$ \\
$(\mathrm{R} 8)$ & $\bullet \mathrm{OH}+\bullet \mathrm{OH} \stackrel{k_{8}}{\rightarrow} \mathrm{H}_{2} \mathrm{O}_{2}$ & $k_{8}=5,5 \times 10^{9} \mathrm{~L} \mathrm{~mol}^{-1} \mathrm{~s}^{-1}$ \\
$(\mathrm{R} 9)$ & $\bullet \mathrm{OH}+\mathrm{HO}_{2}^{\bullet} \stackrel{k_{9}}{\rightarrow} \mathrm{O}_{2}+\mathrm{H}_{2} \mathrm{O}$ & $k_{9}=6,6 \times 10^{9}, \mathrm{~L} \mathrm{~mol}^{-1} \mathrm{~s}^{-1}$ \\
$(\mathrm{R} 10)$ & $\mathrm{HO}_{2}^{\bullet}+\mathrm{HO}_{2}^{\bullet} \stackrel{k_{10}}{\longrightarrow} \mathrm{H}_{2} \mathrm{O}_{2}+\mathrm{O}_{2}$ & $k_{10}=8,3 \times 10^{5} \mathrm{~L} \mathrm{~mol}^{-1} \mathrm{~s}^{-1}$ \\
$(\mathrm{R} 11)$ & $\mathrm{HO}_{2}^{\bullet}+\mathrm{O}_{2}^{\bullet-} \stackrel{k_{11}}{\longrightarrow} \mathrm{HO}_{2}^{-}+\mathrm{O}_{2}$ & $k_{11}=9,7 \times 10^{7} \mathrm{~L} \mathrm{~mol}^{-1} \mathrm{~s}^{-1}$ \\
$(\mathrm{R} 12)$ & $\bullet \mathrm{OH}^{-} \mathrm{O}_{2}^{\bullet-} \stackrel{k_{12}}{\longrightarrow} \mathrm{O}_{2}+\mathrm{OH}^{-}$ & $k_{12}=7,0 \times 10^{9} \mathrm{~L} \mathrm{~mol}^{-1} \mathrm{~s}^{-1}$ \\
$(\mathrm{R} 13)$ & $\mathrm{H}_{2} \mathrm{O}_{2} \rightleftharpoons \mathrm{H}^{+}+\mathrm{HO}_{2}^{-}$ & $\mathrm{pK}_{\mathrm{a}}=11,6$ \\
\hline
\end{tabular}

Considera-se o $\mathrm{H}_{2} \mathrm{O}_{2}$, o ânion $\mathrm{HO}_{2}^{-}$e o fenol como os únicos componentes que absorvem radiação no meio. A taxa de fotólise do $\mathrm{H}_{2} \mathrm{O}_{2}$ é dada por

$$
\begin{aligned}
r_{\mathrm{UV} / \mathrm{H}_{2} \mathrm{O}_{2}}=\phi_{1} I_{0} & \left(\frac{\epsilon_{1}\left[\mathrm{H}_{2} \mathrm{O}_{2}\right]+\epsilon_{2}\left[\mathrm{HO}_{2}^{-}\right]}{\epsilon_{1}\left[\mathrm{H}_{2} \mathrm{O}_{2}\right]+\epsilon_{2}\left[\mathrm{HO}_{2}^{-}\right]+\epsilon_{6}\left[\mathrm{C}_{6} \mathrm{H}_{5} \mathrm{OH}\right]}\right) \times \\
& \times\left[1-\exp \left(-2,303 b\left(\epsilon_{1}\left[\mathrm{H}_{2} \mathrm{O}_{2}\right]+\epsilon_{2}\left[\mathrm{HO}_{2}^{-}\right]+\epsilon_{6}\left[\mathrm{C}_{6} \mathrm{H}_{5} \mathrm{OH}\right]\right)\right)\right]
\end{aligned}
$$

sendo $I_{0}$ a irradiância espectral fotônica $\left(\mathrm{mol} \mathrm{L}^{-1} \mathrm{~s}^{-1}\right)$ e $b$ o caminho óptico (m). Os coeficientes de absorção molares e rendimentos quânticos para esta reação estão listados na Tabela 3.

Tabela 3. Parâmetros da fotólise de fenol pelo processo $\mathrm{UV} / \mathrm{H}_{2} \mathrm{O}_{2}$, com fonte radiante emitindo em 253,7 nm (EDALATMANESH; DHIB; MEHRVAR, 2008).

\begin{tabular}{lcl}
\hline Parâmetro & Notação & Valor \\
\hline Rendimento quântico do $\mathrm{H}_{2} \mathrm{O}_{2}$ & $\phi_{1}$ & 0,5 \\
Rendimento quântico do fenol & $\phi_{2}$ & 0,12 \\
Coeficiente de absorção molar do $\mathrm{H}_{2} \mathrm{O}_{2}$ & $\epsilon_{1}$ & $1800 \mathrm{~L} \mathrm{~mol}^{-1} \mathrm{~m}^{-1}$ \\
Coeficiente de absorção molar do $\mathrm{HO}_{2}^{-}$ & $\epsilon_{2}$ & $22800 \mathrm{~L} \mathrm{~mol}^{-1} \mathrm{~m}^{-1}$ \\
Coeficiente de absorção molar do fenol & $\epsilon_{6}$ & $51600 \mathrm{~L} \mathrm{~mol}^{-1} \mathrm{~m}^{-1}$ \\
\hline
\end{tabular}


Há vários níveis de modelagem para o processo $\mathrm{UV} / \mathrm{H}_{2} \mathrm{O}_{2}$, dependendo dos objetivos e dos recursos computacionais disponíveis. Primo et al. (2007) desenvolveram um modelo considerando cinética de pseudo-primeira ordem em relação ao fenol. A única espécie analisada foi o poluente, cuja concentração inicial foi mantida constante, e os efeitos do campo de radiação e de formação de intermediários foram representados pela pseudoconstante. Dessa forma, o mecanismo da Tabela 2 acaba simplificado para

$$
\mathrm{C}_{6} \mathrm{H}_{5} \mathrm{OH}+\mathrm{H}_{2} \mathrm{O}_{2} \longrightarrow \text { produtos } \quad r_{\mathrm{C}_{6} \mathrm{H}_{5} \mathrm{OH}}=-k_{a p} C_{\mathrm{C}_{6} \mathrm{H}_{5} \mathrm{OH}}
$$

Poulopoulos, Arvanitakis e Philippopoulos (2005) formularam um modelo no qual parte do fenol se decompõe a gás carbônico $\left(\mathrm{CO}_{2}\right)$ e água diretamente, e outra parte é convertida a um intermediário resistente (ácidos orgânicos), ambos oxidados a $\mathrm{CO}_{2}$ e água; todas as etapas são de pseudo-primeira ordem. Na proposta de Alnaizy e Akgerman (2000), são consideradas as reações (R1), (R2), (R9) e (R10) do mecanismo indicado na Tabela 2. Embora não adote pseudocinética de primeira ordem, tal modelo supõe hipótese do estado pseudo-estacionário para os radicais hidroxila e hidroperóxido $\left(\mathrm{HO}_{2}^{\bullet}\right)$.

Os resultados experimentais de Alnaizy e Akgerman (2000) foram subsídios para que Edalatmanesh, Dhib e Mehrvar (2008) propusessem um modelo mais realista para degradação de fenol pelo processo $\mathrm{UV} / \mathrm{H}_{2} \mathrm{O}_{2}$. Em sua formulaçao, não se considera a hipótese do estado pseudo-estacionário para nenhuma espécie. Todas as reações listadas na Tabela 2 são empregadas nas equações das taxas cinéticas. As espécies de interesse são o $\mathrm{H}_{2} \mathrm{O}_{2}$, o radical $\bullet \mathrm{OH}$, o ânion hidroperóxido $\left(\mathrm{HO}_{2}^{-}\right)$, o radical hidroperóxido $\left(\mathrm{HO}_{2}^{\bullet}\right)$, ânion radical superóxido $\left(\mathrm{O}_{2}^{\bullet-}\right)$ e o fenol $\left(\mathrm{C}_{6} \mathrm{H}_{5} \mathrm{OH}\right)$.

$\mathrm{O}$ ataque do radical ${ }^{\bullet} \mathrm{OH}$ ao fenol pode ser descrito de várias formas. Admitindo que os efeitos de formação de intermediários estejam expressos numa constante de segunda ordem, pode-se descrever a mineralização do fenol de forma direta: 
$\cdot \mathrm{OH}+\mathrm{C}_{6} \mathrm{H}_{5} \mathrm{OH} \stackrel{k_{14}}{\longrightarrow}$ int $\longrightarrow \mathrm{CO}_{2}+\mathrm{H}_{2} \mathrm{O} \quad k_{14}=6,6 \times 10^{9} \mathrm{~L} \mathrm{~mol}^{-1} \mathrm{~s}^{-1}$

A radiação UV também é capaz de promover a fotólise direta do fenol, cf. a reação

$$
\mathrm{C}_{6} \mathrm{H}_{5} \mathrm{OH} \stackrel{h v}{\longrightarrow} \text { int } \longrightarrow \mathrm{CO}_{2}+\mathrm{H}_{2} \mathrm{O} \quad r_{\mathrm{UV} / \mathrm{C}_{6} \mathrm{H}_{5} \mathrm{OH}}
$$

cuja lei de velocidade é

$$
\begin{aligned}
r_{\mathrm{UV} / \mathrm{C}_{6} \mathrm{H}_{5} \mathrm{OH}}=\phi_{2} I_{0} & \left(\frac{\epsilon_{6}\left[\mathrm{C}_{6} \mathrm{H}_{5} \mathrm{OH}\right]}{\epsilon_{1}\left[\mathrm{H}_{2} \mathrm{O}_{2}\right]+\epsilon_{2}\left[\mathrm{HO}_{2}^{-}\right]+\epsilon_{6}\left[\mathrm{C}_{6} \mathrm{H}_{5} \mathrm{OH}\right]}\right) \times \\
& \times 1-\exp \left(-2,303 b\left(\epsilon_{1}\left[\mathrm{H}_{2} \mathrm{O}_{2}\right]+\epsilon_{2}\left[\mathrm{HO}_{2}^{-}\right]+\epsilon_{6}\left[\mathrm{C}_{6} \mathrm{H}_{5} \mathrm{OH}\right]\right)\right)
\end{aligned}
$$

O peróxido de hidrogênio e o ânion hidroperóxido formam um par ácido-base descrito na reação (R13). Embora as reações do processo $\mathrm{UV} / \mathrm{H}_{2} \mathrm{O}_{2}$ sejam rápidas, os fenômenos de equilíbrio ocorrem. A hipótese de equilíbrio rápido resolve este ponto ao impor que as espécies com comportamento ácido-base atingem concentrações de equilíbrio imediatas conforme as reações de oxidação ocorrem. Os balanços molares para as espécies de interesse nas reações (R1)-(R15) geram o seguinte sistema de equações diferenciais:

$$
\begin{gathered}
\frac{d\left[\mathrm{H}_{2} \mathrm{O}_{2}\right]}{d t}=\left(\frac{1}{1+k_{a}\left[\mathrm{H}^{+}\right]^{-1}}\right) \times\left(-r_{\mathrm{UV} / \mathrm{H}_{2} \mathrm{O}_{2}}-r_{2}-r_{3}-r_{4}-r_{5}+r_{8}+r_{10}+r_{11}\right) \\
\frac{d[\cdot \mathrm{OH}]}{d t}=2 r_{\mathrm{UV} / \mathrm{H}_{2} \mathrm{O}_{2}}-r_{2}-r_{3}+r_{4}+r_{5}-r_{8}-r_{9}-r_{12}-r_{14} \\
\frac{d\left[\mathrm{C}_{6} \mathrm{H}_{5} \mathrm{OH}\right]}{d t}=-r_{\mathrm{UV} / \mathrm{C}_{6} \mathrm{H}_{5} \mathrm{OH}}-r_{14} \\
\frac{d\left[\mathrm{HO}_{2}^{-}\right]}{d t}=\left(\frac{1}{1+k_{a}^{-1}\left[\mathrm{H}^{+}\right]}\right) \times\left(-r_{\mathrm{UV} / \mathrm{C}_{6} \mathrm{H}_{5} \mathrm{OH}}-r_{2}-r_{3}-r_{4}-r_{5}+r_{8}+r_{10}+r_{11}\right)
\end{gathered}
$$




$$
\begin{gathered}
\frac{d\left[\mathrm{HO}_{2}^{\bullet}\right]}{d t}=r_{2}+r_{3}-r_{4}+r_{6}-r_{7}-r_{9}-r_{10}-r_{11} \\
\frac{d\left[\mathrm{O}_{2}^{\bullet-}\right]}{d t}=-r_{5}-r_{6}+r_{7}-r_{11}-r_{12}
\end{gathered}
$$

As taxas das reações individuais são dadas pelas equação (2.1), (2.3) e por

$$
\begin{cases}r_{2}=k_{2}\left[\mathrm{H}_{2} \mathrm{O}_{2}\right]\left[\bullet^{\bullet} \mathrm{OH}\right] & r_{8}=k_{8}\left[{ }^{\bullet} \mathrm{OH}\right]^{2} \\ r_{3}=k_{3}\left[{ }^{\bullet} \mathrm{OH}\right]\left[\mathrm{HO}_{2}^{-}\right] & r_{9}=k_{9}\left[{ }^{\bullet} \mathrm{OH}\right]\left[\mathrm{HO}_{2}^{\bullet}\right] \\ r_{4}=k_{4}\left[\mathrm{H}_{2} \mathrm{O}_{2}\right]\left[\mathrm{HO}_{2}^{\bullet}\right] & r_{10}=k_{10}\left[\mathrm{HO}_{2}^{\bullet}\right]^{2} \\ r_{5}=k_{5}\left[\mathrm{H}_{2} \mathrm{O}_{2}\right]\left[\mathrm{O}_{2}^{\bullet-}\right] & r_{11}=k_{11}\left[\mathrm{HO}_{2}^{\bullet}\right]\left[\mathrm{O}_{2}^{\bullet-}\right] \\ r_{6}=k_{6}\left[\mathrm{O}_{2}^{\bullet-}\right]\left[\mathrm{H}^{+}\right] & r_{12}=k_{12}\left[\bullet^{\circ} \mathrm{OH}\right]\left[\mathrm{O}_{2}^{\bullet-}\right] \\ r_{7}=k_{7}\left[\mathrm{HO}_{2}^{\bullet}\right] & \end{cases}
$$

A concentração de $\mathrm{H}^{+}$é determinada pelo $\mathrm{pH}$ do meio reacional, suposto constante pelo modelo. Cabe aqui observar que, no balanço do radical $\bullet^{\circ} \mathrm{OH}$, os autores não levaram em conta o consumo de 2 mols desta espécie na reação (R8), da mesma forma que na reação (R10) com o radical $\mathrm{HO}_{2}^{\bullet}$; outros autores (SANTORO et al., 2010; ALPERT; KNAPE; DUCOSTE, 2010) consideram a estequiometria dos radicais.

\subsection{Modelagem matemática de reatores}

\subsubsection{Caracterização macroscópica do escoamento em reatores não-ideais}

Reatores são tradicionalmente modelados com escoamento pistonado (plug flow), como nos reatores tubulares, ou então com a hipótese de mistura perfeita nos tanques agitados (CSTRs). Tais modelos podem dar comportamentos bem diferentes quanto ao tamanho do reator e à distribuição dos produtos. Seu valor reside em sua simplicidade (LEVENSPIEL, 1988). 
Em equipamentos reais, é possivel que o escoamento se desvie dos padrões ideais. Para levar isso em conta, tem sido adotada a distribuição dos tempos de residência (DTR) do material escoando no reator. A ideia de usar a DTR na análise da performance de reatores químicos foi proposta num artigo pioneiro de MacMullin e Weber, mas só foi organizada de forma estruturada por Danckwerts (1958). Num reator tubular ideal, todos os átomos permanecem o mesmo intervalo de tempo em seu interior; o mesmo ocorre num reator em batelada. Esse tempo é chamado de tempo de residência no reator.

Os reatores citados acima são os únicos em que todos os átomos em seu interior têm o mesmo tempo de residência. Nos outros tipos, os vários átomos alimentados ficam diferentes tempos dentro do reator, i.e., existe uma distribuição de tempos de residência do material no reator. Considere um CSTR: a alimentação introduzida em qualquer instante é considerada como completamente misturada ao material que já estava em seu interior. Assim, alguns átomos que entram num CSTR saem quase que imediatamente, pois o fluido é retirado continuamente; outros ficam lá um grande espaço de tempo. A maioria dos átomos, como esperado, deixa o reator num tempo próximo ao tempo médio de residência.

A DTR é representada pela função de distribuição $E(t)$. Ela é definida como

$$
E(t)=\frac{C(t)}{\int_{0}^{\infty} C(t) d t}
$$

sendo $C(t)$ a concentração de uma espécie (traçador, p.ex.) na saída do reator. A quantidade $E(t) d t$ é a fração de fluido saindo do reator que gastou tempo entre $t \mathrm{e}$ $t+d t$ em seu interior, e dessa forma, $\int_{0}^{\infty} E(t) d t=1$ (i.e., em algum momento todo o fluido sai do reator).

O modo mais simples de encontrar a DTR de um reator é usar um traçador nãoreativo. Ele pode ser injetado na forma de um pulso, de um degrau, de uma entrada periódica ou randomicamente. Nas injeções tipo pulso, uma quantidade fixa de traça- 
dor é injetada instantaneamente na corrente de entrada do reator. A concentração de saída é medida como uma funcão do tempo. Fogler (2006) recomenda que o traçador tenha a mesma densidade que o fluido principal e que não seja adsorvido.

Um parâmetro relevante na descrição das curvas de DTR é o tempo médio $\left(t_{m}\right)$, comum a todas as variáveis definidas por uma distribuição estatística. Ele é dado por

$$
t_{m}=\frac{\int_{0}^{\infty} t E(t)}{\int_{0}^{\infty} E(t)}
$$

A variância é outro parâmetro utilizado para comparar DTRs. Ela é definida por

$$
\sigma^{2}=\int_{0}^{\infty} t\left(t-t_{m}\right)^{2} E(t) d t
$$

e sua magnitude indica o espalhamento da distribuição: quanto maior ele for, mais ampla será a curva.

\subsubsection{Caracterização microscópica da fluidodinâmica de reatores não-ideais}

Os sistemas fotoquímicos exibem forte interação entre a cinética das reações de degradação e a distribuição de energia radiante da fonte UV. O campo de velocidades afeta a distribuição de material no interior do reator e, dessa forma, influencia o desenrolar das reações. Logo, há três fenômenos complexos e acoplados entre si que determinam a performance de um tratamento fotoquímico.

A DTR fornece uma visão macroscópica das características do escoamento. Todavia, para compreender o acoplamento entre o campo de velocidades, as taxas de degradação de poluentes e o campo de radiação, não bastam dados macroscópicos: é necessário adotar modelos microscópicos que descrevam a interação entre eles. Tais modelos são derivados das leis de conservação de massa, de energia e de quantidade de movimento e são o tema das seções a seguir. 


\subsubsection{Campo de velocidades}

A aplicação do princípio de conservação de quantidade de movimento gera um conjunto de equações que governam o movimento dos fluidos, usadas para calcular os campos de velocidade e de pressão. Bird, Stewart e Lightfoot (2004) derivam tais equações a partir do balanço diferencial de forças, resultando em

$$
\frac{\partial(\rho U)}{\partial t}+\nabla \cdot(\rho U U)=-\nabla \cdot \pi+\rho g+F
$$

Nesta equação, $U$ é a velocidade do fluido, $\rho$ é sua densidade, $\pi$ é o tensor das tensões e $g$ e $F$ são as acelerações causadas pelo campo gravitacional e por forças externas, respectivamente. O significado físico do primeiro termo é a taxa de variação da quantidade de movimento; o segundo termo representa mudanças na quantidade de movimento causadas por convecção; o quarto e o quinto termos representam a força peso do fluido e as forças de campo, caso sejam relevantes no caso em questão. O terceiro termo representa as contribuições moleculares para a variação da quantidade de movimento, causadas pela pressão (forças normais) e pelas forças viscosas (de cisalhamento); ele é dado por

$$
-\nabla \cdot \pi=-\nabla \cdot P+\nabla \cdot \tau
$$

onde $P$ é a pressão e $\tau$ é o tensor das tensões viscosas.

O escoamento em reatores fotoquímicos é geralmente turbulento (ALPERT; KNAPE; DUCOSTE, 2010). Na abordagem estatística da turbulência, os fenômenos aleatórios do escoamento são vistos como uma combinação de um comportamento médio e de flutuações de pequena escala ao seu redor. O valor instantâneo de qualquer variável é escrito como

$$
\phi=\bar{\phi}+\phi^{\prime}
$$


A barra acima da variável significa média temporal, definida como

$$
\bar{\phi}=\frac{1}{\Delta t} \int_{t}^{t+\Delta t} \phi d t
$$

A média de Reynolds é tomada num intervalo de tempo maior que o das flutuações $\left(\phi^{\prime}\right)$ e obedece às seguintes propriedades:

$$
\overline{\bar{\phi}}=\bar{\phi} \quad \overline{\phi^{\prime}}=0
$$

A equação (2.16) é substituída nas equações fundamentais de transporte de $\phi$ e estas recebem a média temporal para formar as equações de transporte para as quantidades médias, aplicando as propriedades acima.

Com as equações (2.14), (2.16) e (2.17), é possível escrever os balanços de quantidade de movimento e de massa global para um fluido newtoniano e incompressível, considerando efeitos de turbulência. Trata-se da equação de Navier-Stokes com a média de Reynolds (RANS) e da equação da continuidade, respectivamente:

$$
\begin{gathered}
\frac{\partial \overline{U_{i}}}{\partial t}+\frac{\partial\left(\overline{U_{i}} \overline{U_{j}}\right)}{\partial x_{j}}=-\frac{1}{\rho} \frac{\partial P}{\partial x_{i}}+\frac{\partial}{\partial x_{j}}\left[v\left(\frac{\partial \overline{U_{i}}}{\partial x_{j}}+\frac{\partial \overline{U_{j}}}{\partial x_{i}}\right)-\overline{u_{i} u_{j}}\right] \\
\frac{\partial \bar{U}_{i}}{\partial x_{i}}=0
\end{gathered}
$$

Nas equações (2.19) e (2.20), $\bar{U}$ é a média temporal da velocidade do fluido, $u$ é o desvio em relação à média, $p$ é a pressão e $v$ é a viscosidade cinemática do fluido. A estrutura da equação (2.19) é semelhante à da equação (2.14), exceto pelos termos adicionais no segundo membro. Esses termos atuam como as tensões causadas pelo movimento turbulento; são chamados de tensores de Reynolds e definidos por

$$
\left(\tau_{i j}\right)_{\mathrm{turb}}=\rho \overline{u_{i} u_{j}}
$$

O tensor de Reynolds é simétrico, com seis componentes independentes entre si. 
Chega-se aqui ao problema fundamental em turbulência: para calcular as propriedades médias do escoamento, é necessário prover equações constitutivas (modelos) para o tensor de Reynolds. Os modelos de turbulência baseados na equação RANS são divididos em duas classes: os que adotam a hipótese de Boussinesq e os que resolvem diretamente as componentes do tensor de Reynolds.

A hipótese de Boussinesq assume que o tensor de Reynolds pode ser expresso em termos do gradiente da velocidade média. Em sua formulação, é feita uma analogia entre os movimentos moleculares e turbulentos: os turbilhões são vistos como moléculas, colidindo e trocando quantidade de movimento e obedecendo leis semelhantes à teoria cinética dos gases. Matematicamente:

$$
-\overline{u_{i} u_{j}}=v_{t}\left(\frac{\partial \overline{U_{i}}}{\partial x_{j}}+\frac{\partial \overline{U_{j}}}{\partial x_{i}}\right)+\frac{2}{3} k \delta_{i j}
$$

A nova constante, $v_{t}$, é a viscosidade turbulenta: ao contrário da viscosidade molecular, não é uma propriedade do fluido, mas sim dependente do estado local do escoamento. $k$ é a energia cinética de turbulência, correspondente à soma dos elementos da diagonal principal do tensor de Reynolds:

$$
k=\frac{1}{2} \overline{u_{i} u_{i}}
$$

Substituindo a equação (2.22) na equação RANS, forma-se um sistema determinado, desde que a viscosidade turbulenta e a energia cinética de turbulência sejam conhecidas. A forma da equação RANS fica semelhante à da equação (2.14), exceto pela substituição da viscosidade molecular pela viscosidade efetiva $\left(v_{e f f}\right)$ :

$$
v_{e f f}=v+v_{t}
$$

Os modelos de turbulência baseados na hipótese de Boussinesq calculam os parâmetros $v_{t}$ e $k$ para substituí-los na equação RANS. Três modelos desta classe que merecem destaque para a análise de reatores anulares são o $k-\epsilon$, o $k-\omega$ e o SST. 
O modelo $k-\epsilon$ (LAUNDER; SPALDING, 1974) é o modelo de turbulência mais popular na classe dos de duas equações. Ele relaciona a viscosidade turbulenta com a energia cinética de turbulência e com a taxa de dissipação de energia turbulenta $(\epsilon)$ pela seguinte equação:

$$
v_{t}=C_{\mu} k^{2} / \epsilon
$$

onde $C_{\mu}$ é um coeficiente empírico. Os valores locais de $k$ e $\epsilon$ são obtidos resolvendo suas equações de transporte:

$$
\begin{array}{r}
\frac{\partial k}{\partial t}+\overline{U_{j}} \frac{\partial k}{\partial x_{j}}=v_{t}\left(\frac{\partial \overline{U_{i}}}{\partial x_{j}}+\frac{\partial \overline{U_{j}}}{\partial x_{i}}\right) \frac{\partial \overline{U_{i}}}{\partial x_{j}}+\frac{\partial}{\partial x_{j}}\left[\left(v+\frac{v_{t}}{\sigma_{k}}\right) \frac{\partial k}{\partial x_{j}}\right]-\epsilon \\
\frac{\partial \epsilon}{\partial t}+\overline{U_{j}} \frac{\partial \epsilon}{\partial x_{j}}=C_{\epsilon 1} \frac{\epsilon}{k} v_{t}\left(\frac{\partial \overline{U_{i}}}{\partial x_{j}}+\frac{\partial \overline{U_{j}}}{\partial x_{i}}\right) \frac{\partial \overline{U_{i}}}{\partial x_{j}}-C_{\epsilon 2} \frac{\epsilon^{2}}{k}+\frac{\partial}{\partial x_{j}}\left[\left(v+\frac{v_{t}}{\sigma_{\epsilon}}\right) \frac{\partial \epsilon}{\partial x_{j}}\right]
\end{array}
$$

As constantes empíricas usadas no modelo estão indicadas na Tabela 4. Os termos das equações para $k$ e $\epsilon$ são classificados em quatro grupos: transporte difusivo, transporte convectivo, geração e dissipação. O transporte difusivo tem uma componente molecular e outra turbulenta. As flutuações na pressão e na velocidade contribuem para o transporte difusivo da energia cinética de turbulência, assim como nas taxas de dissipação de energia. A geração de energia cinética de turbulência se dá extraindo energia do escoamento médio, enquanto o termo de geração na equação de $\epsilon$ representa o alongamento dos vórtices pelo escoamento. O termo de dissipação na equação de $k$ é simplesmente igual a $\epsilon$.

Na formulação do modelo $k-\epsilon$, há uma série de hipóteses consideradas:

- as flutuações turbulentas são isotrópicas;

- ocorre equilíbrio local dos termos de produção e dissipação;

- o número de Reynolds do escoamento é elevado 
Apesar da robustez e de predizer uma ampla gama de escoamentos de forma satisfatória, ele não lida bem com escoamentos tridimensionais complexos, rotativos e com separação de fluxo (SPEZIALE, 1990).

Tabela 4. Constantes empíricas da formulação do modelo de turbulência $k-\epsilon$ (LAUNDER; SPALDING, 1974).

\begin{tabular}{cc}
\hline Constante & Valor \\
\hline$C_{\epsilon 1}$ & 1,44 \\
$C_{\epsilon 2}$ & 1,92 \\
$C_{\mu}$ & 0,09 \\
$\sigma_{k}$ & 1,0 \\
$\sigma_{\epsilon}$ & 1,3 \\
\hline
\end{tabular}

Embora o modelo $k-\epsilon$ seja o mais popular, o primeiro modelo de turbulência de duas equações foi o $k-\omega$, proposto por Kolmogorov (1942) e revisado posteriormente por diversos autores. Também baseados na hipótese de Boussinesq, escolheram a energia cinética de turbulência como um dos parâmetros a determinar e modelaram sua equação de transporte. O segundo parâmetro modelado foi a taxa de dissipação de energia cinética turbulenta $(\omega)$. Há várias interpretações para o parâmetro:

- Kolmogorov (1942) considerava o recíproco de $\omega$ como a escala de tempo na qual a dissipação de energia cinética ocorre;

- Launder e Spalding (1972) e Wilcox e Alber (1972) identificam $\omega$ como o valor médio quadrático (RMS) das flutuações da vorticidade, também conhecido como enstrofia;

- Para Speziale, Abid e Anderson (1990), é a razão entre $\epsilon$ e $k$, i.e., a taxa de dissipação por unidade de energia cinética de turbulência.

Na formulação original, Kolmogorov postulou uma equação para $\omega$ partindo dos processos físicos típicos no movimento de um fluido (variação temporal, convecção, difusão, dissipação, dispersão e produção) e de análise dimensional. Um aspecto relevante dessa equação é a ausência do termo de produção, consistente com a noção de 
Kolmogorov de que $\omega$ está associado com as menores escalas de turbulência, e portanto não tem interação com o escoamento médio ${ }^{1}$. A forma da equação para $\omega$ mudou conforme o modelo evoluiu nas últimas décadas: todas as revisões acrescentaram um termo de produção. A versão mais verificada foi a proposta por Wilcox (1988), apresentada abaixo:

$$
\begin{gathered}
v_{t}=k / \omega \\
\frac{\partial k}{\partial t}+\overline{U_{j}} \frac{\partial k}{\partial x_{j}}=v_{t}\left(\frac{\partial \overline{U_{i}}}{\partial x_{j}}+\frac{\partial \overline{U_{j}}}{\partial x_{i}}\right) \frac{\partial \overline{U_{i}}}{\partial x_{j}}+\frac{\partial}{\partial x_{j}}\left[\left(v+\sigma^{*} v_{t}\right) \frac{\partial k}{\partial x_{j}}\right]-\beta^{*} k \omega \\
\frac{\partial \omega}{\partial t}+\overline{U_{j}} \frac{\partial \omega}{\partial x_{j}}=\alpha \frac{\omega}{k} v_{t}\left(\frac{\partial \overline{U_{i}}}{\partial x_{j}}+\frac{\partial \overline{U_{j}}}{\partial x_{i}}\right) \frac{\partial \overline{U_{i}}}{\partial x_{j}}+\frac{\partial}{\partial x_{j}}\left[\left(v+\sigma v_{t}\right) \frac{\partial \omega}{\partial x_{j}}\right]-\beta \omega^{2}
\end{gathered}
$$

As constantes empíricas do modelo $k-\omega$ estão definidas na Tabela 5. Ele é um modelo mais preciso e robusto que o $k-\epsilon$ nas regiões próximas a paredes (subcamada viscosa) e é superior a outros modelos de duas equações com respeito à estabilidade numérica (MENTER, 1994).

Tabela 5. Constantes empíricas da formulação do modelo de turbulência $k-\omega$ (WILCOX, 1988).

\begin{tabular}{cc}
\hline Constante & Valor \\
\hline$\beta^{*}$ & 0,09 \\
$\sigma$ & 0,5 \\
$\sigma^{*}$ & 0,5 \\
$\alpha$ & $5 / 9$ \\
$\beta$ & $3 / 40$ \\
\hline
\end{tabular}

Os modelos $k-\epsilon$ e $k-\omega$ apresentam qualidades e pontos sensíveis, como por exemplo:

- o modelo $k-\epsilon$ tende a superestimar a tensão de cisalhamento em escoamentos com gradiente de pressão adverso e requer modificações nas proximidades de paredes (damping functions para número de Reynolds baixo);

\footnotetext{
${ }^{1}$ Apesar do brilhantismo de Kolmogorov, sua lógica falha no sentido de que os turbilhões de larga escala são os responsáveis primários por determinar a escala de tempo apropriada para os fenômenos turbulentos e, por consequência, a taxa de dissipação (WILCOX, 1998).
} 
- o modelo $k-\omega$ lida com o gradiente de pressão adverso melhor que o $k-\epsilon$, porém a equação de $\omega$ é muito sensível aos valores deste parâmetro nas regiões de escoamento desenvolvido. Por esta razão, a equação de $\omega$ não conseguiu superar a de $\epsilon$ para determinar a escala padrão de turbulência, apesar de seu melhor desempenho na subcamada viscosa

Menter (1994) propôs um novo modelo formulado por zonas, o SST (shear stress transport), combinando as qualidades dos dois modelos acima. Ele emprega a formulação do modelo $k-\omega$ na região da subcamada viscosa e altera para o $k-\epsilon$ no núcleo turbulento. A transição é realizada por meio de duas blending functions, que levam em conta a distância do ponto até a parede mais próxima.

O modelo SST foi originalmente criado para aplicações em aeronáutica, mas sua formulação robusta nas regiões de parede graças ao modelo de Wilcox contribuiu para que ele se disseminasse nos códigos comerciais de CFD e em outras aplicações industriais. Menter, Kuntz e Langtry (2003) fizeram pequenas modificações em relação à versão original do modelo SST, resultando no seguinte conjunto de equações:

$$
\begin{gathered}
v_{t}=\frac{a_{1} k}{\max \left(a_{1} \omega, S F_{2}\right)} \\
\frac{\partial k}{\partial t}+\frac{\partial\left(U_{i} k\right)}{\partial x_{i}}=\frac{1}{\rho} \tilde{P}_{k}-\beta^{*} k \omega+\frac{\partial}{\partial x_{i}}\left[\left(v+\sigma_{k} v_{t}\right) \frac{\partial k}{\partial x_{i}}\right] \\
\frac{\partial \omega}{\partial t}+\frac{\partial\left(U_{i} \omega\right)}{\partial x_{i}}=\alpha S^{2}-\beta \omega^{2}+\frac{\partial}{\partial x_{i}}\left[\left(v+\sigma_{k} v_{t}\right) \frac{\partial \omega}{\partial x_{i}}\right]+2\left(1-F_{1}\right) \sigma_{\omega 2} \frac{1}{\omega} \frac{\partial k}{\partial x_{i}} \frac{\partial \omega}{\partial x_{i}}
\end{gathered}
$$

As blending functions empregadas são

$$
F_{1}=\tanh \left(\zeta_{1}^{4}\right) \quad, \quad \zeta_{1}=\min \left[\max \left(\frac{\sqrt{k}}{\beta^{*} \omega y}, \frac{500 v}{y^{2} \omega}\right), \frac{4 \rho \sigma_{\omega 2} k}{C D_{k \omega} y^{2}}\right]
$$




$$
\begin{gathered}
C D_{k \omega}=\max \left(2 \rho \sigma_{\omega 2} \frac{1}{\omega} \frac{\partial k}{\partial x_{i}}, 10^{-10}\right) \\
F_{2}=\tanh \left(\zeta_{2}^{2}\right) \quad, \quad \zeta_{2}=\max \left(\frac{2 \sqrt{k}}{\beta^{*} \omega y}, \frac{500 v}{y^{2} \omega}\right)
\end{gathered}
$$

onde y é a distância até a parede mais próxima e $S$ é a taxa de deformação do fluido. Note que $F_{1}$ é igual a zero longe da parede e transforma a equação de $\omega$ na equação de $\epsilon$ (fazendo $\omega=\epsilon /\left(\beta^{*} k\right), \operatorname{com} \beta^{*}=C_{\mu}$ ), ao passo que muda para 1 dentro da região da subcamada viscosa (modelo $k-\omega)$.

Um fator limitante de produção é empregado no modelo SST para evitar predição excessiva de turbulência em regiões de estagnação:

$$
\begin{gathered}
P_{k}=\mu_{t} \frac{\partial U_{i}}{\partial x_{j}}\left(\frac{\partial U_{i}}{\partial x_{j}}+\frac{\partial U_{j}}{\partial x_{i}}\right) \\
\tilde{P}_{k}=\min \left(P_{k}, 10 \beta^{*} \rho k \omega\right)
\end{gathered}
$$

A Tabela 6 lista as constantes do modelo SST, que, como esperado, são calculadas como uma combinação das constantes correspondentes dos modelos $k-\epsilon$ e $k-\omega$. As modificações de Menter, Kuntz e Langtry (2003) à formulação original de Menter (1994) são o uso da taxa de deformação ao invés da vorticidade na equação (2.31) e do fator 10 no limitante de produção, ao invés de 20.

Tabela 6. Constantes empíricas da formulação do modelo de turbulência SST (MENTER; KUNTZ; LANGTRY, 2003).

\begin{tabular}{cccc}
\hline Constante & Valor & Constante & Valor \\
\hline$\beta^{*}$ & 0,09 & $\alpha_{2}$ & 0,44 \\
$\alpha_{1}$ & $5 / 9$ & $\beta_{2}$ & 0,0828 \\
$\beta_{1}$ & $3 / 40$ & $\sigma_{k 2}$ & 1 \\
$\sigma_{k 1}$ & 0,85 & $\sigma_{\omega 2}$ & 0,856 \\
$\sigma_{\omega 1}$ & 0,5 & & \\
\hline
\end{tabular}


Os modelos de turbulência baseados na hipótese de Boussinesq conseguem predizer bem muitos escoamentos de interesse da engenharia. Porém, há casos notáveis em que eles falham: escoamento com mudanças repentionas na taxa de deformação, sobre superfícies curvas, em dutos com movimentos secundários, com separação da camada limite e em fluidos em rotação (WILCOX, 1998). O ganho potencial de empregar um modelo universal, que incluísse naturalmente os efeitos de curvatura das linhas de corrente, dos movimentos seciundários, etc., motivou Shih et al. (1995) a elaborarem o modelo de tensões de Reynolds (Reynolds stress model, RSM). Ele adota fechamento de segunda ordem, ou seja, aplica equações de transporte para as tensões de Reynolds. Geralmente, ele não considera uma equação de transporte para a energia cinética de turbulência, mas mantém uma equação para alguma escala de turbulência ( $\epsilon$ ou $\omega$ ).

No modelo RSM, a equação de transporte para as tensões de Reynolds é dada por

$$
\frac{\partial \overline{u_{i} u_{j}}}{\partial t}+\overline{U_{k}} \frac{\partial \overline{u_{i} u_{j}}}{\partial x_{k}}=\operatorname{Diff}\left(\overline{u_{i} u_{j}}\right)+P_{i j}+R_{i j}-E_{i j}
$$

Nela, Diff $\left(\overline{u_{i} u_{j}}\right)$ representa o transporte difusivo, modelado por

$$
\operatorname{Diff}\left(u_{i} u_{j}\right)=C_{S} \frac{\partial}{\partial x_{k}}\left(\frac{k}{\bar{\epsilon}} \overline{u_{k} u_{k}} \frac{\partial \overline{u_{i} u_{j}}}{\partial x_{k}}\right)
$$

O termo de produção de tensões, $P_{i j}$, é definido como

$$
P_{i j}=-\left(\overline{u_{i} u_{k}} \frac{\partial \overline{U_{j}}}{\partial x_{k}}+\overline{u_{j} u_{k}} \frac{\partial \overline{U_{i}}}{\partial x_{k}}\right)
$$

$E_{i j}$ é o termo que calcula a destruição das tensões de Reynolds por efeitos viscosos:

$$
E_{i j}=\frac{2}{3} \epsilon \delta_{i j}
$$

Um dos termos mais desafiadores na elaboração do modelo é o de correlação pressão-deformação $\left(R_{i j}\right)$. Ele atua para redistribuir a energia entre as tensões normais e para reduzir as tensões de cisalhamento. Há dois fatores que despertam interesse nele (WILCOX, 1998): 
- sua ordem de grandeza é a mesma do termo de produção, de modo que ele desempenha um papel crítico em escoamentos de interesse da engenharia;

- ele envolve basicamente correlações imensuráveis, abrindo espaço para a criatividade e inteligência dos autores para estabelecer um fechamento racional.

A correlação pressão-deformação é modelada como

$$
\begin{aligned}
R_{i j}=-\left(C_{1} \epsilon+\right. & \left.C_{1 s} P_{k k}\right) b_{i j}+C_{2} \epsilon\left(b_{i k} b_{i j}-b_{m n} b_{m n} \delta_{i j} / 3\right)+\left(C_{3}-C_{3 s} \sqrt{b_{m n} b_{m n}}\right) k S_{i j}+ \\
& +C_{4} k\left(b_{i j} S_{j k}+b_{j k} S_{i k}-2 b_{m n} S_{m n} \delta_{i j} / 3\right)+C_{5} k\left(b_{i k} \Omega_{j k}+b_{j k} \Omega_{i k}\right)
\end{aligned}
$$

onde $b_{i j}, S_{i j}$ e $\Omega_{i j}$ são os tensores de Reynolds anisotrópico, da taxa média de deformação e da vorticidade média, respectivamente. Esses termos são definidos por

$$
\begin{gathered}
b_{i j}=\frac{1}{2} \frac{\overline{u_{i} u_{j}}}{k}-\frac{\delta_{i j}}{3} \\
S_{i j}=\frac{1}{2}\left(\frac{\partial \overline{U_{i}}}{\partial x_{j}}+\frac{\partial \overline{U_{j}}}{\partial x_{i}}\right) \\
\Omega_{i j}=\frac{1}{2}\left(\frac{\partial \overline{U_{i}}}{\partial x_{j}}-\frac{\partial \overline{U_{j}}}{\partial x_{i}}\right)
\end{gathered}
$$

A escala de turbulência é dada pela taxa de dissipação, cuja equação de transporte é

$$
\frac{\partial \epsilon}{\partial t}+\overline{U_{j}} \frac{\partial \epsilon}{\partial x_{j}}=C_{\epsilon} \frac{\partial}{\partial x_{k}}\left(\frac{k}{\bar{\epsilon}} \overline{u_{k} u_{m}} \frac{\partial \epsilon}{\partial x_{m}}\right)+C_{\epsilon 1} \frac{k}{\epsilon} \overline{u_{i} u_{j}} \frac{\partial \overline{U_{i}}}{\partial x_{j}}-C_{\epsilon 2} \frac{\epsilon^{2}}{k}
$$

A Tabela 7 lista as constantes empíricas do modelo RSM. Ele é o mais geral dentre os modelos clássicos de turbulência e tem boa performance para escoamentos complexos e casos de descolamento de camada limite, embora não reproduza bem certos escoamentos devido a problemas com a equação para $\epsilon$ (RANADE, 2002). 
Tabela 7. Constantes empíricas do modelo de turbulência RSM (SHIH et al., 1995).

\begin{tabular}{cccc}
\hline Constante & Valor & Constante & Valor \\
\hline$C_{\epsilon}$ & 0,183 & $C_{1 s}$ & 1,8 \\
$C_{\epsilon 1}$ & 1,44 & $C_{3}$ & 0,8 \\
$C_{\epsilon 2}$ & 1,83 & $C_{3 s}$ & 1,3 \\
$C_{S}$ & 0,21 & $C_{4}$ & 1,25 \\
$C_{1}$ & 3,4 & $C_{5}$ & 0,4 \\
$C_{2}$ & 4,2 & & \\
\hline
\end{tabular}

\subsubsection{Conservação de massa das espécies}

É costume escrever a equação de conservação de massa de cada espécie no meio reacional em termos das frações mássicas, ao invés de concentração molar. Matematicamente:

$$
\frac{\partial\left(\rho x_{A}\right)}{\partial t}+\boldsymbol{\nabla} \cdot\left(\rho U x_{A}\right)=-\nabla \cdot j_{e f f}+S_{A}
$$

Na equação acima, $x_{A}$ é a fração mássica do componente A. O termo difusivo $\left(j_{e f f}\right)$ é composto por duas parcelas: uma considera os efeitos de difusão devido ao gradiente de concentração, seguindo a lei de Fick, e outra considera as flutuações turbulentas:

$$
j_{e f f}=\left(\rho D_{A}+\frac{\mu_{t}}{S c_{t}}\right) \nabla x_{A}
$$

Na expressão do fluxo difusivo, $D_{A}$ é a difusividade da espécie A no meio e $S c_{t}$ é o número de Schmidt turbulento.

O termo $S_{A}$ é a taxa líquida de produção do componente A por unidade de volume, dado pela soma das taxas de reação de A em cada reação do mecanismo considerado. A diferença entre as escalas de tempo do escoamento e das reações pode tornar as equações dos balanços de massa das espécies numericamente stiff com respeito à convecção e difusão (CHUNG, 2002). Isso dificulta a estabilização do processo iterativo ao resolver os balanços de massa das espécies usando técnicas de CFD. É necessária seleção adequada do tamanho das células na malha, do método de solução e do controle de escala de tempo para atingir convergência (PERES; VIANNA JR., 2012). 


\subsubsection{Campo de radiação}

A caracterização do campo de radiação de um reator fotoquímico requer a incorporação de fenômenos ópticos - reflexão, refração, zonas de sombra - e de características da lâmpada à configuração específica do reator. A distribuição de energia radiante em um reator fotoquímico é descrita pela equação de transporte de radiação (radiation transport equation, RTE). Para um dado comprimento de onda, a intensidade de radiação espectral numa posição $\vec{r}$ devido a um raio proveniente da direção $\vec{s}$ é dada por

$$
\frac{d I(\vec{r}, \vec{s})}{d s}=-\left(a_{\lambda}+k_{\lambda}\right) I(\vec{r}, \vec{s})+a_{\lambda} I_{b}(v, T)+\frac{k_{\lambda}}{4 \pi} \int_{4 \pi} I\left(\vec{r}, \overrightarrow{s^{\prime}}\right) \phi\left(\vec{s} \cdot \overrightarrow{s^{\prime}}\right) d \Omega^{\prime}+S
$$

na qual $a_{\lambda}$ e $k_{\lambda}$ são os coeficientes (médios) de absorção e de espalhamento para o comprimento de onda $\lambda ; v$ é a frequência da radiação, $T$ é a temperatura local, $I_{b}$ é a intensidade de emissão de um corpo negro, $\Omega$ é um ângulo sólido, $\phi$ é a função de fase e $S$ é o termo fonte de radiação. O primeiro termo do lado direito da RTE representa a perda de energia radiante por absorção e espalhamento. O termo seguinte é o ganho de energia devido à emissão e é desprezível para sistemas operados à temperatura ambiente. A função de fase representa a probabilidade da radiação se propagando na direção $\vec{s}$ ser espalhada para a direção $\overrightarrow{s^{\prime}}$.

A RTE é uma equação integro-diferencial de primeira ordem para $I$ numa direção fixa $\vec{s}$ cuja solução analítica existe apenas para casos extremamente simplificados e unidimensionais. Por essa dificuldade, foram propostos modelos algébricos para o campo de radiaçao e métodos numéricos para a solução da RTE. Dentre os modelos algébricos, o mais simples é o modelo radial:

$$
I(r)=\frac{P}{2 \pi r L} \exp \left[a_{\lambda}\left(r-r_{L}\right)\right]
$$

onde $I$ é a intensidade de radiação $\left(\mathrm{W} \mathrm{m}^{-2}\right)$ num ponto de distância $r$ da lâmpada, $P$ é a potência de emissão da lâmpada no comprimento de onda de interesse (no caso do 
processo $\mathrm{UV} / \mathrm{H}_{2} \mathrm{O}_{2}$, a $\left.253,7 \mathrm{~nm}\right), L$ é seu comprimento $(\mathrm{m}), r_{L}$ é o raio da lâmpada e $a_{\lambda}=\sum \epsilon_{i} C_{i}$ é o coeficiente de absorção do meio $\left(\mathrm{m}^{-1}\right)$. O modelo assume que a lâmpada é uma fonte reta com emissão normal ao seu eixo. Apesar de não considerar refração nem reflexão e não descrever bem o comportamento próximo aos extremos da lâmpada, é um modelo simples de implementar e de desempenho razoável para as dimensões típicas de reatores fotoquímicos (SOZZI; TAGHIPOUR, 2006b).

Jacob e Dranoff (1970) desenvolveram a técnica da soma de múltiplas fontes pontuais (multiple points source summation, MPSS), que divide uma lâmpada retilínea numa série de $n$ pontos de emissão igualmente espaçados num meio absorvente, e com emissão uniforme em todas as direções. Todavia, este modelo pode elevar exageradamente o processamento computacional quando a discretização da lâmpada envolver muitos pontos (LIU et al., 2004).

Além dos modelos algébricos, foram propostas quatro classes de métodos numéricos para a solução da RTE (CARVALHO; FARIAS, 1998):

- método de zonas: o sistema é dividido em regiões de superfícies e regiões de gás, Conhecidos ou calculando os fatores de troca entre gás-gás, superfície-superfície e gás-superfície, é possível calcular o fator de troca global entre qualquer par de zonas e aplicá-los no balanço de energia de cada uma delas para determinar a distribuição de temperaturas no sistema. É comumente empregado na simulação de câmaras de combustão, mas é difícil acoplá-lo a técnicas de volumes finitos;

- método de Monte Carlo: acompanha a trajetória de fótons no sistema determinando sua probabilidade de ser absorvido ou espalhado a partir dos coeficientes de absorção e espalhamento do meio. É um método facilmente adaptado para qualquer geometria. Para que seus resultados sejam significativos estatisticamente, um número adequado de fótons deve ser rastreado, o que pode torná-lo computacionalmente intensivo; 
- métodos de fluxo: são baseados em simplificações da RTE para a variação angular em qualquer ponto. O modelo matemático do campo de radiação em um ponto assume a forma de um conjunto de equações diferenciais parciais, uma para cada direção angular considerada. O método de ordenada discreta (discrete ordinate, DO) pertence a esta classe;

- métodos híbridos: incorporam características desejáveis das classes acima, facilitando seu acoplamento com métodos para solução das equações de transporte de quantidade de movimento.

O método híbrido mais popular é o discrete transfer (DT), formulado por Lockwood e Shah (1981) e revisado por Coelho e Carvalho (1997) para ser incorporado à técnica de volumes finitos. De forma simplificada, ele funciona da seguinte maneira:

1. Um ponto $P_{i}$ é tomado na fronteira do domínio. Traça-se uma semi-esfera centrada em $P_{i}$ e ela é dividida num determinado número de ângulos sólidos, cada um definindo uma direção. Neste aspecto, há semelhanças com o método de Monte Carlo, exceto que no DT as direções são previamente escolhidas, ao passo que no outro as direções são aleatórias;

2. A partir de $P_{i}$, é traçado um raio na direção de cada ângulo sólido até ele atingir o outro extremo da fronteira, no ponto $Q_{j}$;

3. Começando em $Q_{j}$, o raio é traçado de volta até a origem $P_{i}$ e a RTE é integrada ao longo do raio considerando espalhamento isotrópico, ou seja, função de fase unitária;

4. A intensidade de radiação em cada célula do método dos volumes finitos é calculada somando as contribuições de todos os raios que atravessam a célula. 
Um esquema dos raios empregados no cálculo da intensidade de radiação pelo método DT está indicado na Figura 1. As vantagens do método são a flexibilidade para tratar geometrias complexas, o controle dos recursos computacionais gastos a partir da seleção do número de raios empregados, e a fácil aplicação para qualquer sistema de coordenadas.

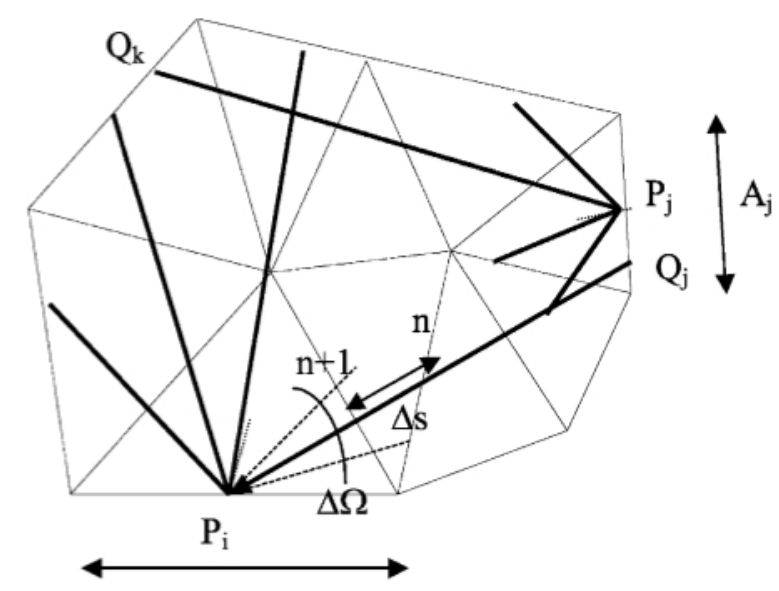

$\mathrm{A}_{\mathrm{i}}$

Figura 1. Discretização do domínio e definição dos raios para solução da RTE pelo método discrete transfer (FELDHEIM; LYBAERT, 2004).

\subsection{Aplicações de CFD a sistemas fotoquímicos}

A fluidodinâmica computacional é uma ferramenta valiosa no projeto e análise de sistemas reacionais. Na última década, despontaram trabalhos de diversos grupos buscando integrar a solução das equações de movimento com modelos para o campo de radiação e cinéticas para processos fotoquímicos.

Pareek et al. (2003) foram pioneiros na simulação de um reator fotocatalítico. Seu sistema consistia num reator com leito de óxido de titânio $\left(\mathrm{TiO}_{2}\right)$ e operando com leito borbulhante para tratar efluentes do processo Bayer. A turbulência nas três fases foi tratada com uma variante do modelo $k-\epsilon$ e o campo de radiação foi determinado pela solução da RTE com o método de ordenada discreta. A reação de degradação do poluente foi tratada com uma cinética de primeira ordem. Os autores verificaram influência 
do posicionamento dos tubos de entrada e saída de líquido sobre a distribuição de reagentes: próximo da entrada ocorria back-mixing e aumentava o tempo de residência do fluido, acarretando menor concentração de reagentes nessa parte. Ocorreu saturação da taxa de reação a partir de uma dada concentração de catalisador, condizente com observações experimentais. A radiação incidente exibiu pouca variação na direção do comprimento da lâmpada, porém grande gradiente na direção radial. Não foi feita a validação do escoamento.

Mohseni e Taghipour (2004) analisaram um reator heterogêneo para oxidação de cloreto de vinila pelo processo $\mathrm{TiO}_{2} / \mathrm{UV}$. Osd autores levantaram pseudoconstantes de primeira ordem em um reator do tipo flat plate, levando em conta a adsorção do cloreto de vinila à superfície do catalisador, sua reação de degradação e a interação com o campo. Tal estratégia evitou o uso de um modelo cinético mais sofisticado para sistemas heterogêneos, como a cinética de Langmuir-Hinshelwood, e de uma equação para o campo de radiação. O escoamento é afetado pela entrada perpendicular do reator, que criou regiões com maior velocidade e provocou maior concentração do contaminante em certas regiões do reator. Um ponto delicado do trabalho é a adoção do modelo laminar para o escoamento, que pode não capturar adequadamente o efeito de entrada. Tais fatos podem explicar os desvios do modelo, que previu concentrações de saída maiores que as observadas experimentalmente.

Qi et al. (2011) também modelaram um reator fotocatalítico multifásico com cinética de primeira ordem para o processo $\mathrm{TiO}_{2} / \mathrm{UV}$ e o modelo $k-\epsilon$ para a turbulência em casa fase, porém adotaram o método discrete transfer para determinar o campo de radiação. A radiação incidente exibiu grande queda numa distância pequena da lâmpada, sugerindo que o uso de múltiplas lâmpadas ou alterações na geometria do reator poderiam otimizar sua eficiência energética. O transporte de massa entre as fases sólida e líquida mostrou-se controlador da reação de fotocatálise. 
Sozzi e Taghipour (2006a) se dedicaram a um levantamento rigoroso do campo de velocidades para duas geometrias comuns em sistemas fotoquímicos, reatores com entrada/saída em L e em U. As dimensões do protótipo estudado são próximas do reator analisado no presente trabalho. Foram analisados os modelos de turbulência $k-\epsilon$, $k-\epsilon$ RNG e RSM, discretizando o domínio computacional com células hexaédricas. Na configuração em U, o campo de velocidades apresentou estrutura complexa devido ao colapso do fluido incidente com a lâmpada, com back-mixing e estruturas observadas em imagens de PIV que não puderam ser capturadas usando a estratégia de média temporal das equações RANS. O fluido seguia a curvatura do reator e se movimentava em direção às partes superiores em diagonal até se desenvolver assumindo caráter pistonado. Na configuração em L, foi necessário fixar a lâmpada com um suporte no interior do reator, que também gerou estruturas turbulentas na seção de entrada.

A partir do estudo fluidodinâmico acima, Sozzi e Taghipour (2006b) se dedicaram à análise de inativação de Escherichia coli no mesmo reator. Partindo do campo de velocidades obtido com o modelo $k-\epsilon$ RNG, foram testados dois modelos para o campo de radiação - o modelo radial e o MPSS - e uma cinética de primeira ordem para a mortalidade da bactéria. Os perfis de radiação indicaram que o modelo MPSS prevê maior intensidade do que o modelo radial próximo à superfície da lâmpada, conforme já observado por (LIU et al., 2004); para regiões afastadas da lâmpada, a intensidade prevista por ambos os modelos é coincidente. Na geometria em U, os efeitos de entrada reduziram a taxa de desinfecção nesta regiãio, efeito que é pronunciado para vazões de operação mais baixas.

Liu et al. (2007) fizeram um estudo abrangente de modelos de turbulência relevantes para as configurações geométricas típicas de sistemas fotoquímicas. Foi um dos primeiros trabalhos a levar em conta outros modelos além do $k-\epsilon$ e do RSM, como o $k-\omega$ e o modelo de dois fluidos (two-fluid model, TFM). Através de imagens de PIV, os autores observaram que o modelo $k-\omega$ reproduziu melhor o campo de velocidades 
nas regiões entre a lâmpada e a parede do reator, enquanto o $k-\epsilon$ não forneceu bons resultados. A discrepância foi atribuída à falta do termo de difusão cruzada na formualação do $k-\omega$, de modo que os modelos $k-\epsilon$ e RSM exibiram melhor desempenho nas regiões livres de choques do fluido entre a lâmpada e a parede. Como aplicação, foi simulada a desinfecção de uma bactéria aplicando o modelo MSSS na descrição do campo de radiação. A diferença nos campos de velocidade previstos por cada modelo de turbulência levou a diferentes intensidades recebidas pela bactéria, ressaltando o acoplamento entre este campo e o de radiação.

A maior parte dos trabalhos encontrados na literatura lidou com reatores heterogêneos ou processos de desinfecção. Sua cinética de degradação utiliza expressôes do tipo lei de potência ou da forma de Langmuir-Hinshelwood, que não requerem atenção especial quanto à convergência (PERES; VIANNA JR., 2012). Todavia, os POAs homogêneos apresentam um mecanismo radicalar com reações altamente competitivas, como se nota pela ordem de grandeza elevada de suas constantes cinéticas (vide tabela 2). Poucos trabalhos foram desenvolvidos para incorporar integralmente essa cinética a um modelo em CFD para a operação de um reator fotoquímico, i.e., incluindo o levantamento dos campos de velocidade e de radiação através de modelos mais sofisticados para a solução da RTE. Na prática, não foi encontrado um trabalho na literatura que adotasse simultaneamente um modelo de degradação rigoroso, como o de Edalatmanesh, Dhib e Mehrvar (2008), combinado a um método rigoroso de solução da RTE.

Mais de doze geometrias distintas foram testadas por Wols et al. (2011) para verificar qual a mais eficaz para a oxidação de atrazina pelo processo $\mathrm{UV} / \mathrm{H}_{2} \mathrm{O}_{2}$ e para inativação de Bacillus subtilis. O campo de radiação foi tratado pelo modelo MSSS. Apesar da grande quantidade de designs avaliados, o modelo cinético adotado para o poluente é fraco: considerou-se apenas a fotólise do $\mathrm{H}_{2} \mathrm{O}_{2}$ e o ataque do radical ${ }^{\bullet} \mathrm{OH}$ à atrazina, sem levar em conta o mecanismo de Haber-Weiss. A concentração de ${ }^{\circ} \mathrm{OH}$ não foi descrita por um balanço diferencial, mas por uma expressão obtida pela apli- 
cação da HEPE à espécie. Essas simplificações podem causar predição incorreta da concentração do radical, já que ele é consumido e gerado pelas reações que se estabelecem quando ele se forma no meio. Dentre as geometrias anulares testadas, o sistema helicoidal mostrou-se o mais eficaz no aproveitamento da energia radiante.

Alpert, Knape e Ducoste (2010) ressaltaram a necessidade de considerar modelos de turbulência mais apropriados para reatores fotoquímicos. A pesquisa contemplou os modelos $k-\epsilon, k-\epsilon$ RNG e $k-\omega$ devido à geometria anular do reator. Não foi feita uma validação especifica para o campo de velocidades: dados de degradação de azul de metileno foram empregados para validar simultaneamente o modelo de turbulência e do campo de radiação, tratado pelos modelos algébricos MSSS e RAD-LSI. A cinética de degradação não incluiu o ânion e o radical hidroperóxido e adotou a HEPE para os radicais ${ }^{\bullet} \mathrm{OH} \mathrm{e} \mathrm{O}_{2}^{\bullet-}$. O modelo de turbulência não afetou significativamente a remoção de azul de metileno, cuja conversão foi menor que a verificada experimentalmente. Devido ao padrão complexo do escoamento, os autores recomendaram que trabalhos futuros avaliassem também o modelo RSM para determinar o campo de velocidades.

Um dos interesses no uso de CFD é o teste de performance de protótipos virtuais, como ferramenta auxiliar no projeto de novos equipamentos e processos. Santoro et al. (2010) criaram dois modelos em CAD representando partes típicas de sistemas oxidativos avançados: um reator anular com lâmpada concêntrica e um reator com lâmpada perpendicular ao escoamento (fluxo cruzado). Foi estudada a degradação de tributil fosfato e tri(2-cloroetil) fosfato. O campo de radiação foi determinado pela solução da RTE com o método de ordenada discreta. Apesar de empregarem um modelo cinético mais rigoroso que o de Alpert, Knape e Ducoste (2010), foi adotado equilíbrio para o ânion e para o radical hidroperóxido $\left(\mathrm{HO}_{2}^{-}\right.$e $\left.\mathrm{HO}_{2}^{\bullet}\right)$. Não houve validação experimental do campo de velocidades, já que se trata de protótipos virtuais. O campo de radiação para as duas configurações estudadas era semelhante a um campo radial. A distribuição de radical ${ }^{\bullet} \mathrm{OH}$ exibiu gradiente intenso na direção radial e a configuração 
anular teve melhor performance oxidativa do que a de fluxo cruzado devido à melhor fluidodinâmica: não houve zonas de recirculação nas quais a cinética de oxidação fica limitada pela difusão do radical ${ }^{\bullet} \mathrm{OH}$. 


\section{METODOLOGIA}

\subsection{Sistema experimental analisado e contextualização do trabalho}

Este trabalho dedicou-se à análise do reator fotoquímico tubular mostrado na Figura 2. Ele é formado por um tubo cilíndrico de vidro borossilicato, com comprimento de 1027 mm e uma lâmpada tubular instalada em posição axial. O diâmetro interno do reator é de $73 \mathrm{~mm}$, reduzido para $61,3 \mathrm{~mm}$ nas extremidades para a adaptação de buchas para vedação e fixação da lâmpada. Por suas dimensões, o volume deste sistema de bancada varia entre 8 e $15 \%$ do de alguns reatores industriais para o processo $\mathrm{UV} / \mathrm{H}_{2} \mathrm{O}_{2}$ (vide Tabela 8).

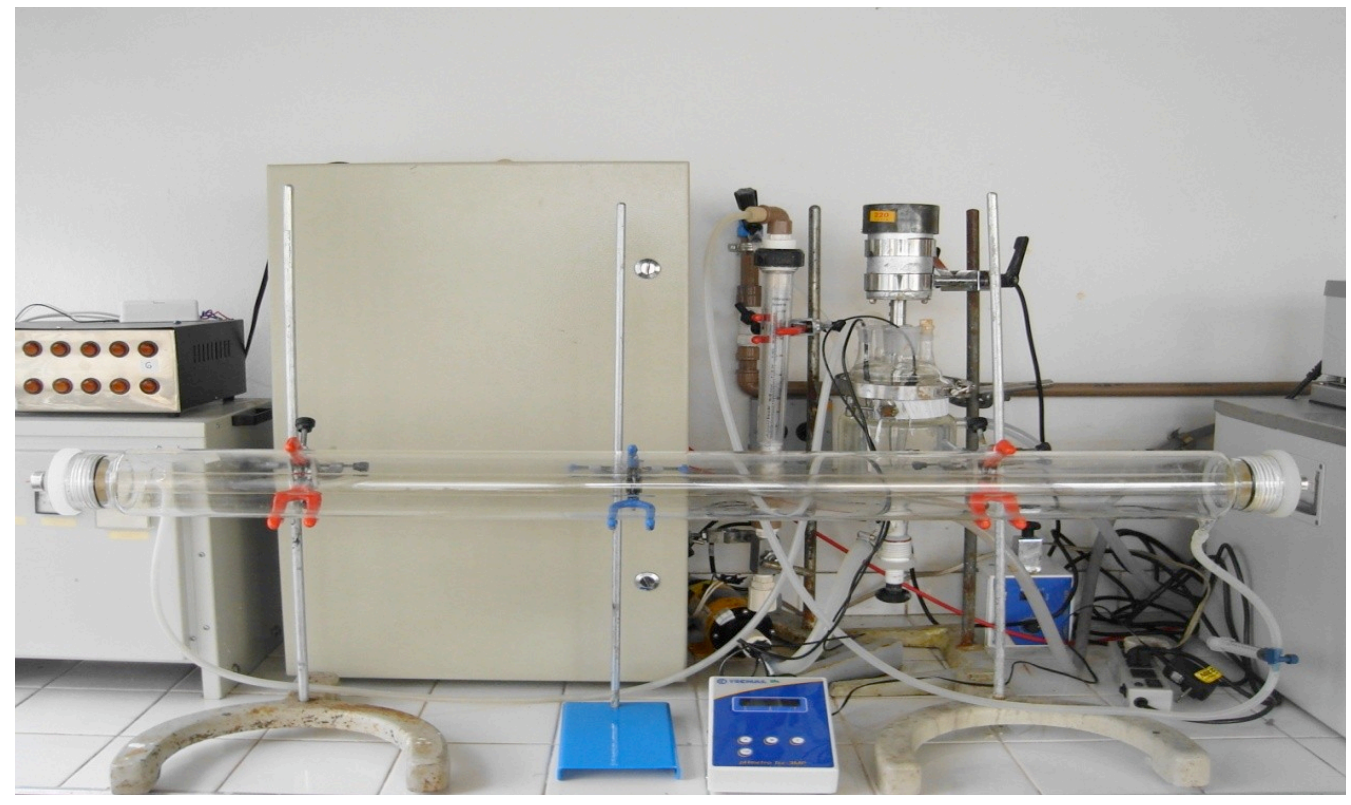

Figura 2. O reator fotoquímico modelado neste trabalho. 
Tabela 8. Comparação do reator analisado neste trabalho com sistemas comerciais para tratamento de efluentes pelo processo $\mathrm{UV} / \mathrm{H}_{2} \mathrm{O}_{2}$ (EPA, 1998).

\begin{tabular}{lcll}
\hline Sistema & $\begin{array}{c}\text { Quantidade } \\
\text { de módulos }\end{array}$ & Volume total $(\mathbf{L})$ & $\begin{array}{l}\text { Potência das } \\
\text { lâmpadas }(\mathbf{W})\end{array}$ \\
\hline $\begin{array}{l}\text { Reator anular deste } \\
\text { trabalho }\end{array}$ & 1 & 3,92 (lâmpada de 25 mm) & 36 ou 75 \\
Calgon Perox-PureTM & 6 & 5,24 (lampada de 37 mm) & 115 \\
Magnum CAV-OX@I & 1 & 40 & 15000 \\
Magnum CAV-OX@II & 2 & 50 & $6 \times 60$ \\
\hline
\end{tabular}

A entrada e saída de fluido no reator são feitas através de tubos posicionados de forma tangencial ao seu corpo. É uma variante da configuração em U (Figura 3), que aumenta o caminho percorrido pelo fluido e, por consequência, seu tempo de residência, sem aumentar o volume do sistema. A alimentação do reator é feita por um tanque de recirculação, também de vidro borossilicato, com volume de 1,5 L e temperatura controlada por um banho termostático em $25 \pm 2{ }^{\circ} \mathrm{C}$. A solução circula pelo sistema com o auxílio de uma bomba centrífuga acoplada a uma válvula agulha e um rotâmetro para regular a vazão. O reator pode operar de forma contínua, alimentado por água da rede, ou em batelada, com seu efluente recirculado para o tanque de mistura. A Figura 4 mostra como a aparelhagem foi montada.

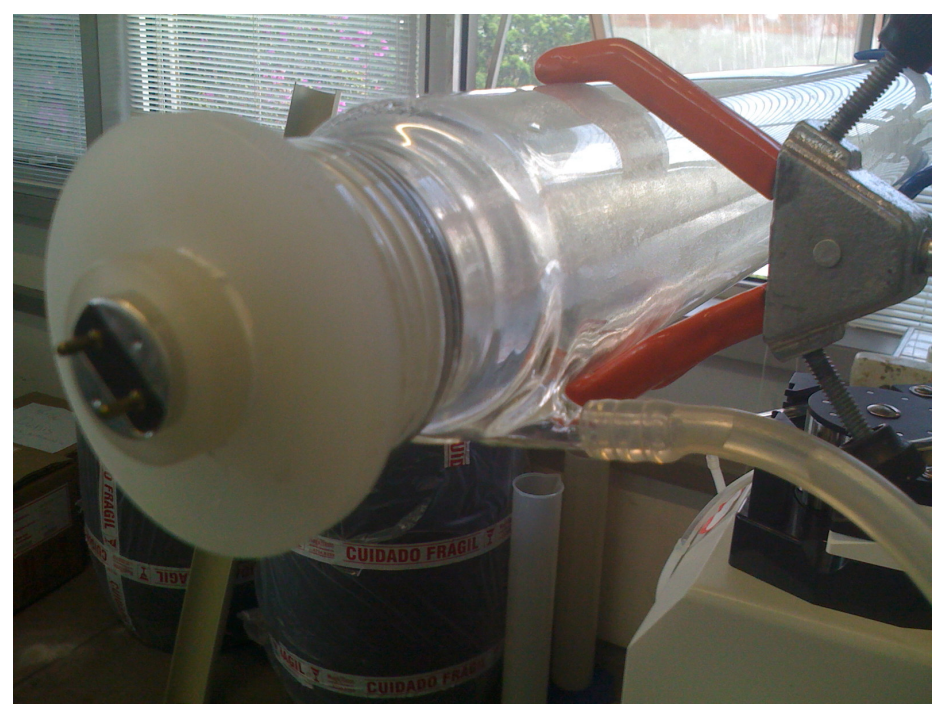

Figura 3. Detalhe da entrada tangente ao corpo do reator. 


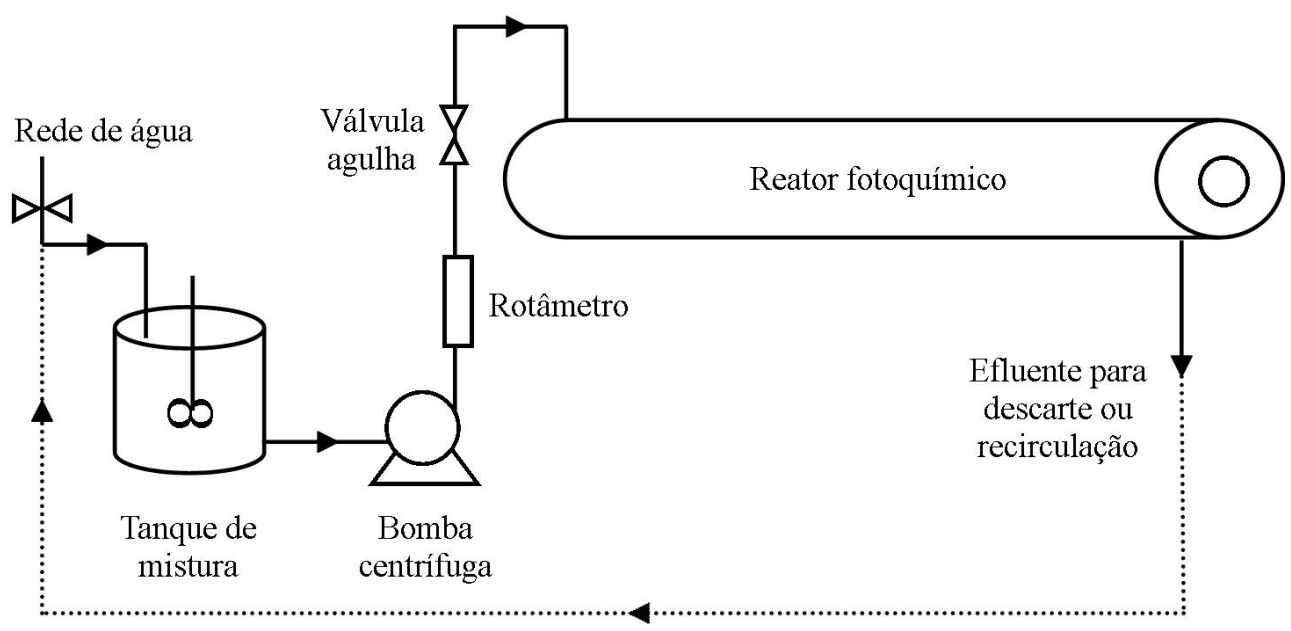

Figura 4. Fluxograma da unidade de degradação analisada.

O reator em questão foi alvo de diversos estudos no Centro de Engenharia de Sistemas Químicos, laboratório do Departamento de Engenharia Química da Escola Politécnica da USP. A Tabela 9 lista os mais relevantes para o presente trabalho.

Tabela 9. Estudos sobre o reator fotoquímico deste trabalho já realizados pelo Centro de Engenharia de Sistemas Químicos.

\begin{tabular}{|c|c|}
\hline Pesquisadores & Análises efetuadas \\
\hline Silvio et al. (2011) & $\begin{array}{l}\text { - levantamento de curvas de DTR } \\
\text { - ajuste de modelos não-ideais de escoamento }\end{array}$ \\
\hline Tambani (2011) & $\begin{array}{l}\text { - levantamento de curvas de DTR } \\
\text { - ajuste de modelos não-ideais de escoamento } \\
\text { - caracterização actinométrica de lâmpadas } \\
\text { - ensaios de degradação de fenol pelo processo UV/ } \mathrm{H}_{2} \mathrm{O}_{2} \\
\text { - desenvolvimento de modelos cinéticos para oxidação de } \\
\text { fenol pelo processo UV/ } \mathrm{H}_{2} \mathrm{O}_{2}\end{array}$ \\
\hline Vianna Jr. et al. (2011) & $\begin{array}{l}\text { - análise numérica das reações do processo } \mathrm{UV} / \mathrm{H}_{2} \mathrm{O}_{2} \\
\text { - estimação de constantes cinéticas para intermediários } \\
\text { da degradação de fenol pelo processo } \mathrm{UV} / \mathrm{H}_{2} \mathrm{O}_{2}\end{array}$ \\
\hline
\end{tabular}

Silvio et al. (2011) levantaram a distribuição de tempos de residência (DTR) do reator e, com essas curvas, estudaram seu escoamento pelo ajuste de modelos nãoideais (tanques em série, dispersão axial, reator de fluxo laminar e de CSTR e PFR em série). Para isso, o sistema da Figura 4 foi ajustado para operar de forma contínua, nas vazões de 30, 60 e $100 \mathrm{~L} \mathrm{~h}^{-1}$, e com lâmpadas de dois diâmetros (25 e $37 \mathrm{~mm}$ ). 
$\mathrm{Na}$ entrada do reator, injetou-se um pulso de $0,5 \mathrm{~mL}$ de azul de metileno, em solução aquosa 7,5\% (concentração mássica). Amostras do efluente foram coletadas e analisadas num espectrofotômetro, com leitura de absorbância em 665 nm. Os experimentos foram duplicados para cada condição experimental. Dentre os modelos avaliados, foi possível concluir, a partir das curvas de DTR, que o modelo de CSTR e PFR em série representa o escoamento do reator de forma mais adequada.

Tambani (2011) também utilizou curvas de DTR para ajustar modelos de escoamento não-ideais para o reator, porém seu estudo foi mais simples que o de Silvio et al. (2011). Seu foco foi a operação do reator em batelada para a oxidação de fenol. O estudo cinético da autora contemplou os seguintes itens:

- determinação da potência de emissão de lâmpadas comerciais na região do UVC (particularmente a 253,7 nm) por actinometria de ferrioxalato (BRAUN; MAURETTE; OLIVEROS, 1991). As lâmpadas avaliadas foram dos modelos TUV TL-D da Phillips, com potência elétrica de 36, 75 e 115 W;

- degradação de fenol pelo processo $\mathrm{UV} / \mathrm{H}_{2} \mathrm{O}_{2}$ para diferentes concentrações iniciais de fenol (50 a $500 \mathrm{mg} \mathrm{L}^{-1}$ ), de peróxido de hidrogênio, vazões de recirculação (62, 72 e $\left.82 \mathrm{~L} \mathrm{~h}^{-1}\right)$ e potência das lâmpadas.

Verificou-se que a conversão de energia elétrica em energia radiante a 253,7 nm não é uniforme: a lâmpada de $115 \mathrm{~W}$ tem potência de $17,7 \mathrm{~W}$ nesse comprimento de onda, enquanto a de $36 \mathrm{~W}$ emite 11,2 W nessa região do espectro, e tais valores são inferiores aos tabelados pelo fabricante. Os experimentos exploratórios de degradação foram realizados por projeto fatorial completo para três variáveis: concentração inicial de fenol, razão molar $\mathrm{H}_{2} \mathrm{O}_{2}$ /fenol e vazão de recirculação. O diagrama de Pareto e o polinômio de correlação entre as variáveis permitiram concluir que a vazão de recirculação tem efeito inferior ao das demais variáveis sobre o processo, de modo que foi mantida constante em $72 \mathrm{~L} \mathrm{~h}^{-1}$ nas etapas posteriores. Os experimentos sistemáticos 
foram realizados num plano com três variáveis pelo método de Doehlert empregando as mesmas variáveis dos experimentos exploratórios, substituindo a vazão de recirculação pela potência elétrica das lâmpadas. A Figura 5 reproduz os resultados de alguns experimentos da autora. Para a condição do ponto central (concentração inicial de fenol $=275 \mathrm{mg} \mathrm{L}^{-1}$ e potência elétrica $=75 \mathrm{~W}$ ) e variação apenas da razão molar, foi observado que a variável manipulada não afetou a taxa de degradação do fenol.

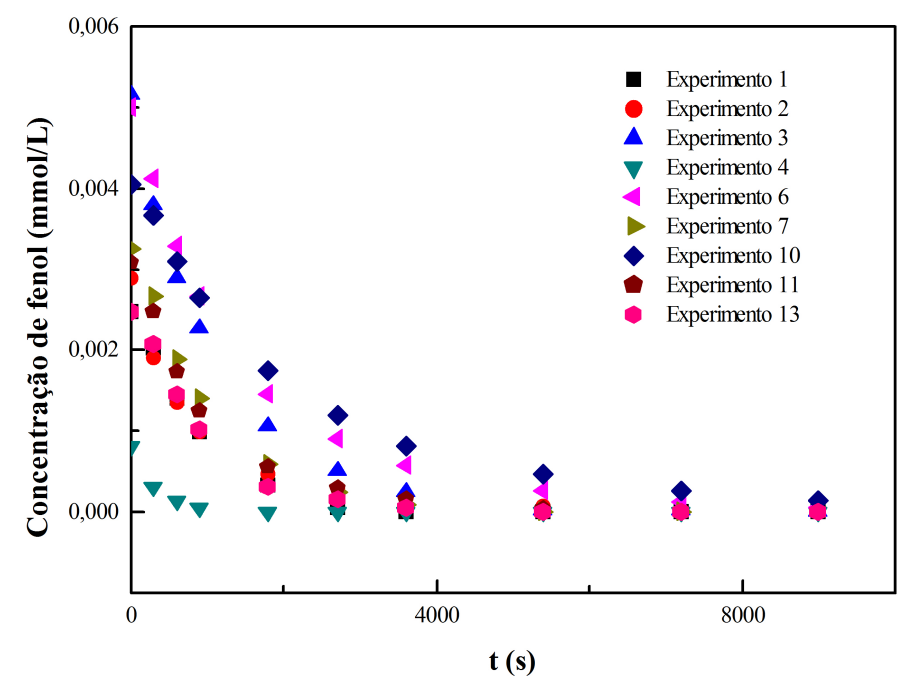

Figura 5. Curvas de degradação de fenol levantadas por Tambani (2011).

Partindo dos dados experimentais de Tambani (2011), Vianna Jr. et al. (2011) investigaram detalhes numéricos para a simulação do processo $\mathrm{UV} / \mathrm{H}_{2} \mathrm{O}_{2}$ e estimaram constantes cinéticas para a formação de catecol e hidroquinona, intermediários após $\mathrm{o}$ ataque do radical hidroxila ao fenol. O mecanismo mecanismo proposto por Edalatmanesh, Dhib e Mehrvar (2008) é composto por reações em cadeia com cinética rápida. A presença de reações com constantes cinéticas com ordem de grandeza muito diferentes (de $10^{0}-10^{10} \mathrm{~L} \mathrm{~mol}^{-1} \mathrm{~s}^{-1}$, vide Tabela 2) faz com que os balanços de massa das espécies envolvidas formem um sistema de equações diferenciais numericamente stiff (CHUNG, 2002). Foi necessário empregar o pacote computacional DASSL em FORTRAN para resolvê-los; ele é baseado no método de Gear, um algoritmo para solução de equações diferenciais stiff (BRENAN; CAMPBELL; PETZOLD, 1989). A Figura 6 
mostra a evolução temporal dos radicais hidroxila $\left({ }^{\bullet} \mathrm{OH}\right)$ e hidroperóxido $\left(\mathrm{HO}_{2}^{\bullet}\right)$ numa das simulações. O comportamento stiff corresponde à grande variação na concentração dessas espécies nos primeiros instantes da reação, que exigem menor passo de integração para manter a solução numérica estável e garantir convergência.

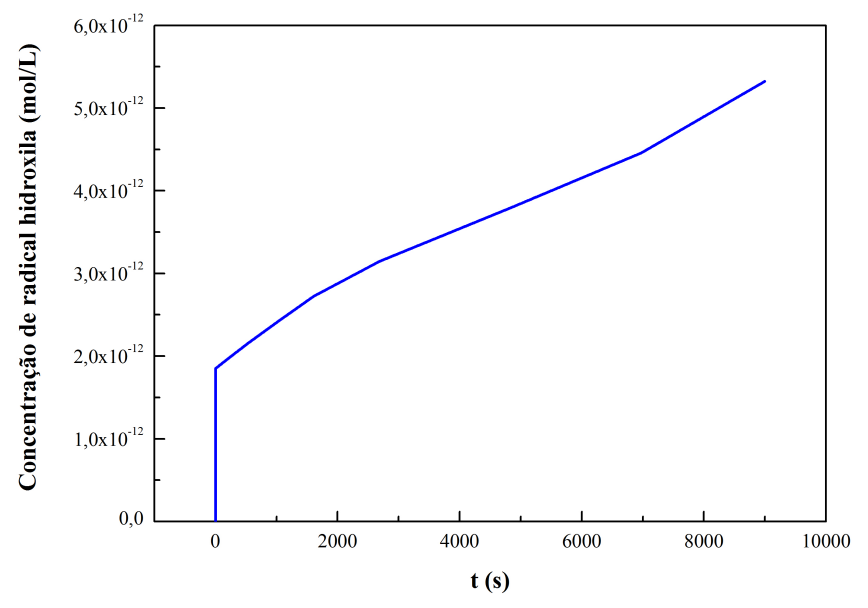

(a)

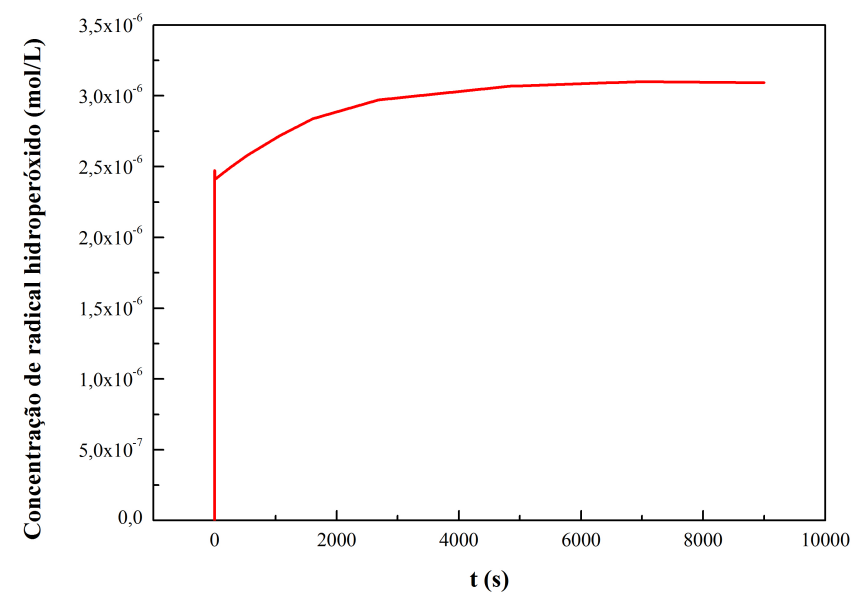

(b)

Figura 6. Demonstração do comportamento numericamente stiff das espécies envolvidas no mecanismo de degradação de fenol proposto por Edalatmanesh, Dhib e Mehrvar (2008): história dos radicais $(a)$ hidroxila e (b) hidroperóxido nas simulações de Vianna Jr. et al. (2011) para experimentos de Tambani (2011).

Os trabalhos discutidos acima foram concebidos para caracterizar o reator de forma macroscópica, através de técnicas de estímulo e resposta. Há certas particulari- 
dades do reator que não conseguem ser capturadas por modelos macroscópicos, como o efeito da posição tangencial do tubo de entrada sobre o escoamento e a possível distribuição de fótons em seu interior, por exemplo. A complexidade desses fenômenos justifica a modelagem e simulação do reator por meio de CFD. O presente trabalho se torna uma progressão natural dos estudos citados na Tabela 9, que constituem as bases de sua validação experimental.

Além disso, não foi encontrado um trabalho na literatura que abordasse o processo $\mathrm{UV} / \mathrm{H}_{2} \mathrm{O}_{2}$ de forma mais rigorosa: como se nota pela revisão bibliográfica (Capítulo 2), ou o campo de radiação era tratado por modelos algébricos ao invés da solução da RTE, ou então a cinética de degradação considerava equilíbrio e/ou estado pseudoestacionário para algumas espécies radicalares. A contribuição deste trabalho é empregar uma plataforma comercial de CFD para simular a degradação de fenol conciliando um modelo cinético mais realista para o processo $\mathrm{UV} / \mathrm{H}_{2} \mathrm{O}_{2}$, proposto por Edalatmanesh, Dhib e Mehrvar (2008), com um método mais elaborado de determinação da energia radiante no interior do reator, caso do método discrete transfer.

A simulação do reator fotoquímico foi realizada na plataforma ANSYS 13.0 (ANSYS Inc., Canonsburg, Estados Unidos). A construção do modelo do reator em CFD foi realizada de forma progressiva, permitindo a validação de cada etapa separadamente. As análises foram divididas em três partes:

1. Construção dos protótipos virtuais e das malhas: representação do reator em CAD e sua discretização espacial;

2. Estudo fluidodinâmico: avaliação da convergência de malhas, do escoamento no reator e seleção dos modelos de turbulência mais adequados para descrevê-lo;

3. Estudo fluidodinâmico: simulação da degradação de fenol pelo processo $\mathrm{UV} / \mathrm{H}_{2} \mathrm{O}_{2}$, para dois modelos cinéticos e de campo de radiação.

O fluxograma da Figura 7 e as seções a seguir detalham cada uma das etapas do estudo. 


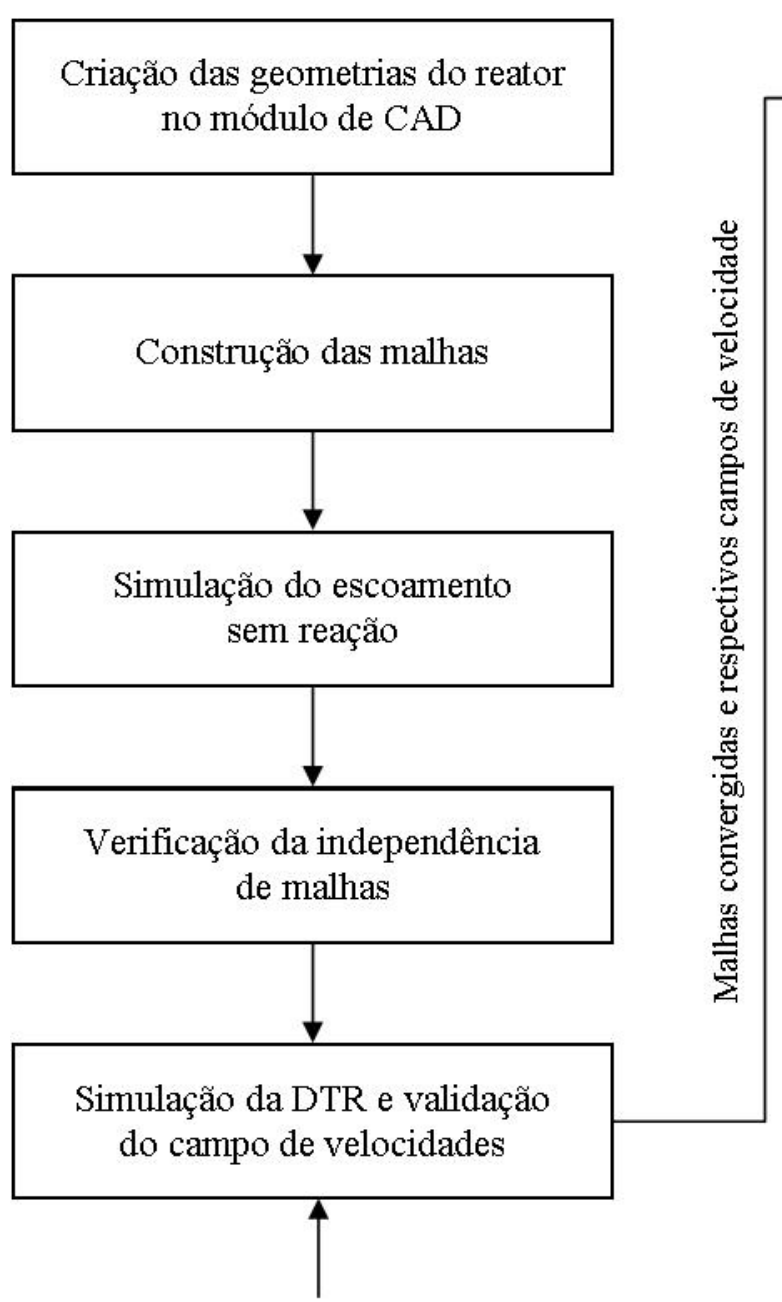

Dados de Silvio et al. (2011)
Simulação da degradação de fenol por pseudocinética

Análise do mecanismo de Edalatmanesh, Dhib e Mehrvar (2008) sem modelos para o campo de radiação

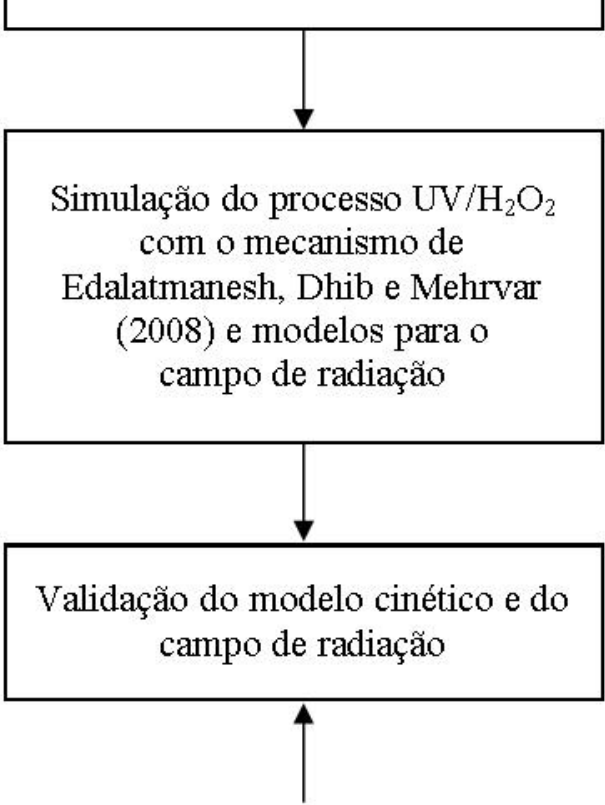

Dados de Tambani (2011)

Figura 7. Sequência de atividades realizadas neste trabalho.

Todas as equações de transporte foram resolvidas pelo método dos volumes finitos (VERSTEEG; MALALASEKERA, 2007). Seus termos convectivos foram discretizados pelo esquema high resolution (ANSYS INC., 2010). O sistema de equações algébricas resultantes pode ser escrito na forma matricial como $\mathbf{A} \phi=\mathbf{b}$, sendo $\mathbf{A}$ a matriz de coeficientes, $\phi$ o vetor de incógnitas e $\mathbf{b}$ o vetor de termos independentes. Ele foi resolvido através de um método multigrid algébrico combinado com uma decomposição LU incompleta (ILU) para aumentar a eficiência do processo iterativo (HUTCHINSON; RAITHBY, 1986; ANSYS INC., 2010). As soluções foram consideradas convergidas quando o valor máximo do resíduo normalizado era de $1 \times 10^{-4}$. 


\subsection{Construção dos protótipos virtuais e das malhas}

A primeira etapa para elaborar o modelo computacional do reator foi reproduzi-lo em CAD. Como as lâmpadas utilizadas no reator possuem diâmetros de 25 e de 37 mm, foram criadas dois protótipos, um para cada diâmetro de lâmpada, no módulo Design Modeler do software. Eles seguem as dimensões reais do reator (Figura 8) e reproduzem as tubulações de entrada e saída de fluido tangenciando seu corpo, os chanfros nas laterais e as lâmpadas, que ficam em contato direto com o fluido. $\mathrm{Na}$ Tabela 10 estão listadas as características dos protótipos e das lâmpadas empregadas nos experimentos de Silvio et al. (2011) e Tambani (2011).

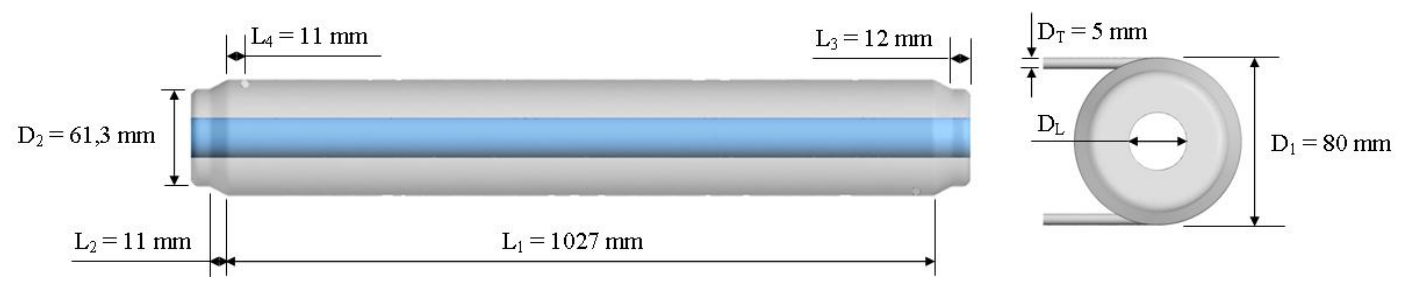

Figura 8. Dimensões do reator analisado.

Tabela 10. Caracterização das lâmpadas utilizadas no reator anular.

\begin{tabular}{ccccc}
\hline Configuração & $\begin{array}{c}\text { Diâmetro da } \\
\text { lâmpada }(\mathbf{m m})\end{array}$ & $\begin{array}{c}\text { Volume do } \\
\text { reator }(\mathbf{L})\end{array}$ & $\begin{array}{c}\text { Potência } \\
\text { elétrica }(\mathbf{W})\end{array}$ & $\begin{array}{c}\text { Potência de } \\
\text { emissão no UV* }\end{array}$ \\
\hline A1 & 25 & 3,92 & 36 & 11,19 \\
A2 & 25 & 3,92 & 75 & 14,89 \\
B & 37 & 3,29 & 115 & 17,66 \\
\hline
\end{tabular}

*Potência determinada por Tambani (2011) através de actinometria de ferrioxalato.

O domínio computacional foi discretizado através de malhas não-estruturadas com elementos tetraédricos, geradas no módulo ANSYS Meshing. O reator é formado apenas por partes cilíndricas, cujas junções são melhor tratadas por malhas desse tipo (WRIGHT; HARGREAVES, 2001). Na região da lâmpada foi colocada uma camada prismática para capturar efeitos viscosos e da emissão de radiação no UVC. Malhas hexaédricas foram avaliadas, porém houve problemas de convergência em parte significativa das simulações do escoamento, daí desconsiderá-las no estudo. 
Para cada geometria, foram geradas diversas malhas, variando apenas a razão de crescimento. Tal parâmetro regula o comprimento das arestas a cada camada de elementos: uma razão de crescimento de 1,2, p.ex., significa que as arestas de uma camada de elementos são $20 \%$ maiores que as da camada anterior. A razão de crescimento foi sendo diminuída até que se atingisse a convergência de malhas.

A convergência de malhas foi avaliada pelo perfil de velocidades em estado estacionário com vazão de $30 \mathrm{~L} \mathrm{~h}^{-1}$, que produz o escoamento mais complexo (vide Seção 4.1.2) e com o modelo de turbulência $k-\omega$. Para isso, a componente $z$ da velocidade foi monitorada em pontos de uma linha paralela ao eixo $x$ e passando pelo centro do reator $(y=0)$, nas seções transversais de coordenadas $z=0,2, z=0,4, z=0,6$, $z=0,8$ e $z=1,0 \mathrm{~m}$ (Figura 9).

\subsection{Estudo fluidodinâmico}

As reações do mecanismo de degradação de fenol são, na grande maioria, reações radicalares com cinética rápida. A etapa limitante para sua ocorrência, portanto, acaba sendo o contato entre os radicais, influenciado pela agitação e pela mistura que se estabelece no interior do reator. O estudo fluidodinâmico se preocupa com a caracterização de seu escoamento, com os seguintes objetivos:

- determinar a quantidade de elementos de volume a partir da qual a solução numérica não se altera (independência de malhas);

- avaliar como é o movimento do fluido, a ocorrência de zonas de estagnação e de recirculção e os efeitos da geometria;

- selecionar os modelos de turbulência mais apropriados para calcular o campo de velocidades;

- validar o campo de velocidades com dados experimentais. 


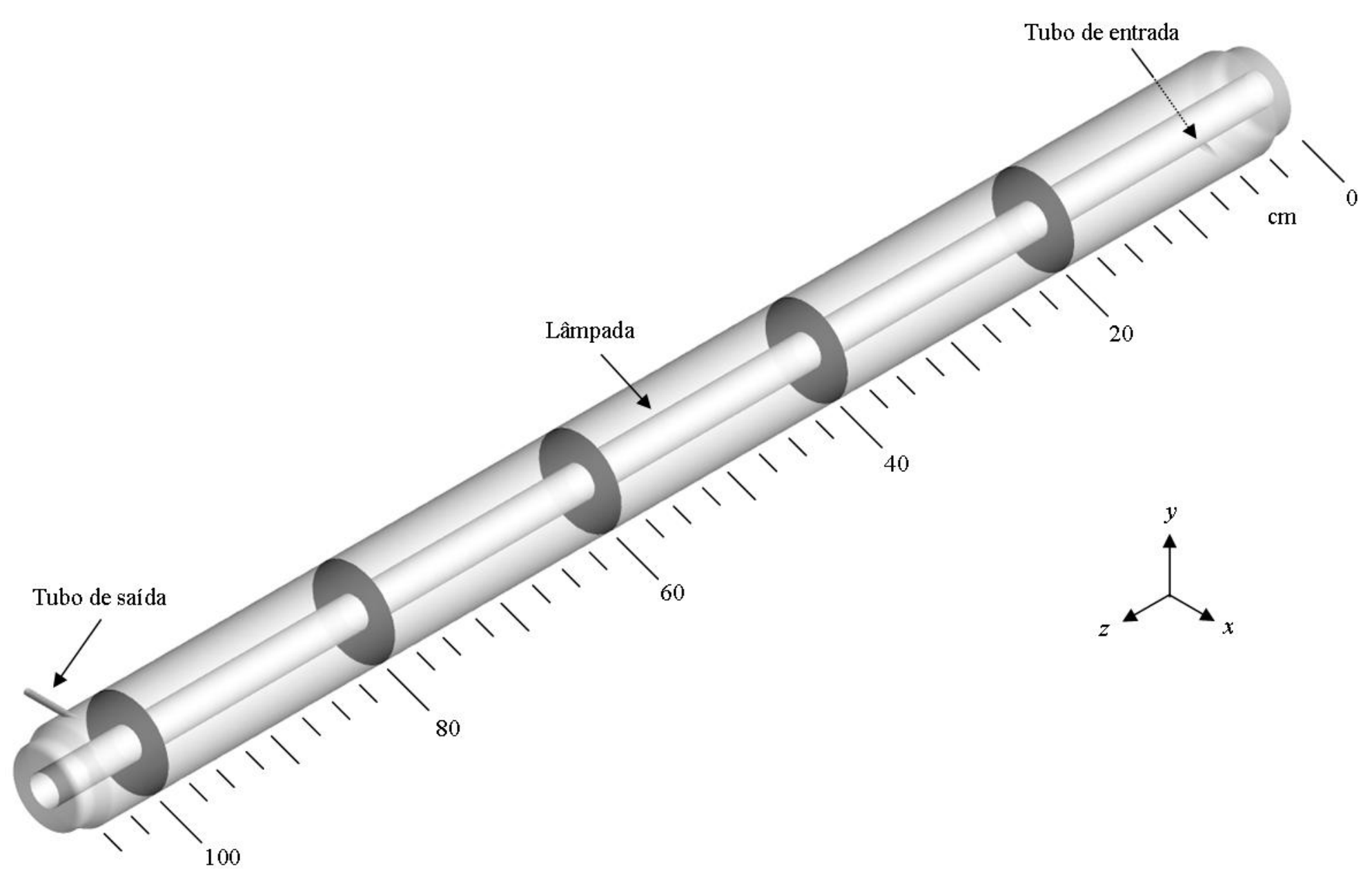

Figura 9. Domínio computacional do reator e seções selecionadas para avaliação de variáveis. 


\subsubsection{Obtenção dos campos de velocidade}

O campo de velocidades do reator foi calculado para a condição de regime permanente usando o CFX 13.0. O fluido de operação foi água a $25^{\circ} \mathrm{C}$, cujas propriedades de transporte estão na Tabela 11. Os efluentes industriais do processo $\mathrm{UV} / \mathrm{H}_{2} \mathrm{O}_{2}$ são formados por água e substâncias dissolvidas em concentrações tais que o fluido pode ser considerado newtoniano e incompressível. Em reatores com lâmpadas de $\mathrm{Hg}$ de baixa pressão, o aquecimento das lâmpadas não é significativo; então o escoamento é isotérmico, e as propriedades do fluido, constantes.

Tabela 11. Propriedades de transporte do fluido simulado (GREEN; PERRY, 2008).

\begin{tabular}{lc}
\hline Propriedade & Valor \\
\hline Densidade $\left(\mathrm{kg} \mathrm{m}^{-3}\right)$ & 977,0 \\
Viscosidade dinâmica $(\mathrm{Pa} . \mathrm{s})$ & 0,890 \\
Condutividade térmica $\left(\mathrm{W} \mathrm{m}{ }^{-1} \mathrm{~K}^{-1}\right)$ & 0,612 \\
Calor específico $\left(\mathrm{J} \mathrm{kg}^{-1} \mathrm{~K}^{-1}\right)$ & $4,07 \times 10^{3}$ \\
\hline
\end{tabular}

Nesta etapa, as equações RANS [eq. (2.19)] e da continuidade [eq. (2.20)] foram resolvidas para cada protótipo (configuração com as lâmpadas de 25 e de $37 \mathrm{~mm}$ de diâmetro) e respectivas malhas. A independência de malhas foi verificada seguindo os critérios expostos na Seção 3.2. Os cenários simulados e demais condições de contorno estão listados na Tabela 12. A Figura 9 indica as regiões do domínio computacional onde cada condição foi aplicada.

Tabela 12. Condições de contorno e cenários para o levantamento dos campos de velocidade do reator.

\begin{tabular}{ll}
\hline Região do domínio & Condições de contorno \\
\hline Entrada & • Escoamento normal ao plano de entrada \\
& • Vazão de alimentação de 30,60 e $100 \mathrm{Lh}^{-1}$ \\
& • Intensidade de turbulência de 1,5 e de $10 \%$ \\
Saída & • Pressão relativa nula (descarga atmosférica) \\
& • Gradiente nulo de todas as outras variáveis \\
Paredes e lâmpada & • Sem escorregamento (no slip) \\
\hline
\end{tabular}


Sozzi e Taghipour (2006a) destacaram a importância de se resolver corretamente o escoamento turbulento em reatores químicos. Para isso, foram avaliados o modelo laminar e quatro modelos de turbulência:

- modelo $k-\epsilon$ [eq. (2.25) - (2.27)], por ser o mais tradicional em casos de Engenharia Química;

- modelo $k-\omega$ [eq. (2.28) - (2.30)], pela precisão para tratar escoamentos confinados;

- modelo SST [eq. ( 2.31) - (2.38)], por combinar a robustez do $k-\epsilon$ com o tratamento da subcamada viscosa do $k-\omega$;

- modelo de tensores de Reynolds (RSM) [eq. (2.39) - ()], pela sugestão de Alpert, Knape e Ducoste (2010) após analisarem um reator anular semelhante ao estudado neste trabalho.

As equações de turbulência foram discretizadas pelo método upwind para manter a robustez do processo. Oscilações na pressão foram evitadas durante a solução empregando solução acoplada com a velocidade, conforme proposto por Rhie e Chow com as modificações de Majumdar (1988).

\subsubsection{Validação do escoamento pela distribuição de tempos de re- sidência}

As simulações do escoamento no reator foram validadas através da sua distribuição de tempos de residência (DTR). Tu (2008) recomenda o procedimento pela simplicidade da parte experimental e por ser um método adequado para a análise de escoamento em equipamentos industriais, cujas informações qualitativas são expandidas pelas análises em CFD.

A DTR do modelo computacional foi obtida pelo método de estímulo-resposta, reproduzindo os experimentos de Silvio et al. (2011). Uma vantagem desse método é 
incluir teoricamente todas as fontes de dispersão do traçador i.e, convecção, difusão molecular e difusão turbulenta (MOULLEC et al., 2008).

Um traçador não-reativo foi criado com as propriedades de transporte da Tabela 11 e com difusividade de $5 \times 10^{-12} \mathrm{~m}^{2} \mathrm{~s}^{-1}$, a mesma do azul de metileno (GUPTA et al., 2004). A Tabela 13 traz as condições de contorno adotadas, para cada protótipo, na simulação da DTR. As malhas adotadas para cada um deles são as malhas nas quais se verificou a independência após a obtenção dos campos de velocidade. Desenvolveu-se um algoritmo para simular a injeção de $0,5 \mathrm{~mL}$ de traçador na forma de um pulso com duração de $1 \mathrm{~s}$. Esse tempo foi estimado com base no tempo que uma pessoa leva para pressionar o êmbolo da seringa e injetar o traçador. A concentração dessa espécie foi monitorada no plano de saída. Detalhes sobre a programação do algoritmo estão disponíveis no Apêndice A.

Tabela 13. Condições de contorno e cenários para o levantamento da distribuição de tempos de residência do reator.

\begin{tabular}{ll}
\hline Região do domínio & Condições de contorno \\
\hline Entrada & - Escoamento normal ao plano de entrada \\
& - Vazão de alimentação de 30,60 e $100 \mathrm{~L} \mathrm{~h}^{-1}$ \\
& • Intensidade de turbulência de $5 \%$ \\
& - Injeção de um pulso de $0,5 \mathrm{~mL}$ de traçador por $1 \mathrm{~s}$ \\
& - Pressão relativa nula (descarga atmosférica) \\
& - Gradiente nulo de todas as outras variáveis \\
& - Cálculo da concentração de traçador no plano de saída \\
Paredes e lâmpada & - Sem escorregamento (no slip) \\
\hline
\end{tabular}

O balanço de massa transiente do traçador, eq. (2.48), foi resolvido desacoplado do campo de velocidades. Dessa forma, não só o tempo de processamento da DTR é otimizado, como também se reproduz a forma como ela foi levantada experimentalmente: primeiro encheu-se o reator de água e aguardou-se o desaparecimento de bolhas; somente quando o escoamento atingisse o regime permanente é que o traçador foi injetado. Todos os modelos de turbulência foram avaliados. Foi adotado o valor 
típico de 0,9 para o número de Schmidt turbulento $\left(S c_{t}\right)$ para transporte do traçador. $\mathrm{O}$ termo de derivada temporal foi discretizado pelo método de Euler de segunda ordem. Para as vazões de 30 e de $60 \mathrm{~L} \mathrm{~h}^{-1}$, a simulação abrangeu o período de $1500 \mathrm{~s}$ após a injeção do traçador, e de $400 \mathrm{~s}$ para a vazão de $100 \mathrm{~L} \mathrm{~h}^{-1}$. A malha do tempo foi dividida com base nos dados experimentais de Silvio et al. (2011) para reduzir o tempo de processamento. Os valores de passo temporal adotados podem ser vistos na Tabela 14.

Tabela 14. Divisão da escala de tempo para simulação da DTR do modelo computacional do reator.

\begin{tabular}{|c|c|c|c|}
\hline \multirow{2}{*}{$\begin{array}{c}\text { Trecho correspondente } \\
\text { na curva de DTR }\end{array}$} & \multicolumn{2}{|c|}{ Intervalo de tempo simulado } & \multirow{2}{*}{$\begin{array}{c}\text { Passo } \\
(\mathbf{s})\end{array}$} \\
\hline & Vazões de 30 e $60 \mathrm{~L} \mathrm{~h}^{-1}$ & Vazão de $100 \mathrm{~L} \mathrm{~h}^{-1}$ & \\
\hline injeção do traçador & $0-1 \mathrm{~s}$ & $0-1 \mathrm{~s}$ & 0,1 \\
\hline $\begin{array}{l}\text { perturbação após } \\
\text { injetar o traçador }\end{array}$ & $1-5 \mathrm{~s}$ & $1-10 \mathrm{~s}$ & 1 \\
\hline $\begin{array}{c}\text { período sem detecção } \\
\text { de traçador }\end{array}$ & $5-205 s$ & & 10 \\
\hline $\begin{array}{c}\text { período pré-detecção } \\
\text { do traçador }\end{array}$ & $205-220 \mathrm{~s}$ & $10-50 \mathrm{~s}$ & 5 \\
\hline $\begin{array}{l}\text { detecção intensa } \\
\text { do traçador }\end{array}$ & $220-500 \mathrm{~s}$ & $50-200 \mathrm{~s}$ & 1 \\
\hline $\begin{array}{l}\text { trecho inicial } \\
\text { da cauda }\end{array}$ & $500-700 \mathrm{~s}$ & $200-300 \mathrm{~s}$ & 5 \\
\hline $\begin{array}{l}\text { detecção branda } \\
\text { do traçador }\end{array}$ & $700-1000 \mathrm{~s}$ & $300-400 \mathrm{~s}$ & $\begin{array}{l}20 \\
10\end{array}$ \\
\hline $\begin{array}{l}\text { trecho final } \\
\text { da cauda }\end{array}$ & $1000-1500 \mathrm{~s}$ & & 250 \\
\hline
\end{tabular}

Com as medidas de concentração do traçador no plano de saída, foram construídas as curvas $E(t)$ do modelo computacional. Sua comparação com os dados experimentais permitiu a escolha do modelo de turbulência mais apropriado para descrever o escoamento no reator, juntamente com o coeficiente de correlação de Pearson. 


\subsection{Estudo cinético}

Conhecido o comportamento fluidodinâmico do reator, pode-se lidar com a ocorrência de escoamentos reativos em seu interior. O estudo de reações desenvolvido neste trabalho foi pautado pelos seguintes objetivos:

- conhecer estratégias para simular reações químicas no CFX;

- utilizar os recursos do software para lidar com os balanços de massa de reações com cinética rápida (numericamente stiff), sem empregar soluções de terceiros [caso do sotware CHEMKIN-CFD (Reaction Design, San Diego, Estados Unidos), por exemplo];

- utilizar os modelos de radiação da biblioteca do CFX para simular a emissão de lâmpadas de $\mathrm{Hg}$;

- acoplar o balanço de radiação ao balanço de massa do peróxido de hidrogênio para calcular sua fotólise e simular a degradação de fenol pelo processo $\mathrm{UV} / \mathrm{H}_{2} \mathrm{O}_{2}$

- validar as simulações com dados experimentais de reações.

\subsubsection{Validação das simulações de degradação do fenol}

Este trabalho foi o primeiro do CESQ a aplicar CFD na modelagem de sistemas fotoquímicos. Como discutido anteriormente, os trabalhos macroscópicos desenvolvidos anteriormente pelo grupo levaram a uma progressão natural para a abordagem microscópica do reator, de modo que optou-se por reproduzir os experimentos sistemáticos de Tambani (2011) no seu modelo em CFD.

A autora realizou diversos experimentos de degradação de fenol, dentre as quais foram selecionados 9 para serem reproduzidos neste trabalho. As curvas de cada um 
deles estão representadas na Figura 5 e as condições experimentais em que foram realizados estão na Tabela 15.

Tabela 15. Experimentos de Tambani (2011) reproduzidos nas simulações do estudo cinético.

\begin{tabular}{|c|c|c|c|c|}
\hline Caso & $\begin{array}{l}\text { Configuração } \\
\text { do reator }\end{array}$ & $\begin{array}{l}\text { Concentração inicial } \\
\text { de fenol }\left(\mathrm{mg} \mathrm{L}^{-1}\right)\end{array}$ & $\begin{array}{c}\text { Razão molar } \\
\mathrm{H}_{2} \mathrm{O}_{2} / \text { fenol }\end{array}$ & $\begin{array}{l}\text { Pseudoconstante* } \\
\qquad\left(10^{-3} s^{-1}\right)\end{array}$ \\
\hline 1 & $\mathrm{~A} 2$ & 233,12 & 47,1 & 1,05 \\
\hline 2 & $\mathrm{~A} 2$ & 274,48 & 5,05 & 1,24 \\
\hline 3 & $\mathrm{~A} 2$ & 479,4 & 30,22 & 0,912 \\
\hline 4 & $\mathrm{~A} 2$ & 77,27 & 14,23 & 3,10 \\
\hline 5 & $\mathrm{~A} 2$ & 469,72 & 13,76 & 0,655 \\
\hline 6 & $\mathrm{~B}$ & 304,65 & 34,77 & 0,936 \\
\hline 7 & A 1 & 378,82 & 23,97 & 0,513 \\
\hline 8 & $\mathrm{~B}$ & 292,34 & 16,1 & 0,962 \\
\hline 9 & $\mathrm{~A} 2$ & 232,18 & 26,62 & 0,996 \\
\hline
\end{tabular}

*Pseudoconstante de primeira ordem em relação ao fenol

Os experimentos foram conduzidos com vazão de $72 \mathrm{Lh}^{-1}$. Utilizando as malhas para as quais se verificou a independência para as configurações A1, A2 e B do reator, e o modelo de turbulência selecionado pelas curvas de DTR, obteve-se o campo de velocidades para essa vazão. Todas as simulações de reações foram realizadas em regime permanente e desacoplando os balanços de massa das espécies do campo de velocidades para otimizar o processamento.

Há uma diferença na operação do reator entre as simulações e os experimentos. A intenção do trabalho é verificar seu comportamento com o escoamento contínuo, emulando parte de um sistema de tratamento de efluentes. Já Tambani (2011) conduziu os experimentos em batelada. A validação das simulações foi realizada tomando-se a concentração de fenol em $t=\tau=1$ tempo de residência do reator.

O tratamento de reações no modelo computacional foi feito em duas etapas, descritas nas seções a seguir. 


\subsubsection{Análises iniciais}

Uma abordagem progressiva foi empregada para incluir reações no modelo computacional. A primeira estratégia foi tomar o modelo cinético mais simples possível: considerar pseudocinética de primeira ordem em relação ao fenol, como fez Primo et al. (2007). Supõe-se que todo o mecanismo das reações (R1) a (R14) pode ser simplificado para a Equação 2.2. Para cada caso listado na Tabela 15 foi determinada a pseudoconstante correspondente pelo método dos mínimos quadrados. Ela engloba os efeitos da concentração inicial de $\mathrm{H}_{2} \mathrm{O}_{2}$ e da intensidade de radiação.

A Tabela 16 lista as condições de contorno empregadas na simulações. Em termos de programação, nas análises iniciais as reações foram inseridas através da criação de um subdomínio abrangendo todo o volume do reator. No subdomínio foram incluídos termos fonte para cada componente, descritos por sua taxa global de reação. Nos casos de pseudocinética, o único componente monitorado foi o fenol.

Tabela 16. Condições de contorno para a simulação de reações por pseudocinética.

\begin{tabular}{|c|c|}
\hline Região do domínio & Condições de contorno e de modelagem \\
\hline Entrada & $\begin{array}{l}\text { - Escoamento normal ao plano de entrada } \\
\text { - Vazão de alimentação de } 72 \mathrm{~L} \mathrm{~h}^{-1} \\
\text { - Intensidade de turbulência de } 5 \% \\
\text { - Fração mássica de fenol indicada na Tabela } 15\end{array}$ \\
\hline Saída & $\begin{array}{l}\text { - Pressão relativa nula (descarga atmosférica) } \\
\text { - Gradiente nulo de todas as outras variáveis } \\
\text { - Cálculo da concentração de traçador no plano de saída }\end{array}$ \\
\hline Paredes e lâmpada & $\begin{array}{l}\text { - Sem escorregamento (no slip) } \\
\text { - Efeitos de emissão da lâmpada considerados } \\
\text { na pseudoconstante }\end{array}$ \\
\hline Todo o domínio & $\begin{array}{l}\text { - Componentes: fenol e água (constraint) } \\
\text { - Balanço inserido via termos fonte de subdomínio }\end{array}$ \\
\hline
\end{tabular}

Os cenários de pseudocinética lidaram com a ocorrência de apenas uma reação, com pseudoconstante de baixa ordem de grandeza. O mecanismo de degradação de Edalatmanesh, Dhib e Mehrvar (2008) traz dois desafios: (a) existência de múltiplas 
espécies participando de reações em série e paralelo, e $(b)$ reações radicalares com cinética rápida e constantes com ordem de grandeza elevada $\left(\sim 10^{7}-10^{10} \mathrm{~L} \mathrm{~mol}^{-1} \mathrm{~s}^{-1}\right)$. Chung (2002) aponta que os balanços de massa de reações radicalares geram um sistema de equações diferenciais numericamente stiff e exigem tratamento especial nos códigos de CFD. Vianna Jr. et al. (2011) fez o tratamento dessa cinética em FORTRAN e demonstraram esse comportamento pela intensa variação na concentração dos radicais ${ }^{\bullet} \mathrm{OH}$ e $\mathrm{HO}_{2}^{\bullet}$, como discutido na Seção 3.1 (vide também Figura 6).

Um estudo paralelo ao de Vianna Jr. et al. (2011) foi conduzido no modelo em CFD. O objetivo era avaliar apenas a parte térmica do mecanismo de Edalatmanesh, Dhib e Mehrvar (2008), manipulando parâmetros do software para garantir estabilidade do processo de convergência e reduzir o tempo de processamento. Foram consideradas todas as espécies do mecanismo, cujos balanços de massa são dados pelas Equações (2.4) - (2.10). A reação de fotólise do $\mathrm{H}_{2} \mathrm{O}_{2}$ foi tratada com uma constante de primeira ordem arbitrária, já que nesta etapa ainda não se desejava avaliar o campo de radiação.

Os balanços de massa também foram inseridos através de subdomínio. O parâmetros manipulados foram o passo de tempo adotado e os coeficientes de termo fonte das espécies. Tais coeficientes interferem na forma de linearização dos termos fonte e alteram o caminho de convergência, sem afetar os resultados finais (ANSYS INC., 2010). Na Tabela 17 estão listadas as condições de contorno adotadas. Vale destacar que o estudo da parte térmica do mecanismo tem fins qualitativos, visando apenas demonstrar como se manifesta o caráter stiff das reações radicalares e determinar os parâmetros ótimos para resolvê-las sem empregar soluções de terceiros, como o sotware CHEMKIN-CFD.

\subsubsection{Degradação de fenol pelo processo $\mathrm{UV} / \mathrm{H}_{2} \mathrm{O}_{2}$}

A etapa de análises iniciais forneceu noções elementares sobre a inclusão de reações no modelo computacional e o tratamento necessário para mecanismos com cinética rápida. A etapa final do trabalho foi reproduzir os experimentos da tabela ?? 
Tabela 17. Condições de contorno e cenários para o estudo de mecanismos cinéticos numericamente stiff.

\begin{tabular}{ll}
\hline Região do domínio & Condições de contorno e de modelagem \\
\hline Entrada & - Escoamento normal ao plano de entrada \\
& - Vazão de alimentação de $72 \mathrm{~L} \mathrm{~h}^{-1}$ \\
& - Intensidade de turbulência de $5 \%$ \\
& - Fração mássica de fenol indicada na Tabela 15 \\
& - Fração mássica de $\mathrm{H}_{2} \mathrm{O}_{2}$ calculada pela Tabela 15 \\
& - Fração mássica das demais espécies $=0$ \\
& - Pressão relativa nula (descarga atmosférica) \\
& - Gradiente nulo de todas as outras variáveis \\
& - Cálculo da concentração de traçador no plano de saída \\
& - Sem escorregamento $($ no slip) \\
Paredes e lâmpada & - Componentes: fenol, $\mathrm{H}_{2} \mathrm{O}_{2},{ }^{\bullet} \mathrm{OH}, \mathrm{HO}_{2}^{-}, \mathrm{HO}_{2}^{\bullet}, \mathrm{O}_{2}^{\bullet-}$ \\
& - Balanços inseridos via termos fonte de subdomínio \\
& - Balanços dados pelas Equações $(2.4)-(2.10)$ \\
& - Passo de tempo: $10^{0}, 10^{-3}, 10^{-5}, 10^{-7} \mathrm{~s}$ \\
& - Coeficientes de termo fonte: $10^{0}-10^{15} \mathrm{~kg} \mathrm{~m}^{-3} \mathrm{~s}^{-1}$ \\
& - Número de Schmidt turbulento: $S c_{t}=0,9$
\end{tabular}

empregando o mecanismo de degradação proposto por Edalatmanesh, Dhib e Mehrvar (2008) e um modelo para o campo de radiação. Novamente, foram consideradas todas as espécies do mecanismo, cujos balanços de massa são dados pelas Equações (2.4) (2.10). A taxa de fotólise do $\mathrm{H}_{2} \mathrm{O}_{2}$ foi descrita de forma semelhante à de Alpert, Knape e Ducoste (2010):

$$
r_{\mathrm{UV} / \mathrm{H}_{2} \mathrm{O}_{2}}=\phi_{1} E_{C F D}\left(\epsilon_{1}\left[\mathrm{H}_{2} \mathrm{O}_{2}\right]+\epsilon_{2}\left[\mathrm{HO}_{2}^{-}\right]\right)
$$

Na Equação 3.1, $E_{C F D}$ é a taxa volumétrica de fótons incidentes, calculada a partir da intensidade de radiação incidente, $I_{U V}$ :

$$
E_{C F D}=\frac{I_{U V}\left(\mathrm{~W} \mathrm{~m}^{-2}\right) \times 100\left(\mathrm{~cm} \mathrm{~m}^{-1}\right)}{U_{254}\left(\mathrm{~J} \mathrm{Ein}^{-1}\right) \times 1000\left(\mathrm{~L} \mathrm{~m}^{-3}\right)}
$$

No cálculo de $E_{C F D}, U_{254}=471528 \mathrm{~J} \mathrm{Ein}^{-1}$ é a energia de $1 \mathrm{~mol}$ de fótons de comprimento de onda de $253,7 \mathrm{~nm}$. Os demais parâmetros das equações acima foram 
registrados na Tabela 3.

Para calcular a taxa de radiação incidente, $I_{U V}$, que corresponde ao campo de radiação, foram avaliados dois modelos:

- o modelo de campo radial, equação (2.51);

- a determinação do campo pela soluçao da RTE, equação (2.50), através do método discrete transfer, existente na biblioteca interna do CFX. Esta é a maior contribuição do trabalho, pois gera simulações com um modelo cinético mais realista do que os encontrados na literatura juntamente com um método mais rigoroso de cálculo do campo de radiação.

As lâmpadas empregadas por Tambani (2011) eram monocromáticas em 253,7 nm, como indica seu espectro de emissão na Figura 10. Como eram lâmpadas germicidas e de vapor de Hg de baixa pressão, elas não tinham envelope de quartzo e permaneciam em contato direto com o fluido. Isso elimina a necessidade de levar em conta a refração no envelope. Supôs-se que a emissão das lâmpadas ocorria na direção normal ao seu eixo e de maneira uniforme em seu comprimento. As paredes do reator são de vidro borossilicato, o que justifica a ausência de reflexão nelas. As demais condições de contorno estão indicadas na Tabela 18. Nestas simulações foi adotada outra estratégia para resolver os balanços de massa: empregou-se o editor de reações do CFX, para aproveitar o tratamento especializado de mecanismos radicalares de combustão; também é uma contribuição do trabalho ao estender as técnicas de Engenharia Mecânica com foco em combustão para escoamentos reativos de interesse em Engenharia Química. 
Tabela 18. Condições de contorno e cenários para a simulação do processo de degradação de fenol pelo mecanismo de Edalatmanesh, Dhib e Mehrvar (2008).

\begin{tabular}{|c|c|}
\hline Região do domínio & Condições de contorno e de modelagem \\
\hline Entrada & $\begin{array}{l}\text { - Escoamento normal ao plano de entrada } \\
\text { - Vazão de alimentação de } 72 \mathrm{Lh}^{-1} \\
\text { - Intensidade de turbulência de } 5 \% \\
\text { - Fração mássica de fenol indicada na Tabela } 15 \\
\text { - Fração mássica de } \mathrm{H}_{2} \mathrm{O}_{2} \text { calculada pela Tabela } 15 \\
\text { - Fração mássica das demais espécies = } 0\end{array}$ \\
\hline Saída & $\begin{array}{l}\text { - Pressão relativa nula (descarga atmosférica) } \\
\text { - Gradiente nulo de todas as outras variáveis } \\
\text { - Cálculo da concentração de traçador no plano de saída }\end{array}$ \\
\hline Paredes & $\begin{array}{l}\text { - Sem escorregamento (no slip) } \\
\text { - Não ocorre reflexão (paredes de vidro) }\end{array}$ \\
\hline Lâmpada & $\begin{array}{l}\text { - Sem escorregamento (no slip) } \\
\text { - Emissão normal ao corpo da lâmpada } \\
\text { - Emissão uniforme sobre a superfície da lâmpada } \\
\text { - Emissão monocromática em } 253,7 \mathrm{~nm} \\
\text { - Não há refração (lâmpada em contato direto com o fluido) }\end{array}$ \\
\hline Todo o domínio & $\begin{array}{l}\text { - Componentes: fenol, } \mathrm{H}_{2} \mathrm{O}_{2},{ }^{\bullet} \mathrm{OH}, \mathrm{HO}_{2}^{-}, \mathrm{HO}_{2}^{\bullet}, \mathrm{O}_{2}^{\bullet-} \\
\text { - Balanços inseridos via editor de reações } \\
\text { - Balanços dados pelas Equações }(2.4)-(2.10) \\
\text { - Passo de tempo: controle automático pelo CFX-Solver } \\
\text { - Número de Schmidt turbulento: } S c_{t}=0,9\end{array}$ \\
\hline
\end{tabular}

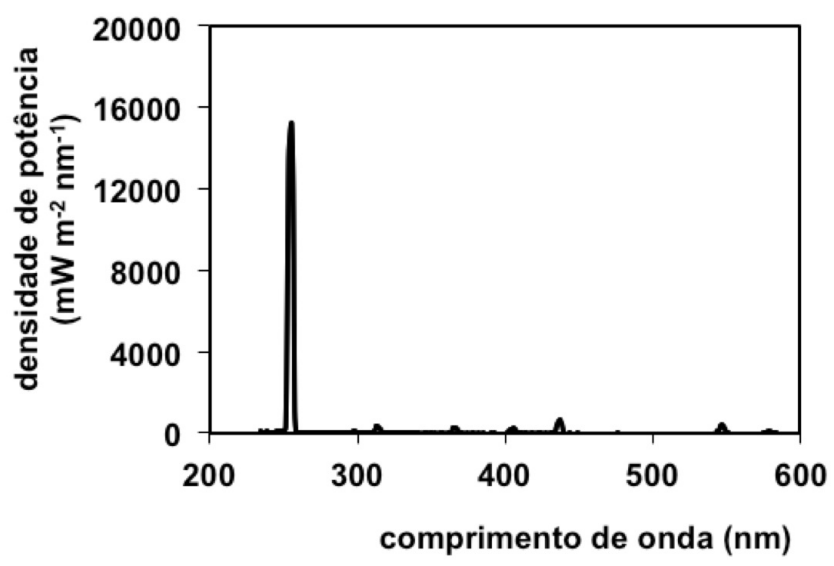

Figura 10. Espectro de emissão das lâmpadas empregadas no reator fotoquímico (TAMBANI, 2011). 


\section{RESULTADOS E DISCUSSÕES}

\subsection{Estudo fluidodinâmico do reator}

\subsubsection{Avaliação de independência de malhas}

Para determinar a discretização ótima do domínio computacional, foram geradas malhas tetraédricas para os dois diâmetros existentes de lâmpadas. O número de elementos foi variado entre 276129 e 1175 448, alterando apenas oa razão de crescimento. Na Figura 11 é visto o efeito desse parâmetro sobre o comp[rimento das arestas de cada elemento. A Tabela 19 indica as características de cada malha. As configurações A1 e A2 representam o protótipo com lâmpadas de 25 mm de diâmetro, e a configuração $\mathrm{B}$, com $37 \mathrm{~mm}$ de diâmetro.

Tabela 19. Descrição das malhas empregadas para discretizar o reator anular.

\begin{tabular}{ccccc}
\hline Identificação & $\begin{array}{c}\text { Configuração } \\
\text { do sistema }\end{array}$ & $\begin{array}{c}\text { Quantidade } \\
\text { de nós }\end{array}$ & $\begin{array}{c}\text { Quantidade } \\
\text { de elementos }\end{array}$ & $\begin{array}{c}\text { Razão de } \\
\text { crescimento }\end{array}$ \\
\hline Malha A & A1/A2 & 109302 & 390427 & 1,2 \\
Malha B & A1/A2 & 160945 & 666469 & 1,1 \\
Malha C & A1/A2 & 206272 & 911751 & 1,075 \\
Malha D & A1/A2 & 255297 & 1175448 & 1,060 \\
Malha E & B & 80700 & 276129 & 1,2 \\
Malha F & B & 116951 & 440218 & 1,1 \\
Malha G & B & 147975 & 590476 & 1,075 \\
Malha H & B & 179438 & 741767 & 1,060 \\
Malha I & B & 213856 & 909903 & 1,050 \\
\hline
\end{tabular}


(a)

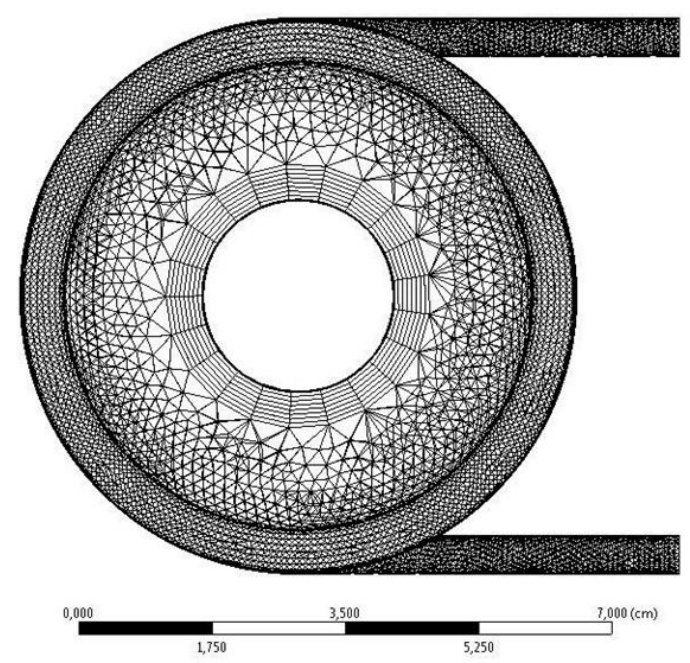

(b)

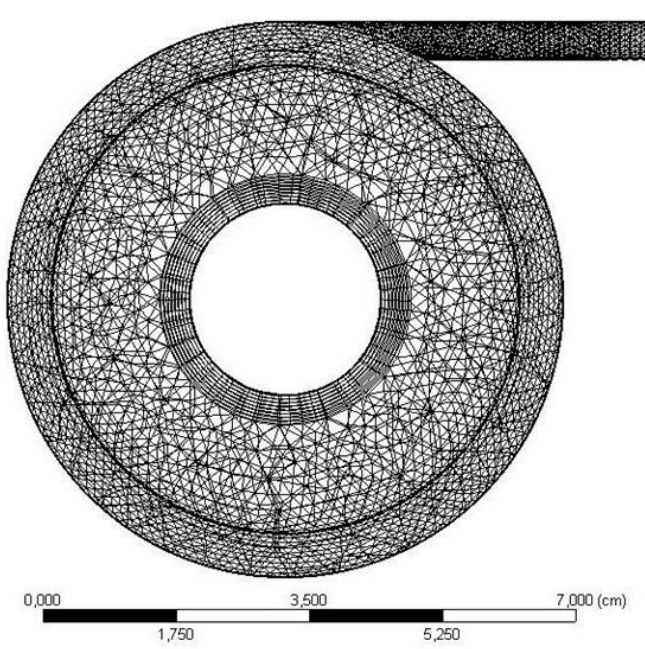

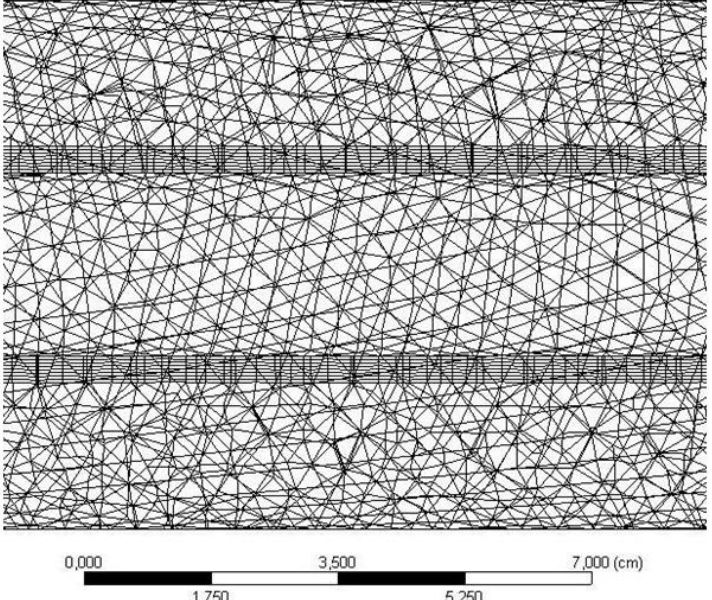

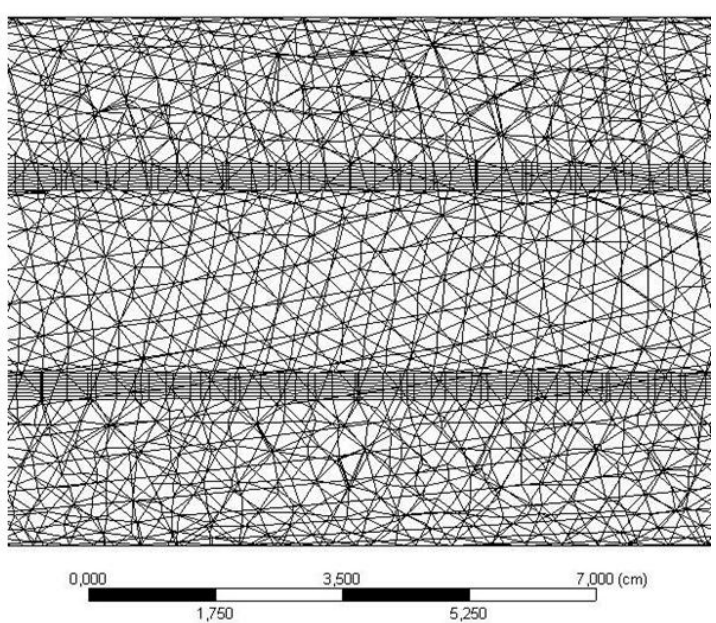

Figura 11. Vistas lateral e frontal das malhas $(a) \mathrm{A} \mathrm{e}(b) \mathrm{C}$ desenvolvidas para o reator anular. 
A avaliação de independência de malhas foi feita comparando o perfil de velocidade nas seções indicadas na Figura 9, com escoamento resolvido pelo modelo $k-\omega$ e vazão de alimentação de $30 \mathrm{~L} \mathrm{~h}^{-1}$. As Figuras 12 e 13 indicam o comportamento do perfil de velocidades para as malhas referentes às configurações A do reator, cujo diâmetro de lâmpada é de 25 mm, enquanto as Figuras 14 e 15 indicam os resultados para a configuração B (lâmpada de 37 mm de diâmetro). Observa-se que, para as configurações $\mathrm{A}$, o campo de velocidades se torna independente da discretização do domínio para malhas superiores a 911751 elementos (malha C), e, para a configuração B, para 909903 elementos (malha I). Estas malhas foram as empregadas no estudo do campo de velocidades e na simulação de reações químicas para cada configuração do sistema.

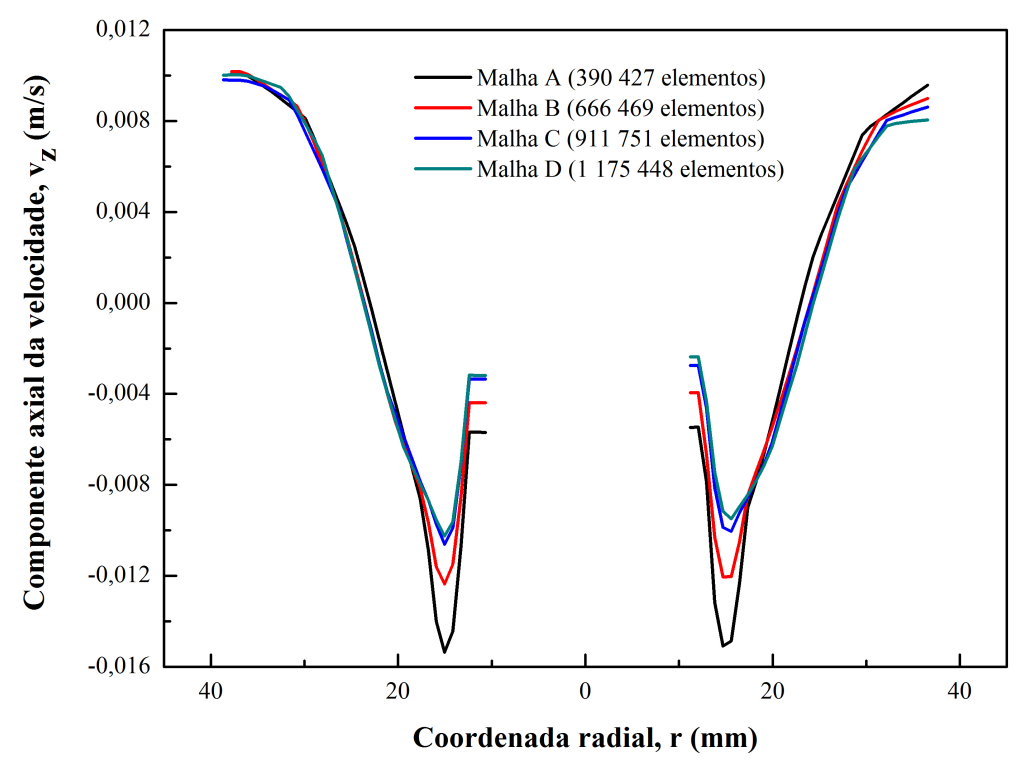

Figura 12. Análise de independência de malhas do modelo computacional do reator através dos perfis de velocidade em $z=20 \mathrm{~cm}$, para as configurações A e vazão de $30 \mathrm{~L} \mathrm{~h}^{-1}$. 


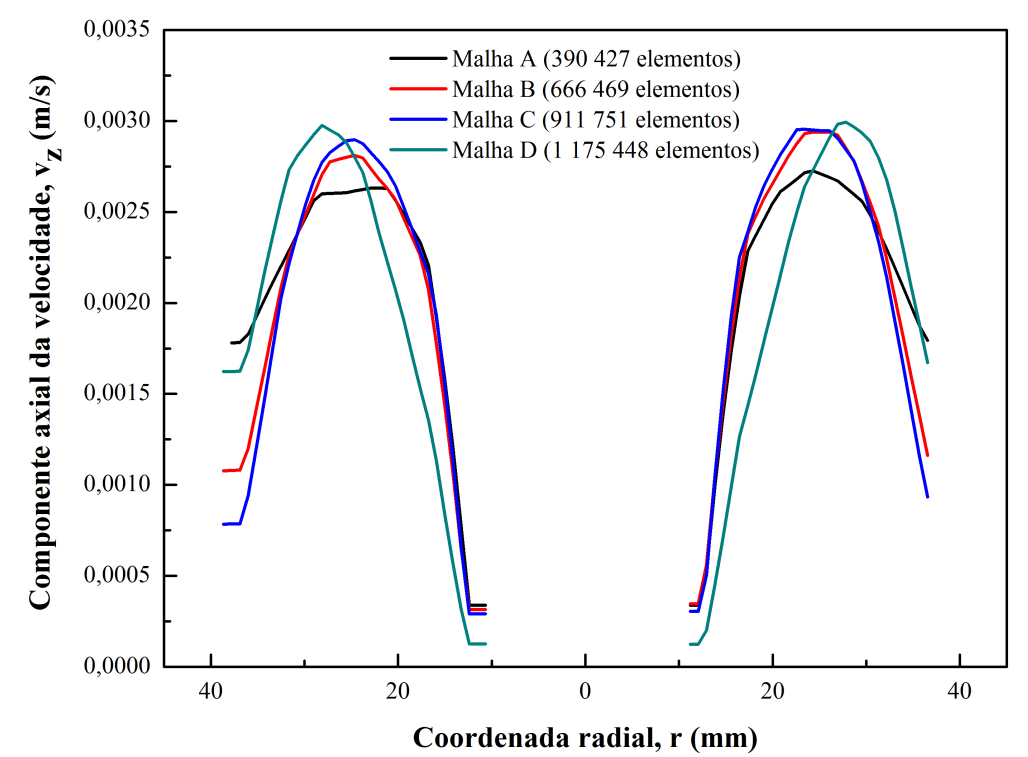

Figura 13. Análise de independência de malhas do modelo computacional do reator através dos perfis de velocidade em $z=80 \mathrm{~cm}$, para as configurações A e vazão de $30 \mathrm{~L} \mathrm{~h}^{-1}$.

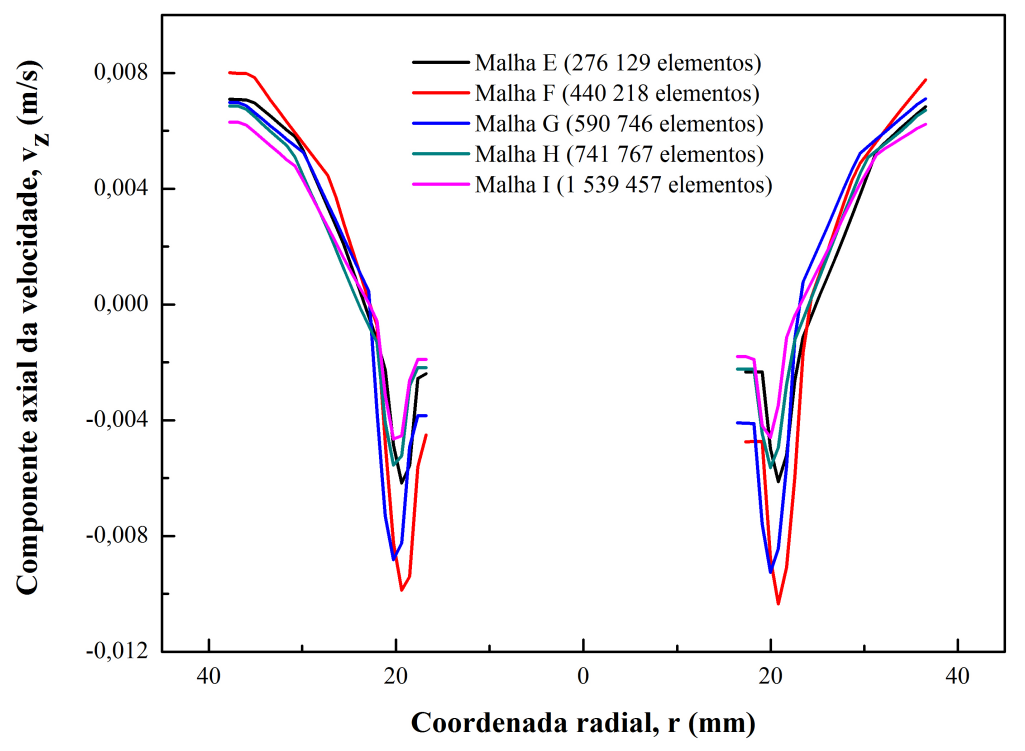

Figura 14. Análise de independência de malhas do modelo computacional do reator através dos perfis de velocidade em $z=20 \mathrm{~cm}$, para a configuração $B$ e vazão de $30 \mathrm{~L} \mathrm{~h}^{-1}$. 


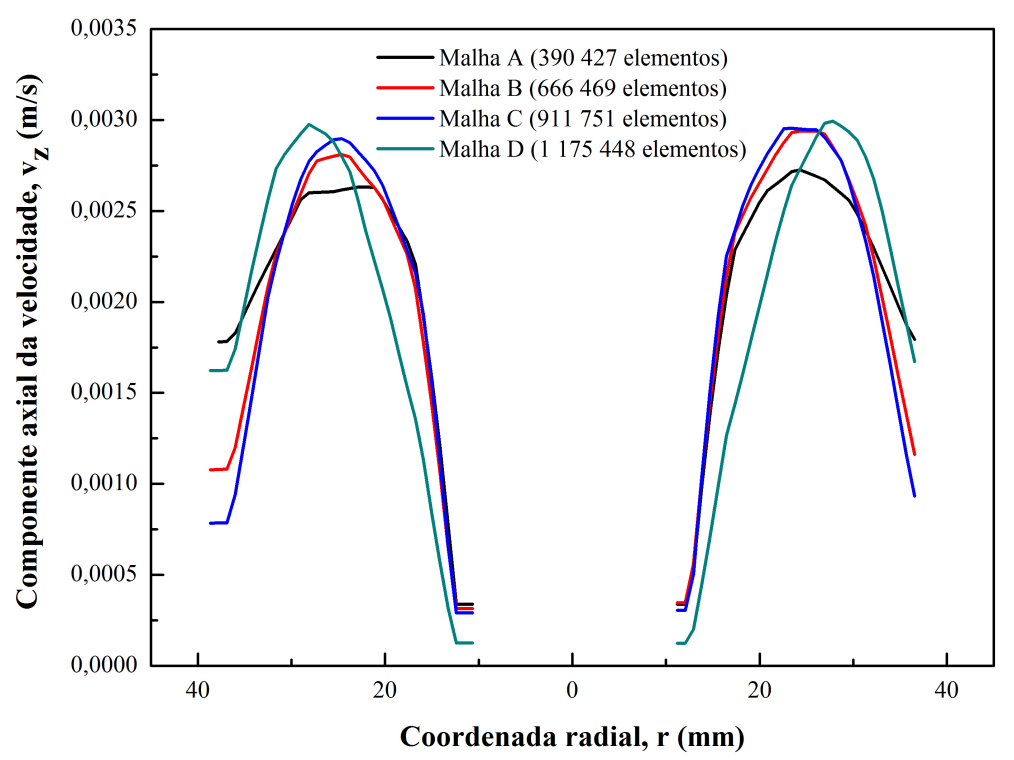

Figura 15. Análise de independência de malhas do modelo computacional do reator através dos perfis de velocidade em $z=80 \mathrm{~cm}$, para a configuração $B$ e vazão de $30 \mathrm{Lh}^{-1}$.

\subsubsection{Descrição do campo de velocidades}

Nas simulações foi constatado que o padrão de escoamento no reator depende da vazão de alimentação. Na vazão de $100 \mathrm{Lh}^{-1}$, ele permanece em formato helicoidal por toda extensão do sistema. Nas vazões de 30 e de $60 \mathrm{~L} \mathrm{~h}^{-1}$, porém, ocorre um ponto de transição depois da metade do reator, no qual o fluido deixa de girar e se desenvolve de forma semelhante a um sistema pistonado (Figuras 16 e 17). Silvio et al. (2011) verificaram que o modelo macroscópico mais apropriado para descrever o reator é o de CSTR + PFR em série. O padrão de escoamento ajuda a justificar qualitativamente esse fato, já que nos trechos de espiral a agitação é semelhante a de um tanque de mistura. 


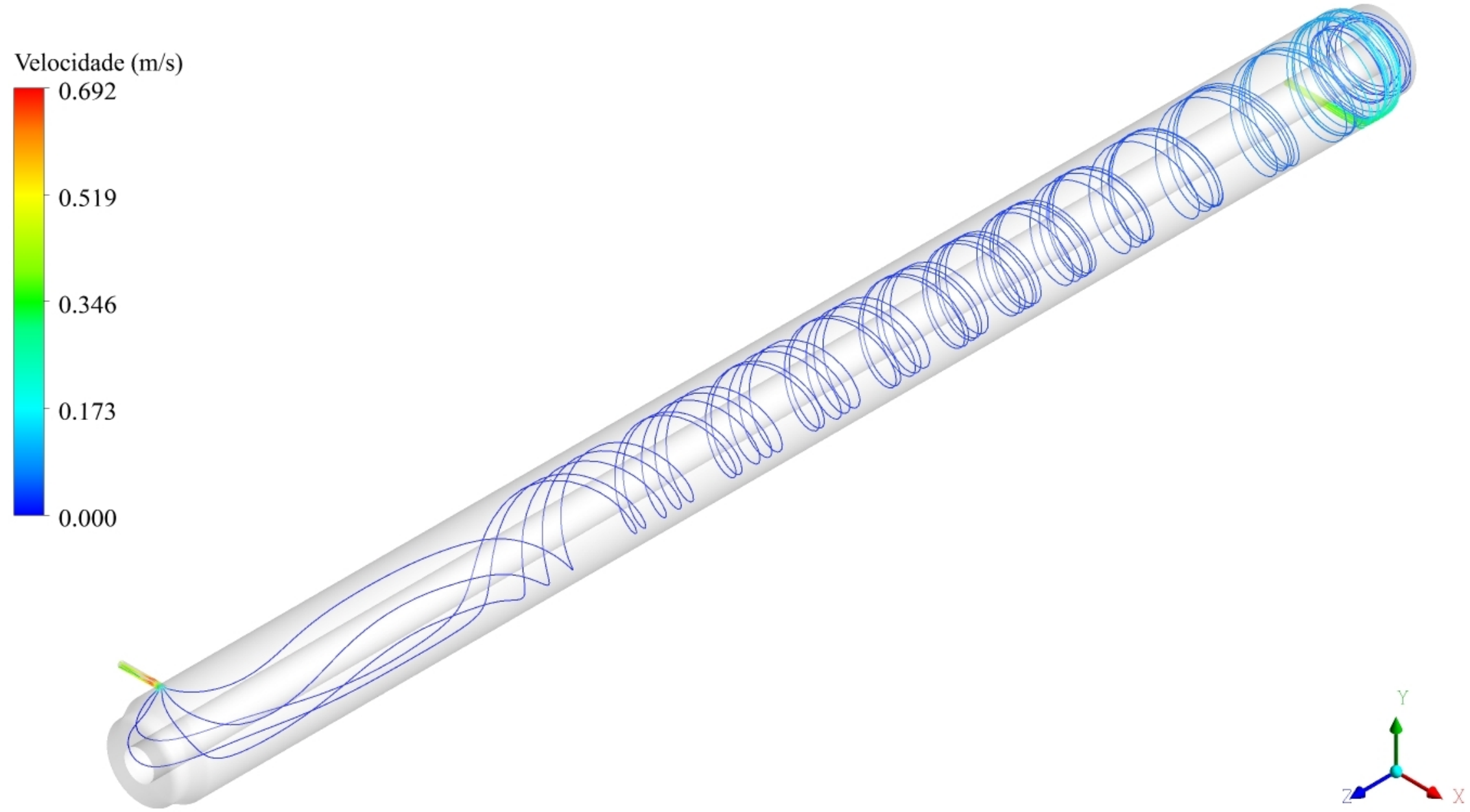

Figura 16. Padrão de escoamento ao longo da extensão do reator para as configurações A e vazão de $30 \mathrm{Lh}^{-1}$. 


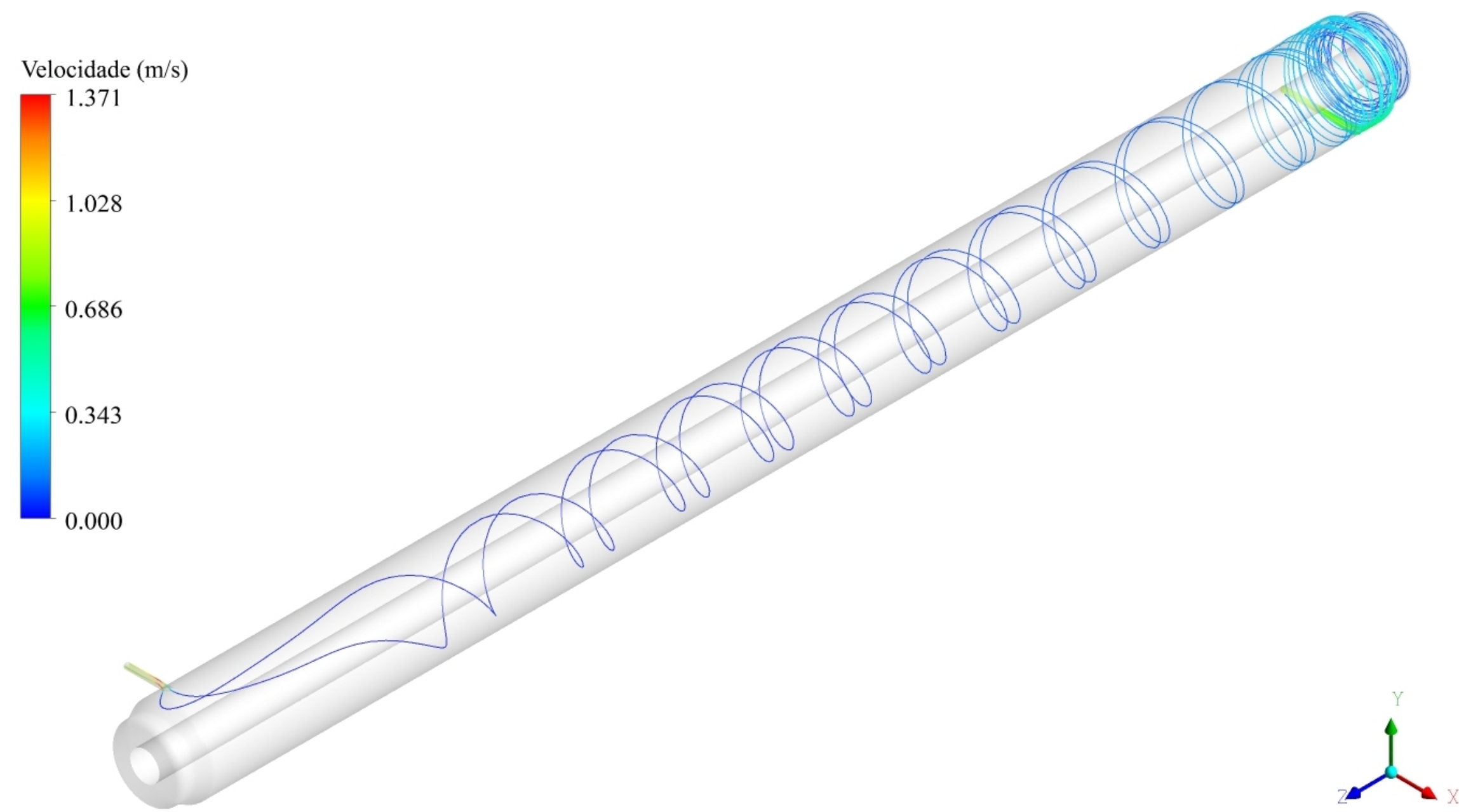

Figura 17. Padrão de escoamento ao longo da extensão do reator para as configurações A e vazão de $60 \mathrm{Lh}^{-1}$. 
Para compreender como ocorre a transição do escoamento helicoidal para o pistonado, é interessante observar a variação das componentes axial (direção $z$ ) e tangencial (direção y) ao longo do reator. Devido à posição tangencial da entrada, o fluido entra no reator com movimento ascendente e descendente na direção diagonal; a maior parte avança em direção à saída, mas uma porção sofre retorno (backflow) (vide Figura 18). Conforme o fluido avança, as forças viscosas atenuam o efeito de entrada e as espirais vão se alongando na direção axial. Na Figura 19 vê-se que a componente axial passa a assumir valores positivos na seção $z=60 \mathrm{~cm}$ para a vazão de $30 \mathrm{~L} \mathrm{~h}^{-1}$ e que há redução significativa no módulo dessa componente para a vazão de $60 \mathrm{Lh}^{-1}$, até o escoamento se desenvolver como pistonado nas seções finais do reator para as menores vazões (Figura 20).
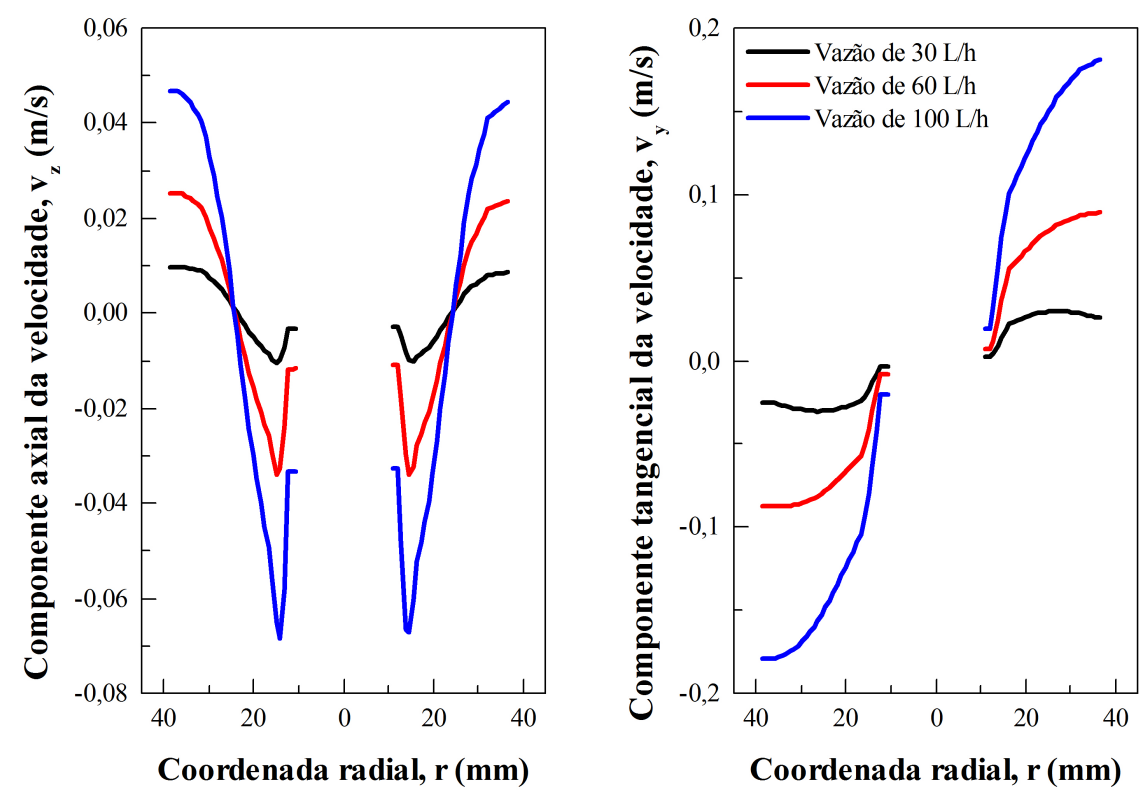

Figura 18. Componentes axial $\left(v_{z}\right)$ e tangencial $\left(v_{y}\right)$ da velocidade na seção transversal em $z=20 \mathrm{~cm}$, para as configurações A1/A2. 

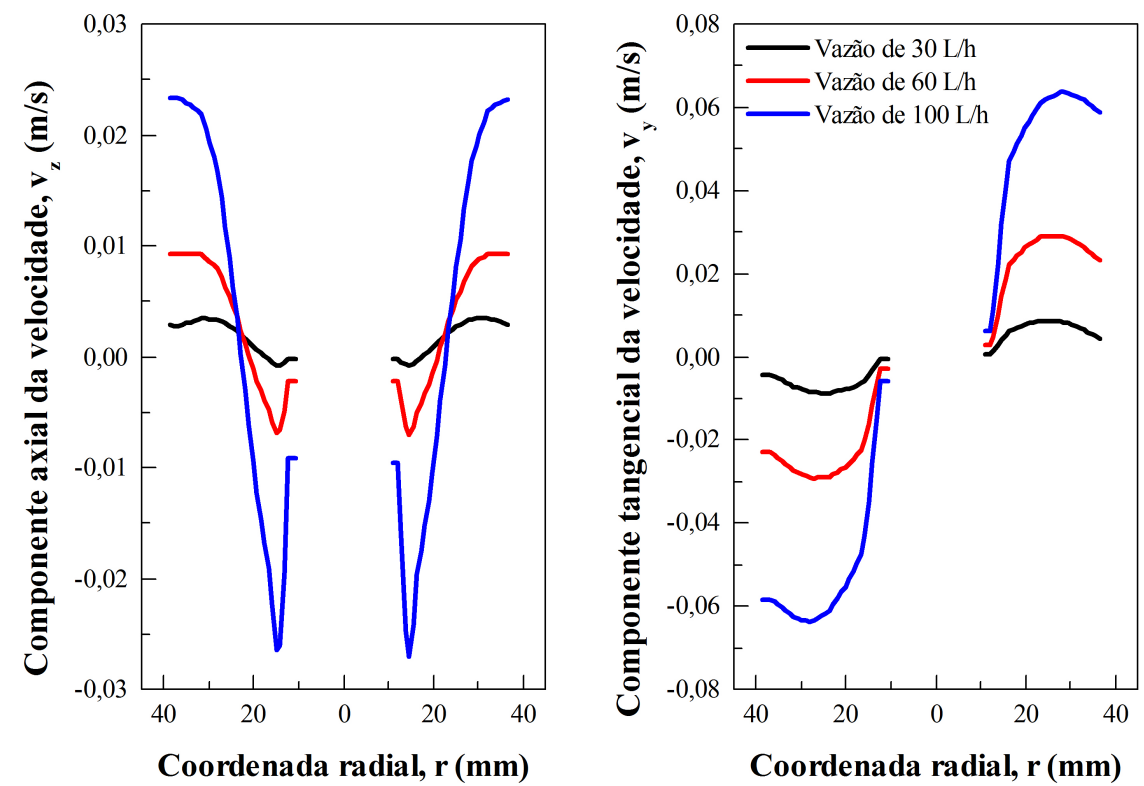

Figura 19. Componentes axial $\left(v_{z}\right)$ e tangencial $\left(v_{y}\right)$ da velocidade na seção transversal em $z=60 \mathrm{~cm}$, para as configurações A1/A2.
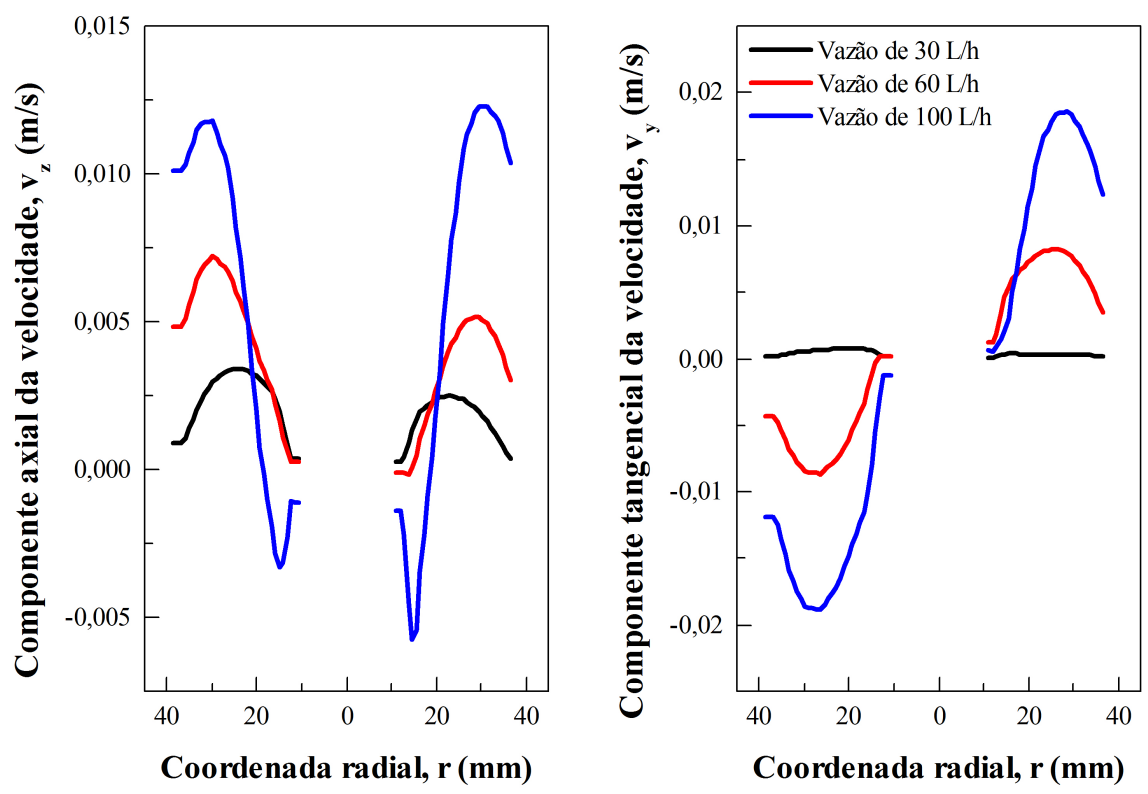

Figura 20. Componentes axial $\left(v_{z}\right)$ e tangencial $\left(v_{y}\right)$ da velocidade na seção transversal em $z=100 \mathrm{~cm}$, para as configurações A1/A2.

Sozzi e Taghipour (2006a) investigaram um reator de dimensões semelhantes ao deste trabalho, com tubos de entrada e saída posicionados em U e na vertical. No reator construído pelo CESQ esses tubos foram deslocados da porção central do reator 
e colocados na horizontal, tangenciando seu corpo. Uma consequência da entrada tangencial é a atenuação e zonas de recirculação na entrada vista na Fiura 21, pois não há choque da corrente que entra com a lâmpada. Todavia, há uma característica comum às duas configurações: em ambas o efeito de entrada faz com que a velocidade do fluido seja maior nas regiões próximas à parede externa, influenciando a distribuição de espécies como será discutido posteriormente.

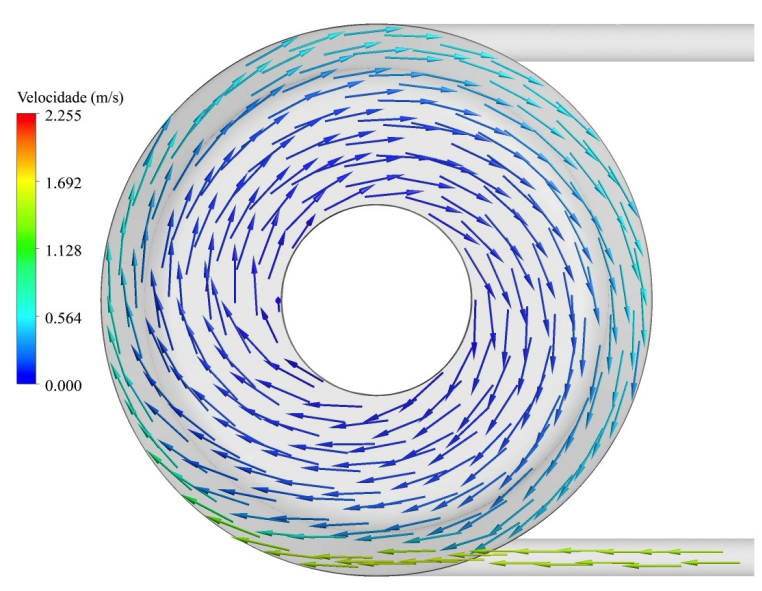

(a)

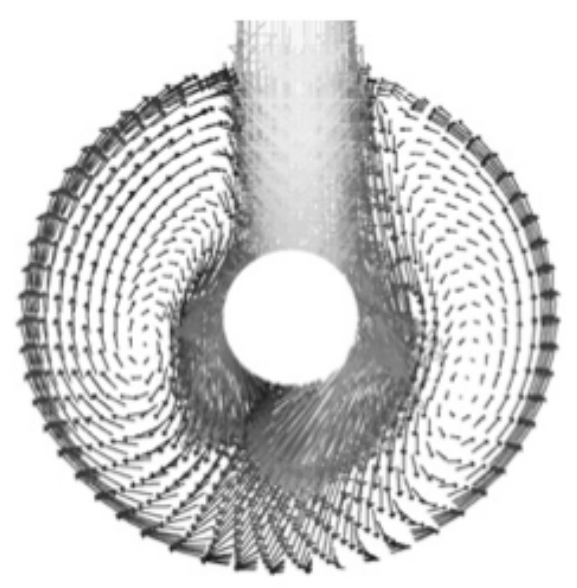

(b)

Figura 21. Comparação do efeito de entrada causado pela (a) geometria em U analisada por Sozzi e Taghipour (2006a) e (b) pela configuração tangencial proposta pelo CESQ.

\subsubsection{Distribuição de tempos de residência e validação do campo de velocidades}

A DTR foi empregada para validar o escoamento e auxiliar na seleção do modelo de turbulência mais apropriado para o reator. As Tabelas 20 e 21 trazem os parâmetros das distribuições calculados para cada modelo de turbulência analisado. Ao comparar as curvas previstas por cada modelo com os dados experimentais de Silvio et al. (2011), verifica-se que o escoamento não é laminar, como era de se esperar, devido aos efeitos de entrada e saída e ao movimento helicoidal. As Figuras 22 e 24 indicam que o modelo $k-\epsilon$ não trouxe resultados satisfatórios devido a sua imprecisão ao lidar com escoamentos rotacionais e com número de Reynolds baixo (SPEZIALE, 1990). 
Tabela 20. Parâmetros da distribuição de tempos de residência do modelo computacional para as configurações A do reator.

\begin{tabular}{cccccc}
\hline Vazão $\left(\mathbf{L ~ h}^{-\mathbf{1}}\right)$ & Modelo de turbulência & $\mathbf{t}_{\mathbf{m}}(\mathbf{s})$ & $\sigma^{\mathbf{2}}\left(\mathbf{s}^{\mathbf{2}}\right)$ & $\sigma^{\mathbf{2}} / \mathbf{t}_{\mathbf{m}}^{\mathbf{2}}$ & $\mathbf{R}^{\mathbf{2}}$ \\
\hline \multirow{4}{*}{30} & laminar & 478,6 & 62868,4 & 0,27 & 0,8581 \\
& $k-\epsilon$ & 476,5 & 23147,6 & 0,10 & 0,8705 \\
& $k-\omega$ & 474,9 & 42226,7 & 0,18 & 0,9566 \\
& $\mathrm{SST}$ & 476,6 & 33340,3 & 0,15 & 0,9566 \\
& $\mathrm{RSM}$ & 477,0 & 44829,8 & 0,20 & 0,9449 \\
& Experimental & 462,5 & 30133,8 & 0,14 & - \\
\hline \multirow{6}{*}{60} & laminar & 244,9 & 37299,2 & 0,62 & 0,4890 \\
& $k-\epsilon$ & 238,9 & 11608,8 & 0,20 & 0,9446 \\
& $k-\omega$ & 240,5 & 21761,3 & 0,38 & 0,9723 \\
& SST & 239,2 & 18882 & 0,33 & 0,9646 \\
& $\mathrm{RSM}$ & 242,3 & 29559,5 & 0,50 & 0,7444 \\
& Experimental & 235,6 & 8708,7 & 0,16 & - \\
\hline \multirow{6}{*}{100} & laminar & 147,7 & 14440,1 & 0,66 & 0,4200 \\
& $k-\epsilon$ & 143,3 & 4772,5 & 0,23 & 0,8537 \\
& $k-\omega$ & 143,7 & 9023,28 & 0,44 & 0,8901 \\
& SST & 143,8 & 9486,63 & 0,46 & 0,8901 \\
& RSM & 144,9 & 10513,7 & 0,50 & 0,8901 \\
& Experimental & 139,9 & 2757,6 & 0,14 & - \\
\hline
\end{tabular}

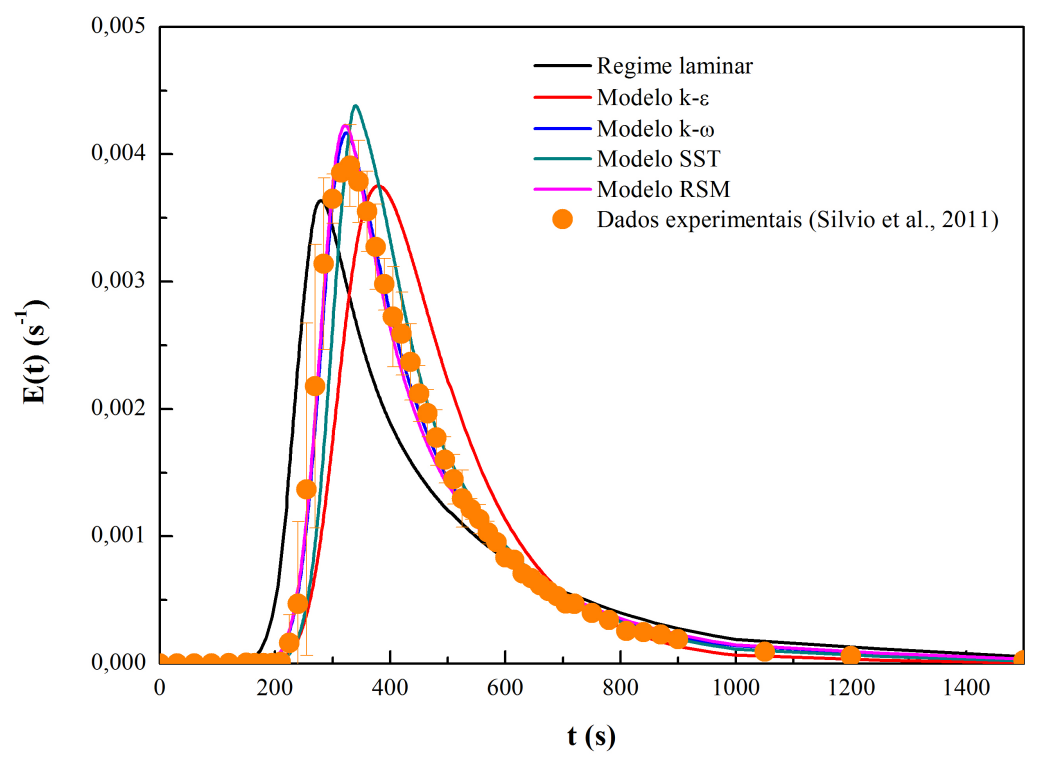

Figura 22. Validação do modelo computacional do escoamento no reator por meio da sua distribuição de tempos de residência, para as configurações A e vazão de $30 \mathrm{~L} \mathrm{~h}^{-1}$ 
Tabela 21. Parâmetros da distribuição de tempos de residência do modelo computacional para a configuração B do reator.

\begin{tabular}{cccccc}
\hline Vazão $\left(\mathbf{L ~ h}^{-\mathbf{1}}\right)$ & Modelo de turbulência & $\mathbf{t}_{\mathbf{m}}(\mathbf{s})$ & $\sigma^{\mathbf{2}}\left(\mathbf{s}^{\mathbf{2}}\right)$ & $\sigma^{\mathbf{2}} \mathbf{t}_{\mathbf{m}}^{\mathbf{2}}$ & $\mathbf{R}^{\mathbf{2}}$ \\
\hline \multirow{4}{*}{30} & laminar & 393,5 & 35052,9 & 0,23 & 0,7468 \\
& $k-\epsilon$ & 395,6 & 5612,0 & 0,04 & 0,6436 \\
& $k-\omega$ & 398,4 & 14099,7 & 0,09 & 0,7936 \\
& SST & 397,6 & 12821,2 & 0,08 & 0,8358 \\
& $\mathrm{RSM}$ & 398,1 & 13962,2 & 0,09 & 0,7978 \\
& Experimental & 394,3 & 33311 & 0,21 & - \\
\hline \multirow{6}{*}{60} & laminar & 200,4 & 12507,0 & 0,31 & 0,8066 \\
& $k-\epsilon$ & 200,8 & 5112,1 & 0,12 & 0,714 \\
& $k-\omega$ & 201,7 & 7208,2 & 0,18 & 0,8865 \\
& SST & 201,3 & 7074,5 & 0,17 & 0,8708 \\
& RSM & 201,7 & 7943,6 & 0,19 & 0,8698 \\
& Experimental & 202,9 & 6258,9 & 0,15 & - \\
\hline \multirow{4}{*}{100} & laminar & 120,8 & 5448,9 & 0,37 & 0,4716 \\
& $k-\epsilon$ & 119,5 & 1027,4 & 0,07 & 0,8399 \\
& $k-\omega$ & 119,7 & 1651,6 & 0,11 & 0,9826 \\
& SST & 119,8 & 2250,4 & 0,16 & 0,9469 \\
& RSM & 120,3 & 3077,7 & 0,21 & 0,9799 \\
& Experimental & 116,6 & 1837,9 & 0,14 & - \\
\hline
\end{tabular}

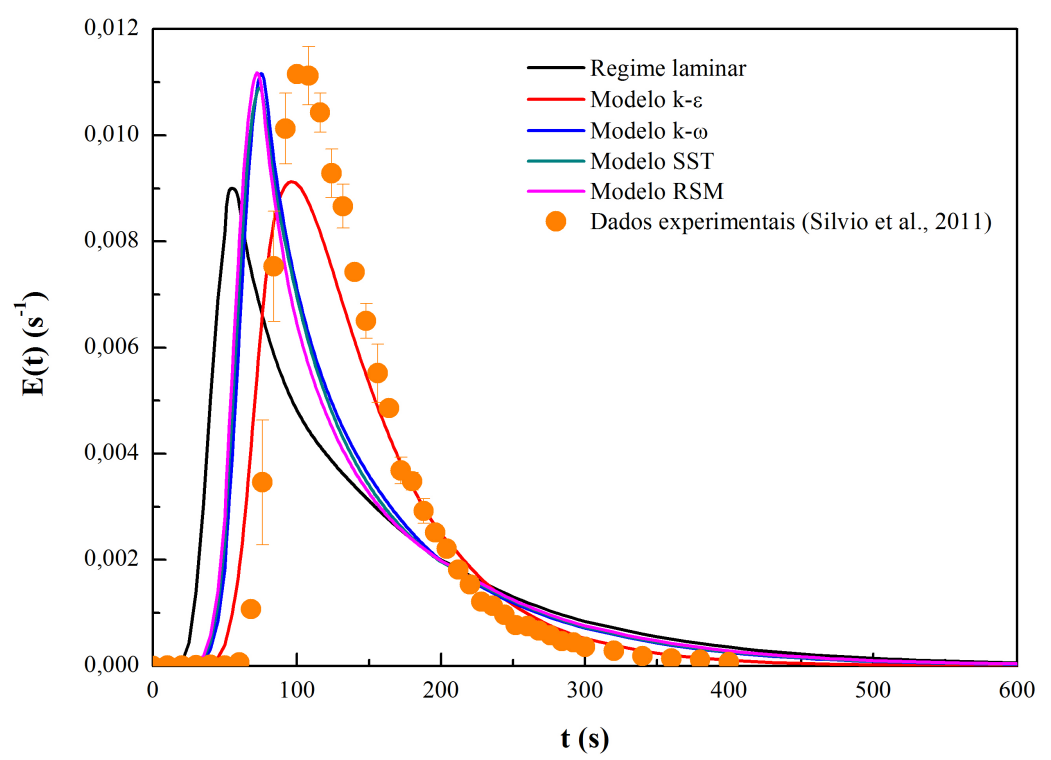

Figura 23. Validação do modelo computacional do escoamento no reator por meio da sua distribuição de tempos de residência, para as configurações A e vazão de $100 \mathrm{Lh}^{-1}$ 


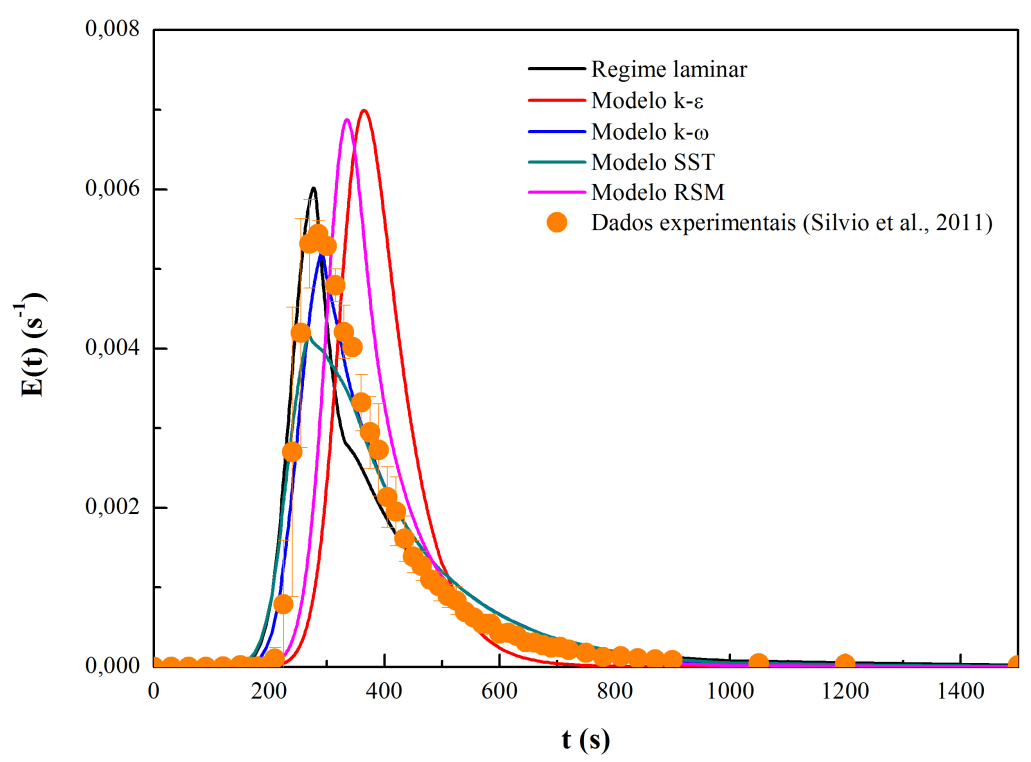

Figura 24. Validação do modelo computacional do escoamento no reator por meio da sua distribuição de tempos de residência, para a configuração B e vazão de $30 \mathrm{Lh}^{-1}$

Na Seção 2.2.2.1, foi discutido que o modelo $k-\epsilon$ é mais apropriado para número de Reynolds elevado. Além disso, a distância entre as paredes na região anular é pequena, daí talvez fosse melhor usar a equação para $\omega$ no espaço. Liu et al. (2007) verificaram uma situação semelhante: no reator que analisaram, o modelo $k-\omega$ reproduziu melhor os dados de PIV no pequeno espaço entre uma das lâmpadas e uma haste (região 2 da Figura 25).

Para complementar a seleção do modelo de turbulência, obteve-se a distribuição da variável $y^{+}$, a distância adimensional até a parede. As Figuras 27 e 26 indicam as situações de maior e menor variação de $y^{+}$encontradas, respectivamente. Menter, Kuntz e Langtry (2003) e ANSYS Inc. (2010) apontam que os modelos $k-\omega$ e SST foram formulados de modo a contornar a forte restrição de $y^{+}=1$ do modelo $k-\epsilon$. Dessa forma, são modelos apropriados para o caso em questão. 


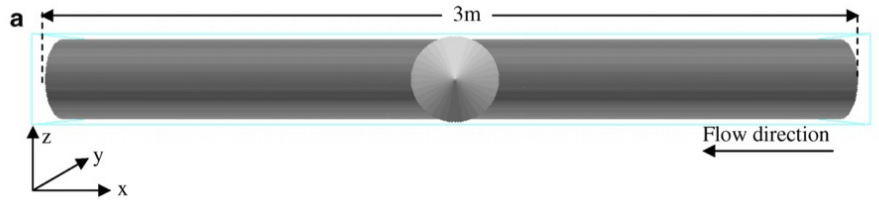

b
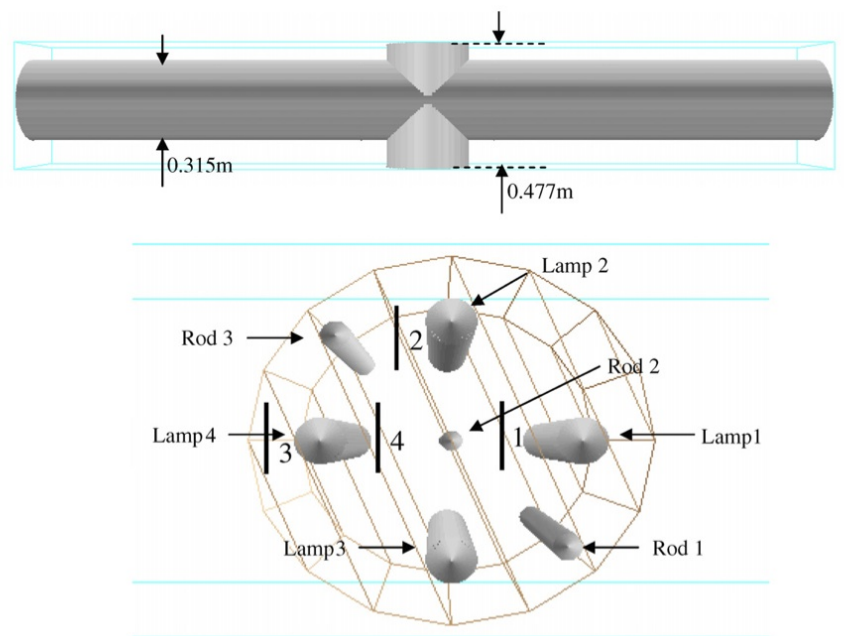

Figura 25. Reator analisado por Liu et al. (2007): (a) vista lateral, (b) vista superior e (c) vista lateral do interior do reator.

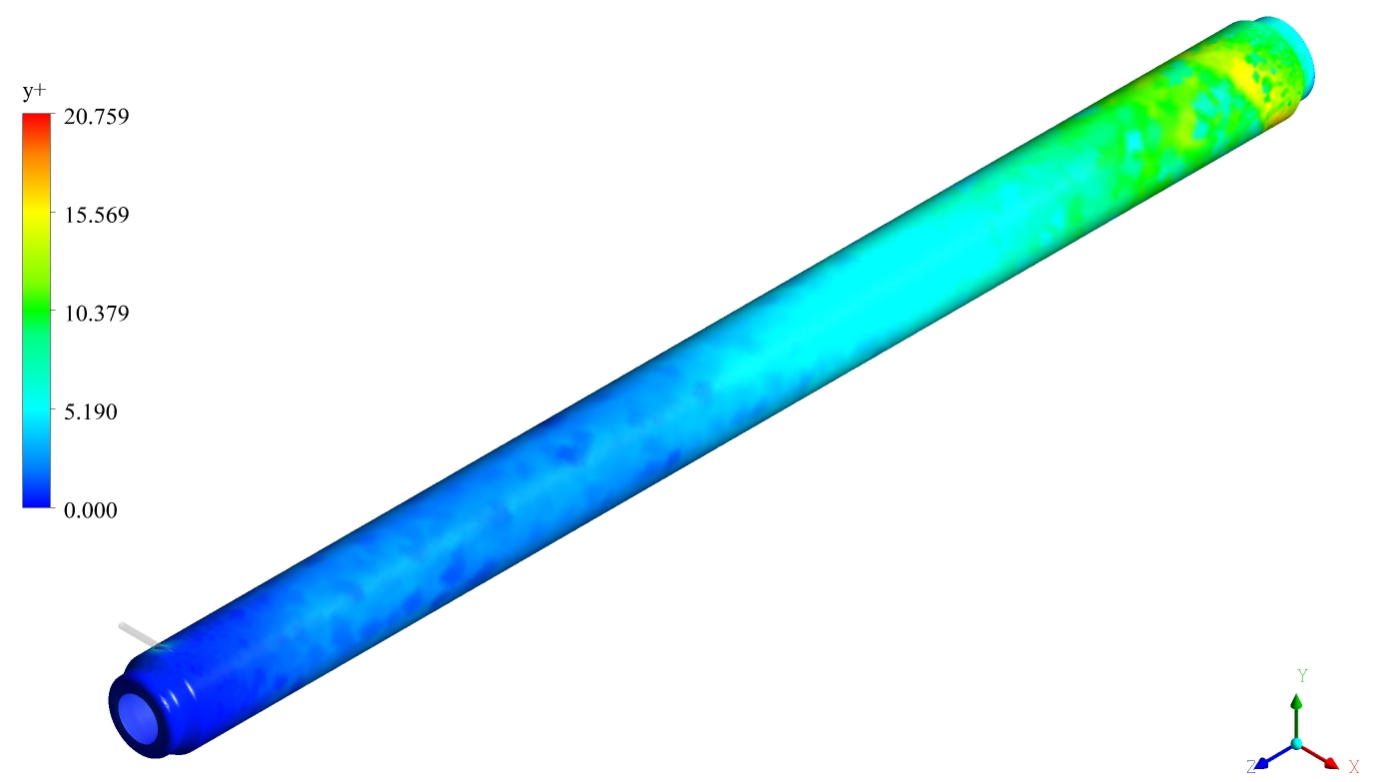

Figura 26. Mapa da distância adimensional até a parede $\left(y^{+}\right)$para a configuração B e vazão de $30 \mathrm{Lh}^{-1}$.

As curvas de DTR indicadas neste Capítulo, no Apêndice A e as Tabelas 20 e 21 permitem concluir que os modelos $k-\omega$, SST e RSM foram satisfatórios na reprodução do campo de velocidades, com destaque para o primeiro devido à simplicidade, 


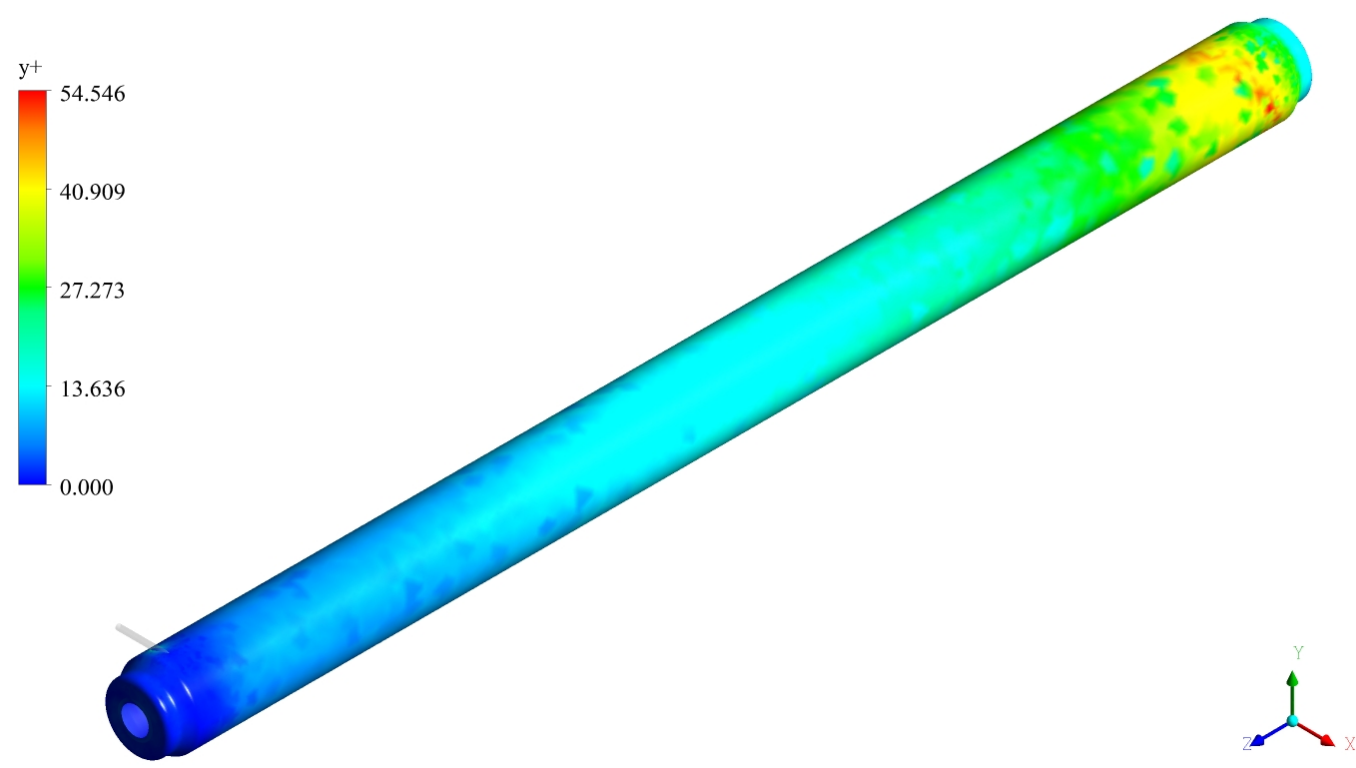

Figura 27. Mapa da distância adimensional até a parede $\left(y^{+}\right)$para as configurações A1/A2 e vazão de $100 \mathrm{Lh}^{-1}$.

a ser pouco explorado em Engenharia Química e por Liu et al. (2007) também verificarem sua eficácia em regiões com escoamento confinado. Dessa forma, optou-se pelo modelo $k-\omega$ para elaborar o campo de velocidades do reator para a vazão de $72 \mathrm{~L} \mathrm{~h}^{-1}$, que será empregado na simulação do processo de degradação de fenol nas seções posteriores. A intensidade de turbulência na entrada foi fixada em 5\%, pois não influenciou o campo de velocidades nas condições analisadas (Figura 28).

Não há simetria nas curvas experimentais de DTR, indicando que existe uma contribuição associada a um modelo CSTR (LEVENSPIEL, 1988). A dispersão destas curvas também indica um número de Peclet alto, o que foi confirmado pelo tratamento de dados feito anteriormente (SILVIO et al., 2011). As simulações representaram estes fatos de forma adequada, apresentando assimetria e dispersão próxima dos dados experimentais. Os experimentos de DTR são muito mais simples do que as técnicas de visualização modernas como PIV (particle image velometry), contudo foram suficientes para validar os campos de velocidades gerados pelas simulações com CFD. 


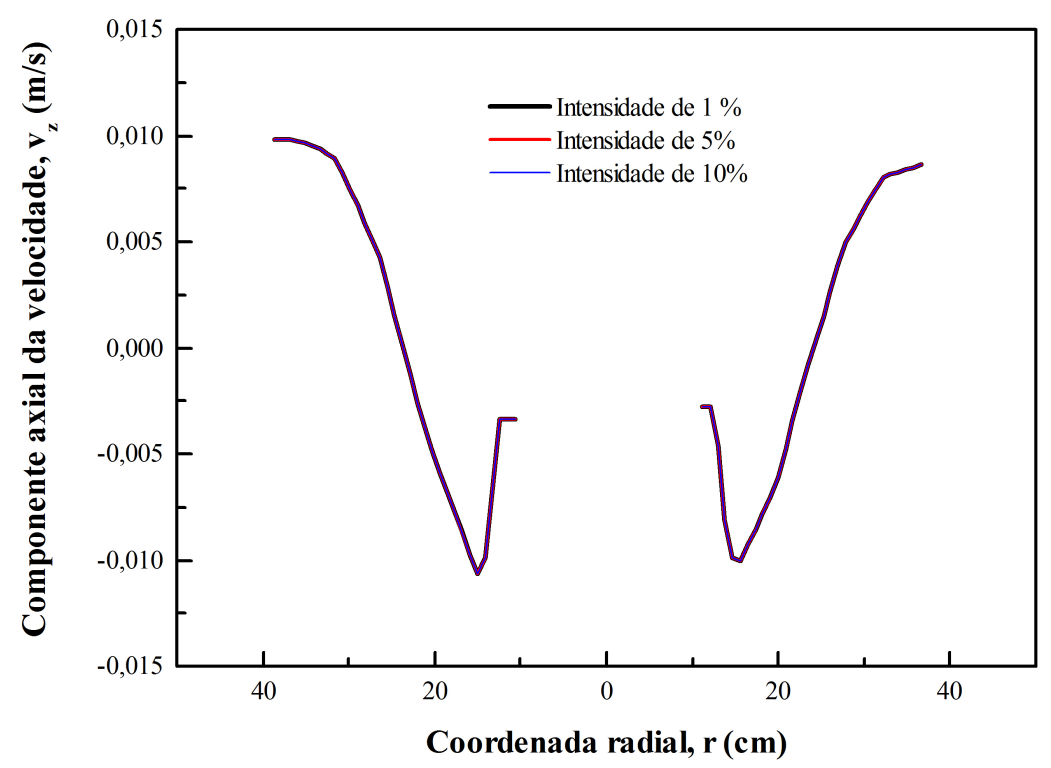

(a)

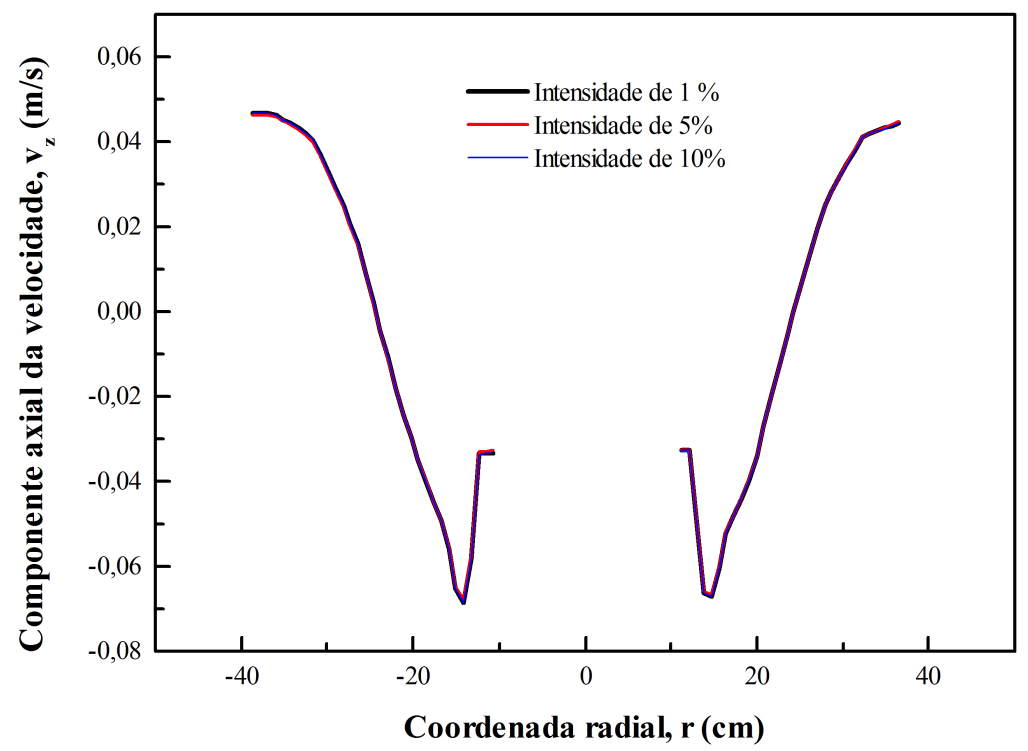

(b)

Figura 28. Avaliação da influência da intensidade de turbulência na entrada sobre o campo de velocidades na seção transversal em $z=20 \mathrm{~cm}$, com vazões de (a) $30 \mathrm{e}(b) 100 \mathrm{~L} \mathrm{~h}^{-1}$ para as configurações A1/A2. 


\subsection{Estudo cinético do reator}

\subsubsection{Análises iniciais}

As primeiras simulações envolvendo reações químicas modelaram a degradação de fenol por pseudocinética de primeira ordem em relação a esse componente. A Figura 29 apresenta as concentrações do fenol ao longo do reator para o primeiro caso da Tabela 15. Os valores de concentração de fenol na saída do reator foram similares aos obtidos experimentalmente por Tambani (2011), como se vê na Tabela 22.

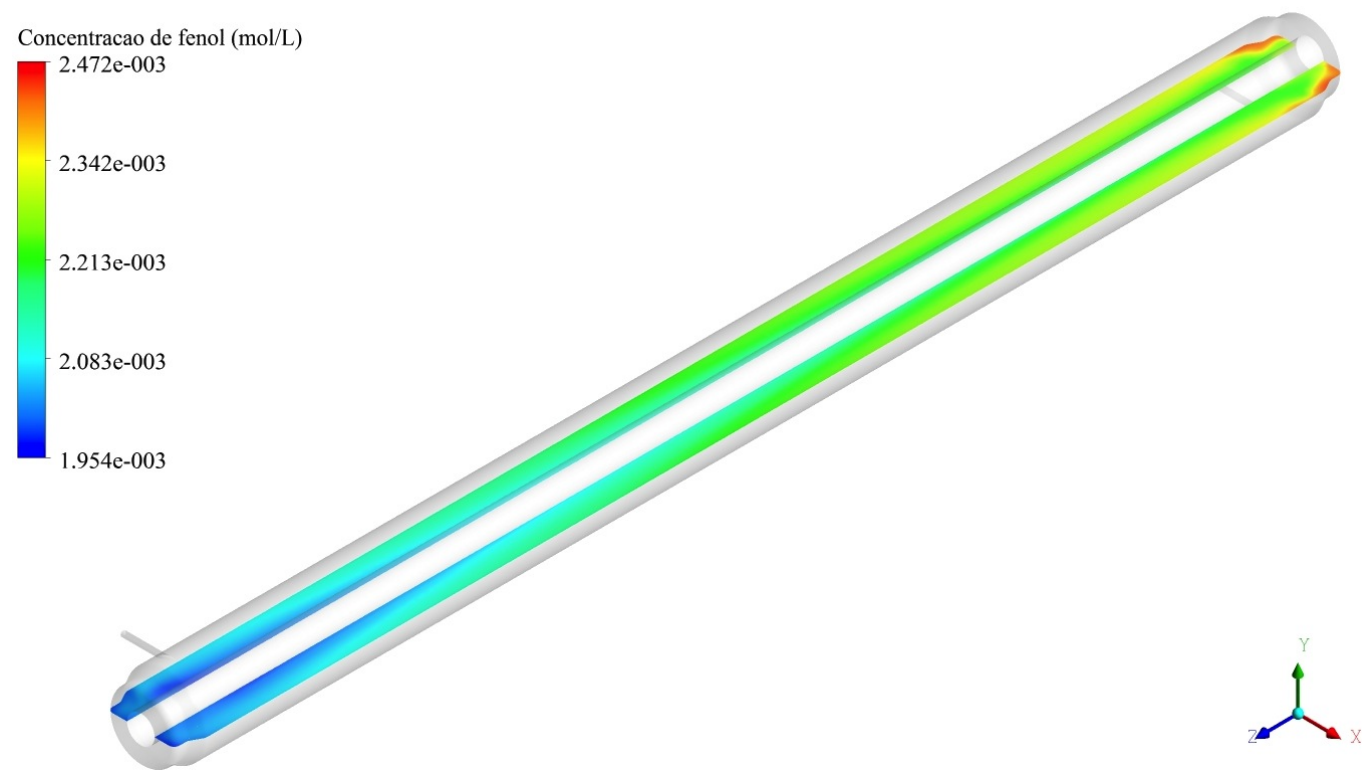

Figura 29. Perfil de concentração de fenol para o caso de reação 1 considerando pseudocinética.

Como apresentado no Capítulo 3, o mecanismo de degradação de fenol proposto por Edalatmanesh, Dhib e Mehrvar (2008) é numericamente stiff. Tal comportamento é evidenciado nas Figura 30, que mostra o histórico de convergência típico dos casos da Tabela 17: mesmo com passo de $1 \times 10^{-5} \mathrm{~s}$, se os coeficientes de termo fonte não forem adequadamente ajustados, os resíduos não são reduzidos até o critério de convergência estabelecido. Os coeficientes foram modificados para $10^{15} \mathrm{~kg} \mathrm{~m}^{-3} \mathrm{~s}^{-1}$, com a inicialização das frações mássicas por algoritmos do software. A convergência foi estabilizada e alcançada após 3 dias de processamento (Figura 31). 
Tabela 22. Resultados do modelo computacional de degradação de fenol pelo processo UV/ $\mathrm{H}_{2} \mathrm{O}_{2}$ para experimentos de Tambani (2011), considerando pseudocinética de priemira ordem em relação ao fenol.

\begin{tabular}{|c|c|c|c|c|c|c|}
\hline \multirow[t]{2}{*}{ Caso } & \multirow{2}{*}{$\begin{array}{l}\text { Configuração } \\
\text { do reator }\end{array}$} & \multirow{2}{*}{$\begin{array}{l}\text { Concentração } \\
\text { inicial de fenol } \\
\quad\left(\mathrm{mg} \mathrm{L}^{-1}\right)\end{array}$} & \multirow{2}{*}{$\begin{array}{l}\text { Razão molar } \\
\mathrm{H}_{2} \mathrm{O}_{2} / \text { fenol }\end{array}$} & \multicolumn{2}{|c|}{$\begin{array}{l}\text { Concentração de fenol no } \\
\text { efluente do reator }\left(\mathrm{mg} \mathrm{L}^{-1}\right)\end{array}$} & \multirow{2}{*}{$\begin{array}{c}\text { Desvio em } \\
\text { relação ao } \\
\text { experimental }(\%)\end{array}$} \\
\hline & & & & modelo em CFD & experimental & \\
\hline 1 & $\mathrm{~A} 2$ & 233,12 & 47,1 & 189,69 & 189,76 & 0,04 \\
\hline 2 & $\mathrm{~A} 2$ & 274,48 & 5,05 & 211,97 & 215,26 & 1,53 \\
\hline 3 & A2 & 479,4 & 30,22 & 402,23 & 400,93 & 0,32 \\
\hline 4 & A2 & 77,27 & 14,23 & 51,49 & 42,08 & 22,36 \\
\hline 5 & $\mathrm{~A} 2$ & 469,72 & 13,76 & 387,09 & 413,13 & 6,30 \\
\hline 6 & $\mathrm{~B}$ & 304,65 & 34,77 & 260,76 & 261,18 & 0,16 \\
\hline 7 & A1 & 378,82 & 23,97 & 339,43 & 342,58 & 0,92 \\
\hline 8 & $\mathrm{~B}$ & 292,34 & 16,1 & 246,66 & 249,55 & 1,16 \\
\hline 9 & $\mathrm{~A} 2$ & 232,18 & 26,62 & 207,46 & 191,00 & 8,61 \\
\hline
\end{tabular}




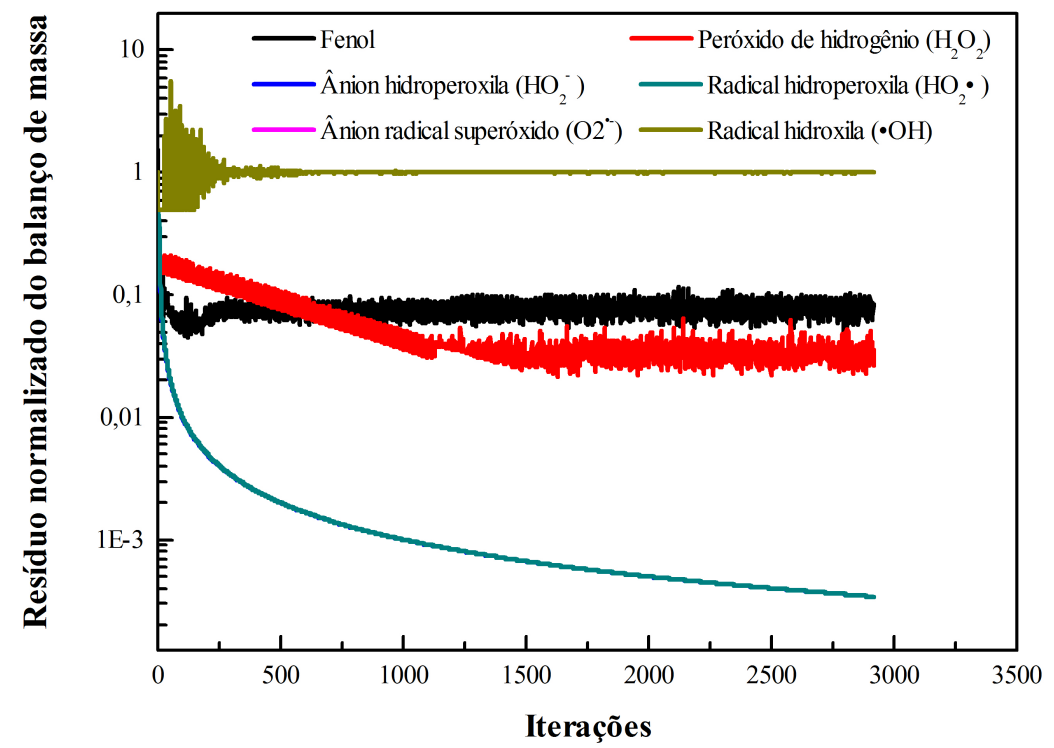

Figura 30. Comportamento dos balanços de massa da parte térmica do mecanismo de degradação do fenol com coeficientes do termo fonte inadequados.

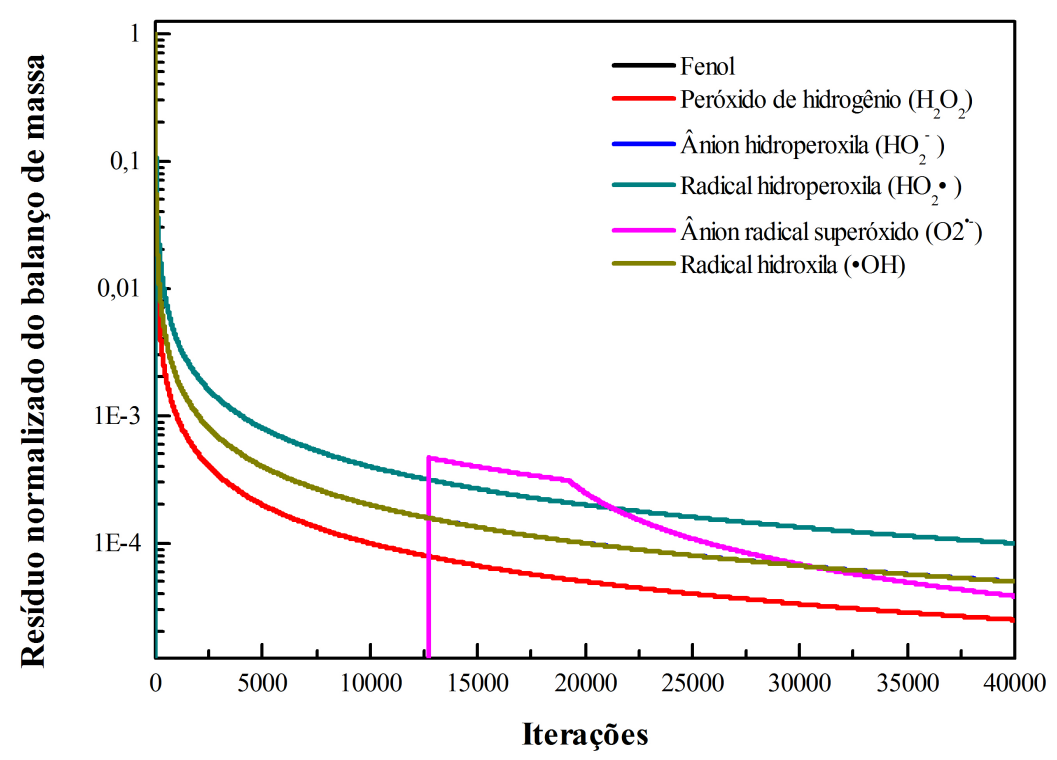

Figura 31. O impacto de coeficiente de termo fonte de $10^{15} \mathrm{~kg} \cdot \mathrm{m}^{-3} \cdot \mathrm{s}^{-1}$ sobre os balanços de massa da parte térmica do mecanismo de degradação do fenol (Inicialização em modo automático e passo de $\left.1 \times 10^{-5} \mathrm{~s}\right)$. 
Visando otimizar o processo de convergência, os coeficientes do termo fonte foram reduzidos para $10^{12} \mathrm{~kg} \mathrm{~m}^{-3} \mathrm{~s}^{-1}$. O tempo de processamento caiu para 1,5 dia, mas o balanço do ânion radical superóxido $\left(\mathrm{O}_{2}^{\bullet-}\right)$ oscilou muito (Figura 32). Num outro caso, ilustrado na Figura 33, apenas o coeficiente do $\mathrm{O}_{2}^{\bullet-}$ foi alterado para $10^{13} \mathrm{~kg} \mathrm{~m}^{-3} \mathrm{~s}^{-1}$ e o domínio foi inicializado pelo caso com coeficientes de $10^{15} \mathrm{~kg} \mathrm{~m}^{-3} \mathrm{~s}^{-1}$; o balanço da espécie oscilou bem menos e a convergência foi alcançada em 1,5 dia. Percebe-se então que esse radical é o limitante na estabilidade do processo iterativo.

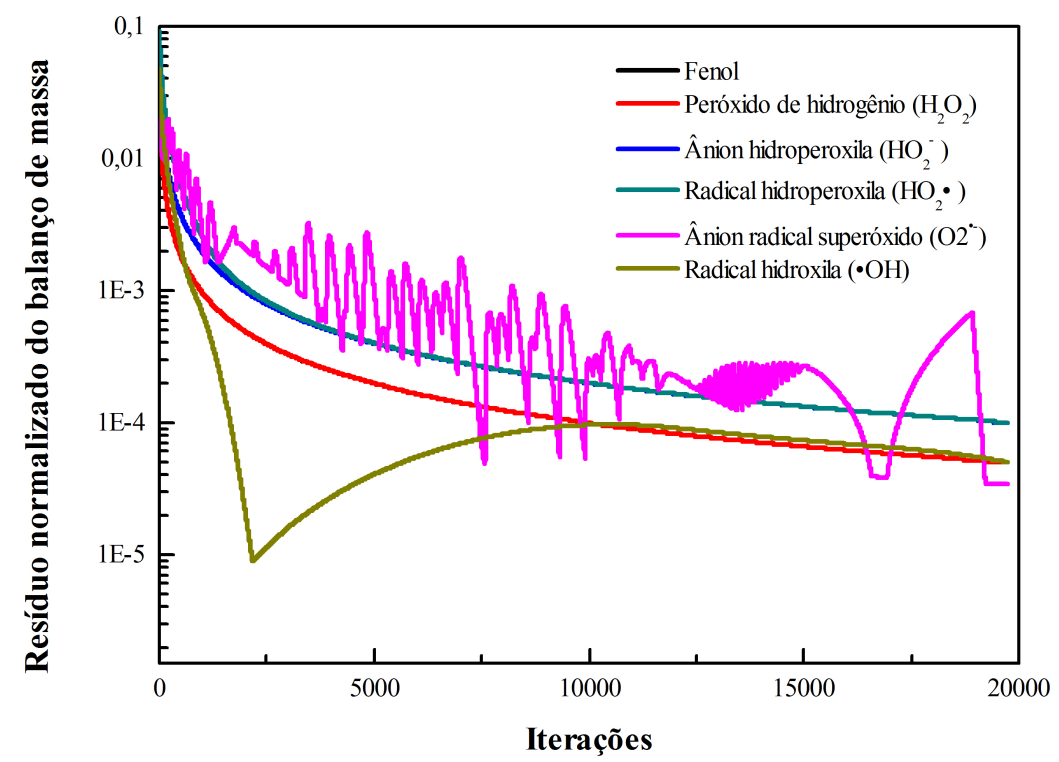

Figura 32. $\mathrm{O}$ impacto do coeficiente de termo fonte de $10^{15} \mathrm{~kg} \mathrm{~m}^{-3} \mathrm{~s}^{-1}$ sobre os balanços de massa do mecanismo de degradação do fenol (Inicialização em modo automático e passo de $\left.1 \times 10^{-5} \mathrm{~s}\right)$. 


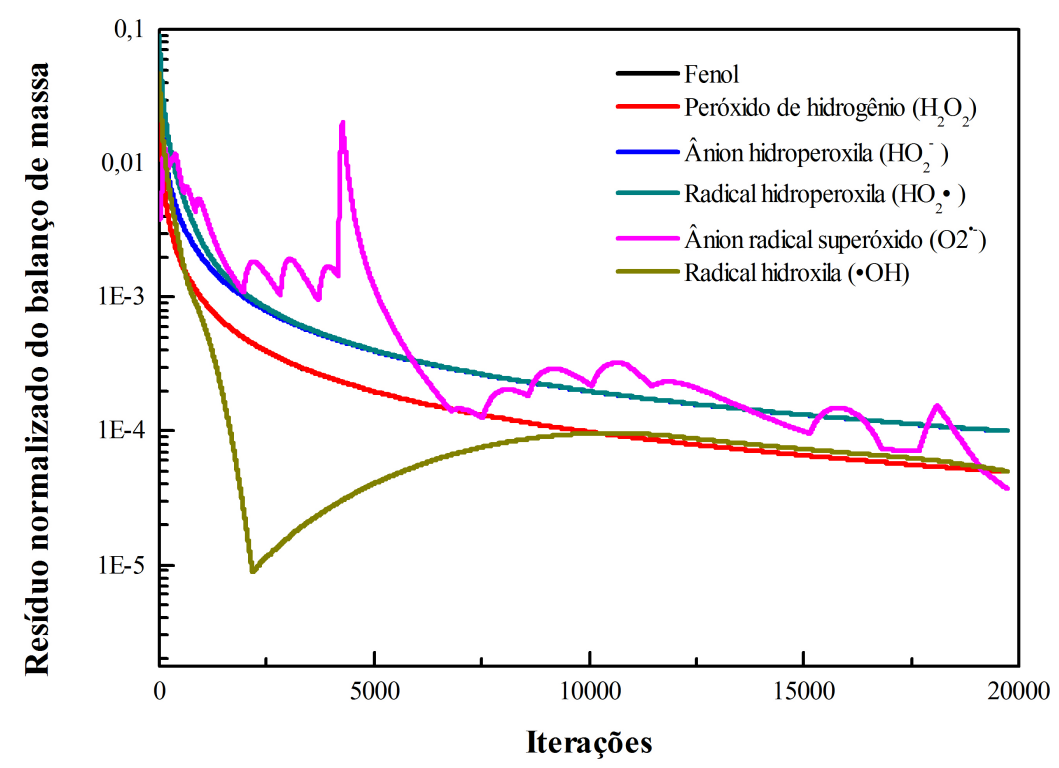

Figura 33. O impacto do coeficiente de termo fonte de $10^{15} \mathrm{~kg} \mathrm{~m}^{-3} \mathrm{~s}^{-1}$ sobre os balanços de massa do mecanismo de degradação do fenol (Inicialização em modo automático e passo de $\left.1 \times 10^{-5} \mathrm{~s}\right)$.

\subsubsection{Degradação de fenol pelo processo $\mathrm{UV} / \mathrm{H}_{2} \mathrm{O}_{2}$ com campo de radiação radial}

Nesta Seção serão discutidas as simulações dos cenários da Tabela 18 utilizando o modelo radial para o campo de radiação e o mecanismo de Edalatmanesh, Dhib e Mehrvar (2008).

O modelo de campo radial supõe que a intensidade varia exponencialmente com a distância ao centro do reator, conforme a Equação (2.51). Ele é reconhecido na literatura por predizer valores de intensidade de radiação frequentemente mais baixos do que os reais, caso fossem medidos. A performance do reator considerando este modelo para o campo de radiação está indicada na Tabela 23. 
Tabela 23. Resultados do modelo computacional de degradação de fenol pelo processo UV/ $\mathrm{H}_{2} \mathrm{O}_{2}$ para experimentos de Tambani (2011), considerando o mecanismo proposto por Edalatmanesh, Dhib e Mehrvar (2008) e campo de radiação pelo modelo radial.

\begin{tabular}{|c|c|c|c|c|c|c|}
\hline \multirow[t]{2}{*}{ Caso } & \multirow{2}{*}{$\begin{array}{l}\text { Configuração } \\
\text { do reator }\end{array}$} & \multirow{2}{*}{$\begin{array}{l}\text { Concentração } \\
\text { inicial de fenol } \\
\qquad\left(\mathrm{mg} \mathrm{L}^{-1}\right)\end{array}$} & \multirow{2}{*}{$\begin{array}{l}\text { Razão molar } \\
\mathrm{H}_{2} \mathrm{O}_{2} / \text { fenol }\end{array}$} & \multicolumn{2}{|c|}{$\begin{array}{l}\text { Concentração de fenol no } \\
\text { efluente do reator }\left(\mathrm{mg} \mathrm{L}^{-1}\right)\end{array}$} & \multirow{2}{*}{$\begin{array}{c}\text { Desvio em } \\
\text { relação ao } \\
\text { experimental }(\%)\end{array}$} \\
\hline & & & & modelo em CFD & experimental & \\
\hline 1 & $\mathrm{~A} 2$ & 233,12 & 47,1 & 198,90 & 189,76 & 4,82 \\
\hline 2 & $\mathrm{~A} 2$ & 274,48 & 5,05 & 231,99 & 215,26 & 7,77 \\
\hline 3 & A2 & 479,4 & 30,22 & 414,07 & 400,93 & 3,28 \\
\hline 4 & $\mathrm{~A} 2$ & 77,27 & 14,23 & 64,50 & 42,08 & 53,27 \\
\hline 5 & $\mathrm{~A} 2$ & 469,72 & 13,76 & 400,35 & 413,13 & 3,09 \\
\hline 6 & $\mathrm{~B}$ & 304,65 & 34,77 & 265,36 & 261,18 & 1,60 \\
\hline 7 & A1 & 378,82 & 23,97 & 331,16 & 342,58 & 3,33 \\
\hline 8 & $\mathrm{~B}$ & 292,34 & 16,1 & 252,95 & 249,55 & 1,36 \\
\hline 9 & $\mathrm{~A} 2$ & 232,18 & 26,62 & 197,96 & 191,00 & 3,64 \\
\hline
\end{tabular}


O campo de radiação radial possui o mesmo perfil independentemente da posição axial, como se nota na Figura 35. É observada uma variação radial que pode ser considerada a mesma em quase todo o reator, tendo um campo mais intenso próximo à lâmpada e uma ordem de grandeza menor na parede externa do reator. A Figura 34 mostra a variação típica da intensidade de radiação observada no plano central do reator $(y=0)$ para os casos analisados.

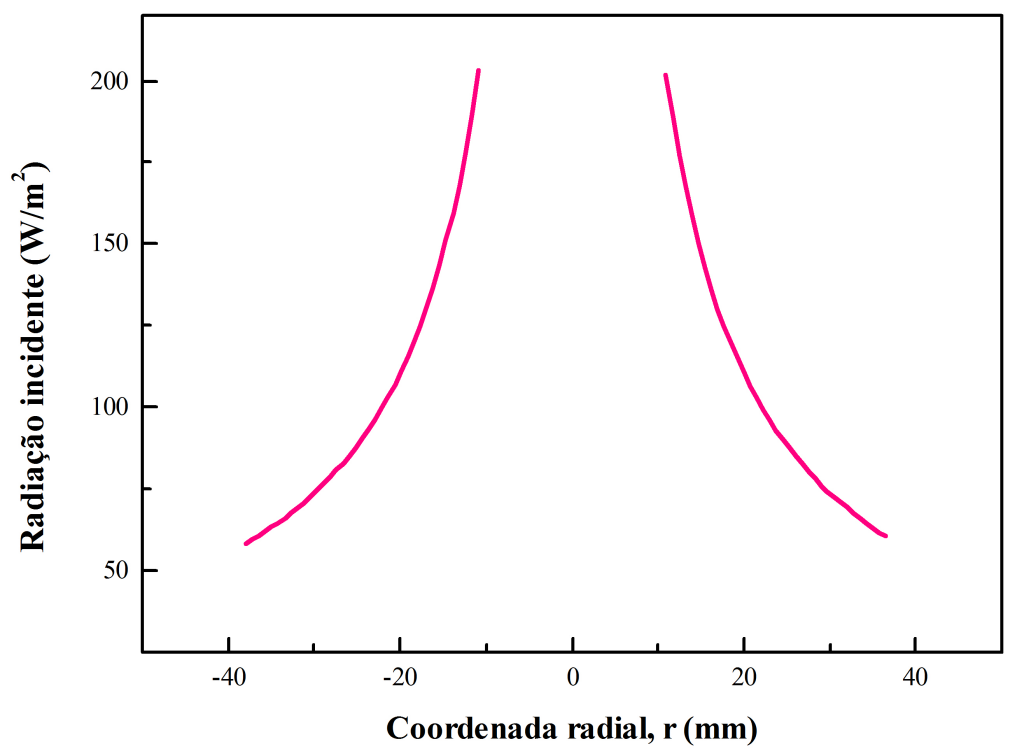

Figura 34. Perfil do campo de radiação na seção transversal $z=60 \mathrm{~cm}$ para o caso de reação 1 , com o modelo de campo de radiação radial. 


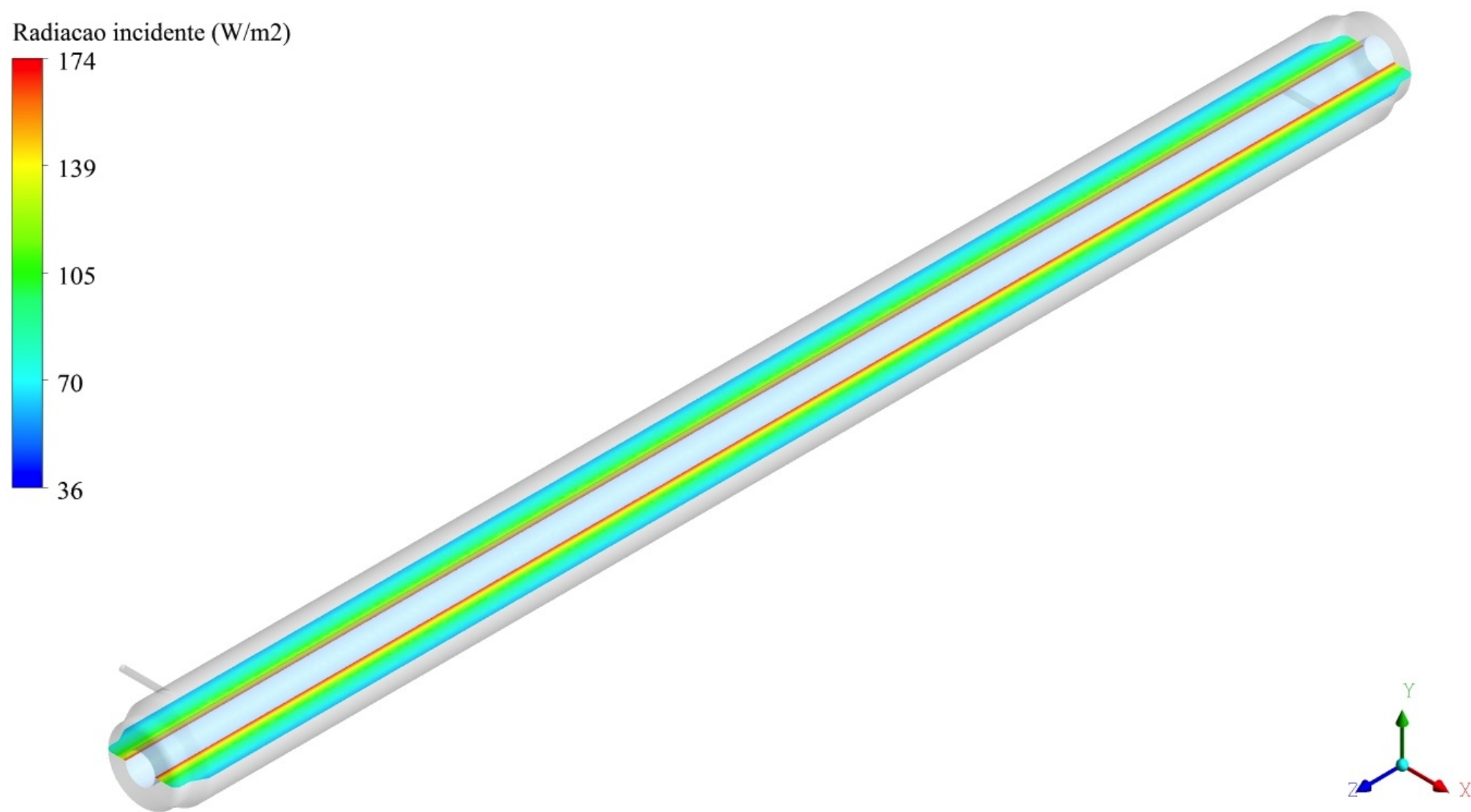

Figura 35. Campo de radiação típico para a configuração A1 determinado pelo modelo radial. 
A distribuição de espécies no reator foi afetada pelos campos de velocidade e de radiação. A Figura 36 mostra que os reagentes se concentram na região da parede externa do reator próximo à seção de entrada e depois migram para as vizinhanças da lâmpada, enquanto os produtos se difundem de forma oposta. Isso ocorre porque as velocidades do escoamento são maiores perto da parede devido ao efeito de entrada. A elevada intensidade de radiação perto da superfície da lâmpada gerou uma faixa estreita ao seu redor na qual a fotólise do $\mathrm{H}_{2} \mathrm{O}_{2}$ ocorreu com maior intensidade (Figura 38). Os radicais ${ }^{\bullet} \mathrm{OH}$ gerados nessa camada foram transportados para as regiões da parede externa por convecção. Isso faz com que parte significativa do fenol seja consumida na segunda metade do reator, conforme a Figura 37. Ocorreu também acúmulo do radical próximo à lâmpada na região da saída (Figura 39), já que o poluente nesta região já havia sido oxidado e a fotólise do $\mathrm{H}_{2} \mathrm{O}_{2}$ ainda prosseguia.

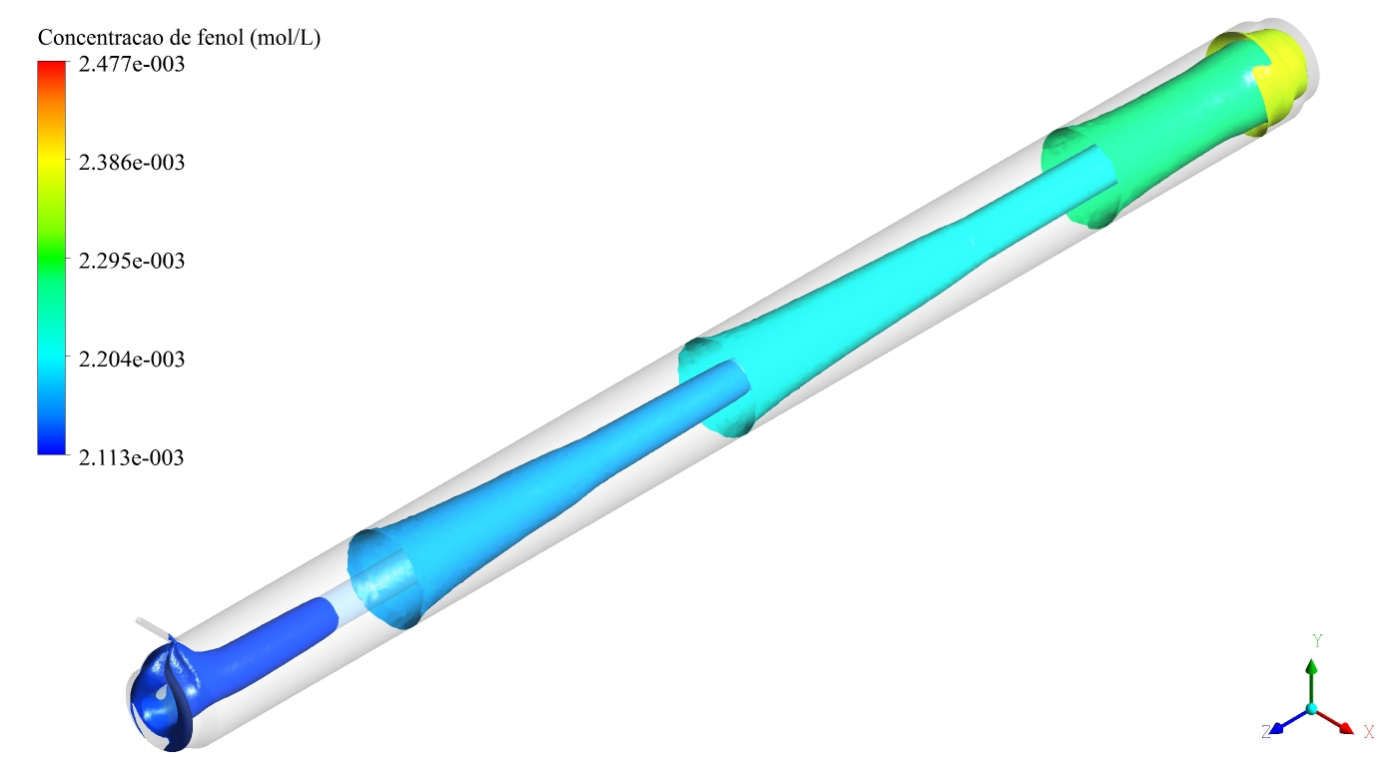

Figura 36. Distribuição de fenol no caso 1 simulado pelo modelo de campo radial e vista através de isosuperfícies de concentração molar. 


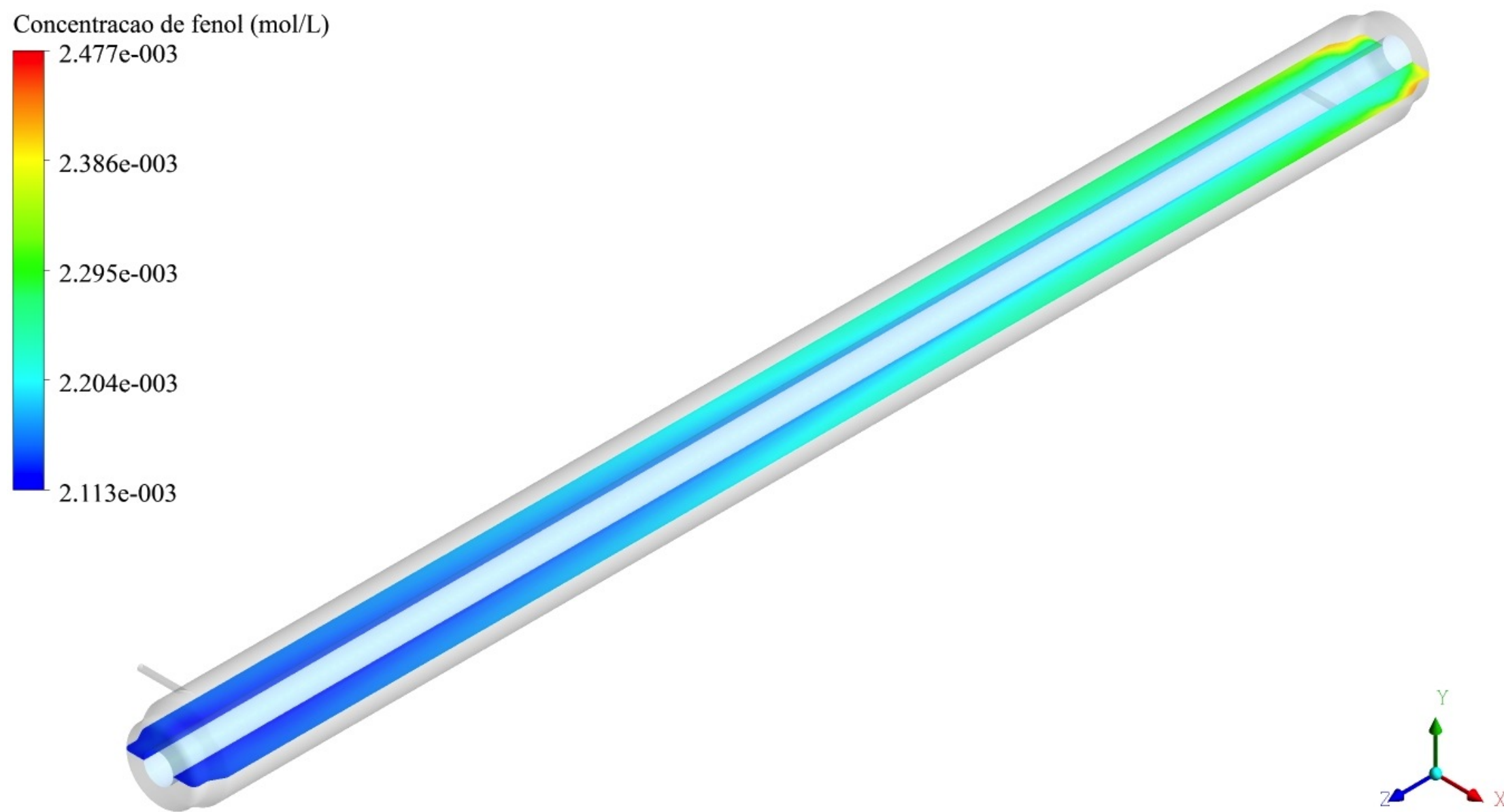

Figura 37. Perfil de concentração de fenol, para o caso de reação 1, com campo de radiação radial. 


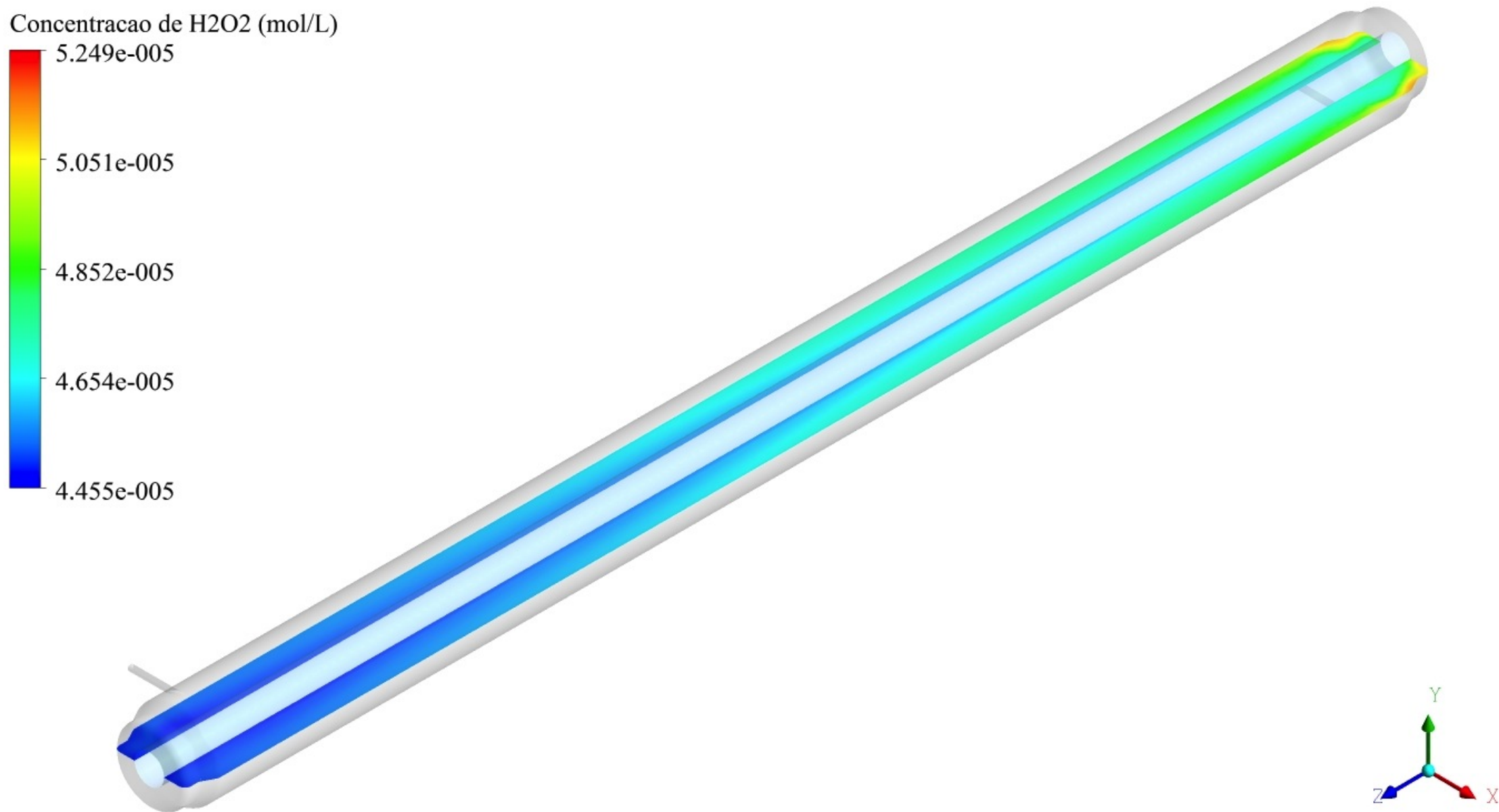

Figura 38. Perfil de concentração de $\mathrm{H}_{2} \mathrm{O}_{2}$ para o caso de reação 1, com campo de radiação radial. 


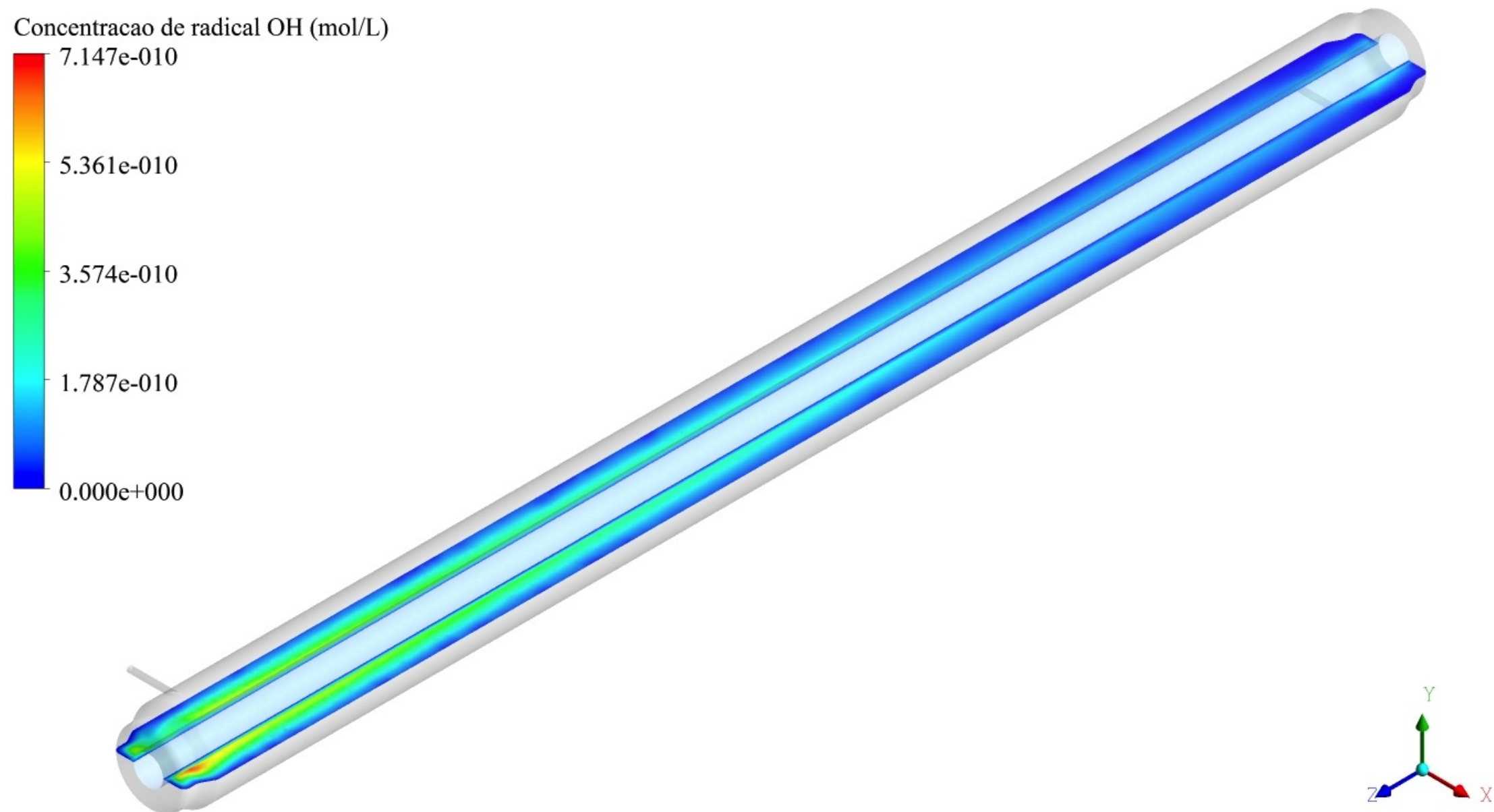

Figura 39. Perfil de concentração do radical hidroxila para o caso de reação 1, com campo de radiação radial. 


\subsubsection{Degradação de fenol pelo processo $\mathrm{UV} / \mathrm{H}_{2} \mathrm{O}_{2}$ com campo re- solvido pelo método discrete transfer}

O método discrete transfer (DT) resolve numericamente a RTE, eq. (2.50). Embora seja uma das formas mais sofisticadas de determinar o campo de radiação, não houve aumento do tempo de processamento gasto para convergir em relação ao modelo radial, considerando a opção padrão de 8 raios para aquele. Reforça-se então a importância de um tratamento adequado aos balanços de massa stiff para garantir o sucesso e otimização do processo de converêwncia de reações radicalares inseridas em códigos de CFD. O desempenho do modelo do reator em CFD para o método DT está indicado na Tabela 24.

O campo de radiação obtido pelo método DT (Figura 42), possui um perfil diferente do radial. Embora ainda possa se considerar poucas variações ao longo do eixo axial, o perfil radial não decai tão rapidamente como no caso anterior. A Figura 40 indica o perfil típico encontrado, que é semelhante ao obtido por (QI et al., 2011) usando um reator com geometria diferente e processo heterogêneo de degradação, mas determinando o campo pelo mesmo método (Figura 41). Outras diferenças notáveis são:

- a ordem de grandeza do campo: o método DT previu que a radiação incidente tem uma ordem de grandeza a mais que o modelo radial;

- o contorno do campo nas extremidades da lâmpada, indicando claramente a diferença entre as duas estratégias de modelagem. Sozzi e Taghipour (2006b) verificaram o mesmo fato ao comparar o modelo radial com o modelo MSSS. 
Tabela 24. Resultados do modelo computacional de degradação de fenol pelo processo UV/ $\mathrm{H}_{2} \mathrm{O}_{2}$ para experimentos de Tambani (2011), considerando o mecanismo proposto por Edalatmanesh, Dhib e Mehrvar (2008) e campo de radiação obtido pelo método discrete transfer.

\begin{tabular}{|c|c|c|c|c|c|c|}
\hline \multirow[t]{2}{*}{ Caso } & \multirow{2}{*}{$\begin{array}{l}\text { Configuração } \\
\text { do reator }\end{array}$} & \multirow{2}{*}{$\begin{array}{l}\text { Concentração } \\
\text { inicial de fenol } \\
\qquad\left(\mathrm{mg} \mathrm{L}^{-1}\right)\end{array}$} & \multirow{2}{*}{$\begin{array}{l}\text { Razão molar } \\
\mathrm{H}_{2} \mathrm{O}_{2} / \text { fenol }\end{array}$} & \multicolumn{2}{|c|}{$\begin{array}{l}\text { Concentração de fenol no } \\
\text { efluente do reator }\left(\mathrm{mg} \mathrm{L}^{-1}\right)\end{array}$} & \multirow{2}{*}{$\begin{array}{c}\text { Desvio em } \\
\text { relação ao } \\
\text { experimental }(\%)\end{array}$} \\
\hline & & & & modelo em CFD & experimental & \\
\hline 1 & $\mathrm{~A} 2$ & 233,12 & 47,1 & 197,21 & 189,76 & 3,93 \\
\hline 2 & $\mathrm{~A} 2$ & 274,48 & 5,05 & 228,14 & 215,26 & 5,98 \\
\hline 3 & A2 & 479,40 & 30,22 & 410,22 & 400,93 & 2,32 \\
\hline 4 & $\mathrm{~A} 2$ & 77,268 & 14,23 & 46,79 & 42,08 & 11,19 \\
\hline 5 & $\mathrm{~A} 2$ & 469,72 & 13,76 & 395,83 & 413,13 & 4,19 \\
\hline 6 & $\mathrm{~B}$ & 304,65 & 34,77 & 265,36 & 261,18 & 1,60 \\
\hline 7 & A1 & 378,82 & 23,97 & 320,82 & 342,58 & 6,35 \\
\hline 8 & $\mathrm{~B}$ & 292,34 & 16,1 & 251,73 & 249,55 & 0,87 \\
\hline 9 & $\mathrm{~A} 2$ & 232,18 & 26,62 & 196,18 & 191,00 & 2,71 \\
\hline
\end{tabular}




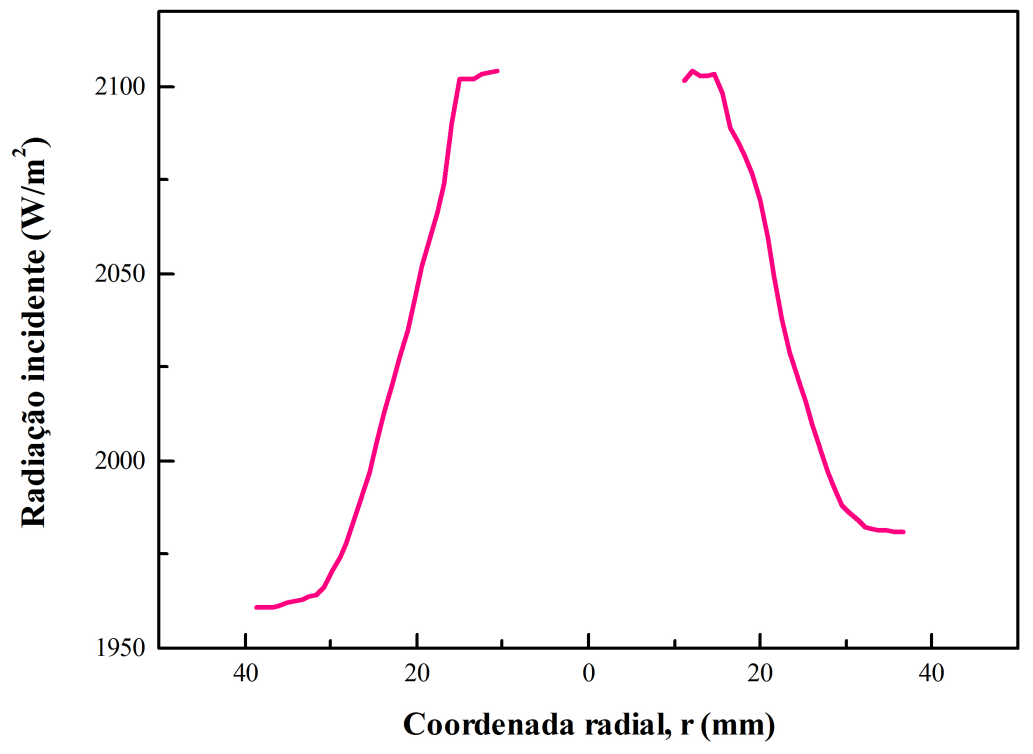

Figura 40. Perfil do campo de radiação na seção transversal $z=60 \mathrm{~cm}$ para o caso de reação 1, determinado pelo método discrete transfer.

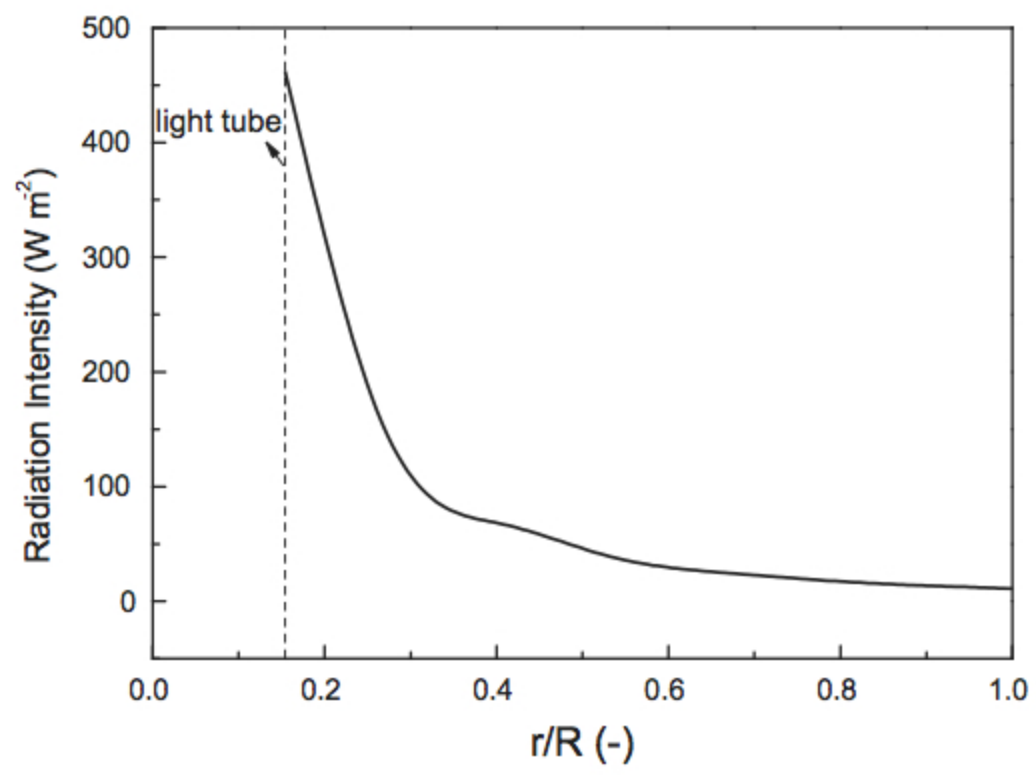

Figura 41. Perfil radial do campo determinado por Qi et al. (2011) na degradação de poluentes orgânicos pelo processo $\mathrm{TiO}_{2} / \mathrm{UV}$ e usando o método discrete transfer. 


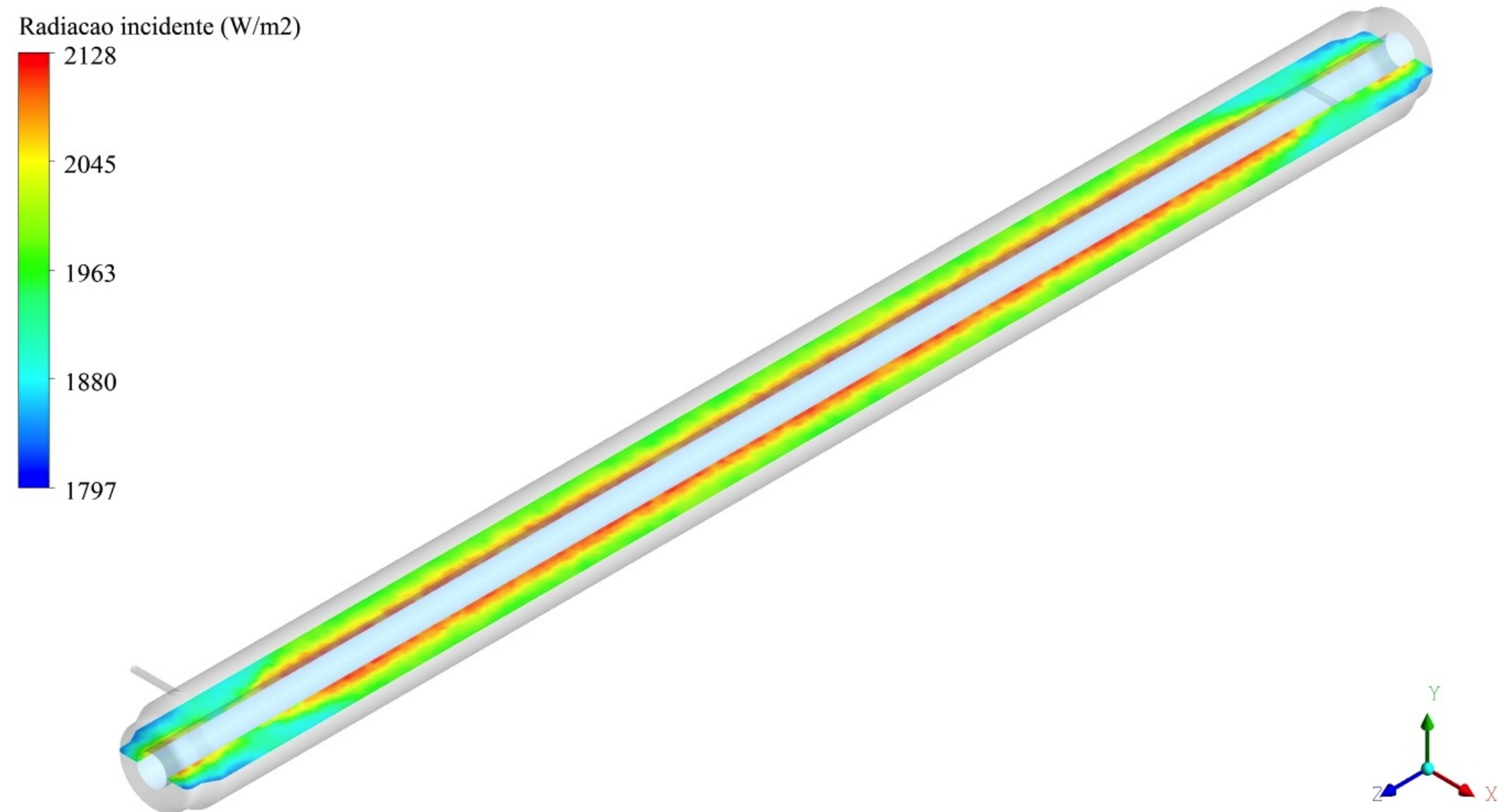

Figura 42. Campo de radiação típico da configuração A1 para solução da RTE pelo método discrete transfer. 
A distribuição de fenol e de $\mathrm{H}_{2} \mathrm{O}_{2}$ previstas com o método DT (Figuras 43 e 44, respectivamente) seguiram as mesmas conclusões dessas espécies para o modelo radial. Contudo, a concentração do radical hidroxila, embora com perfil semelhante, apresentou valores três ordens de grandeza superior ao campo radial devido à maior intensidade de radiação prevista pelo método DT. A concentração de fenol na saída da parede ficou mais homogênea, o que indica um maior grau de homogeneidade, resultado de uma melhor irradiação ao longo do reator.

Comparando os resultados de conversão de fenol para as duas estratégias de modelagem do campo de radiação, não foram observadas diferenças significativas entre elas. O método DT leva a resultados mais próximos dos experimentais na maioria dos casos simulados, embora sua conversão seja pouco maior que a do modelo radial (Figuras 46 a 48). Todavia, não é possível afirmar categoricamente qual deles representa melhor o sistema porque não há medidas exclusivas da intensidade de radiação em seu interior. Assim, também não é possível afirmar qual das distribuições de radical • $\mathrm{OH}$ é mais próxima da realidade (inclusive pela falta de técnicas para mapear essa espécie no interior do reator). Conclui-se então que os dois modelos reproduziram bem os dados experimentais. 


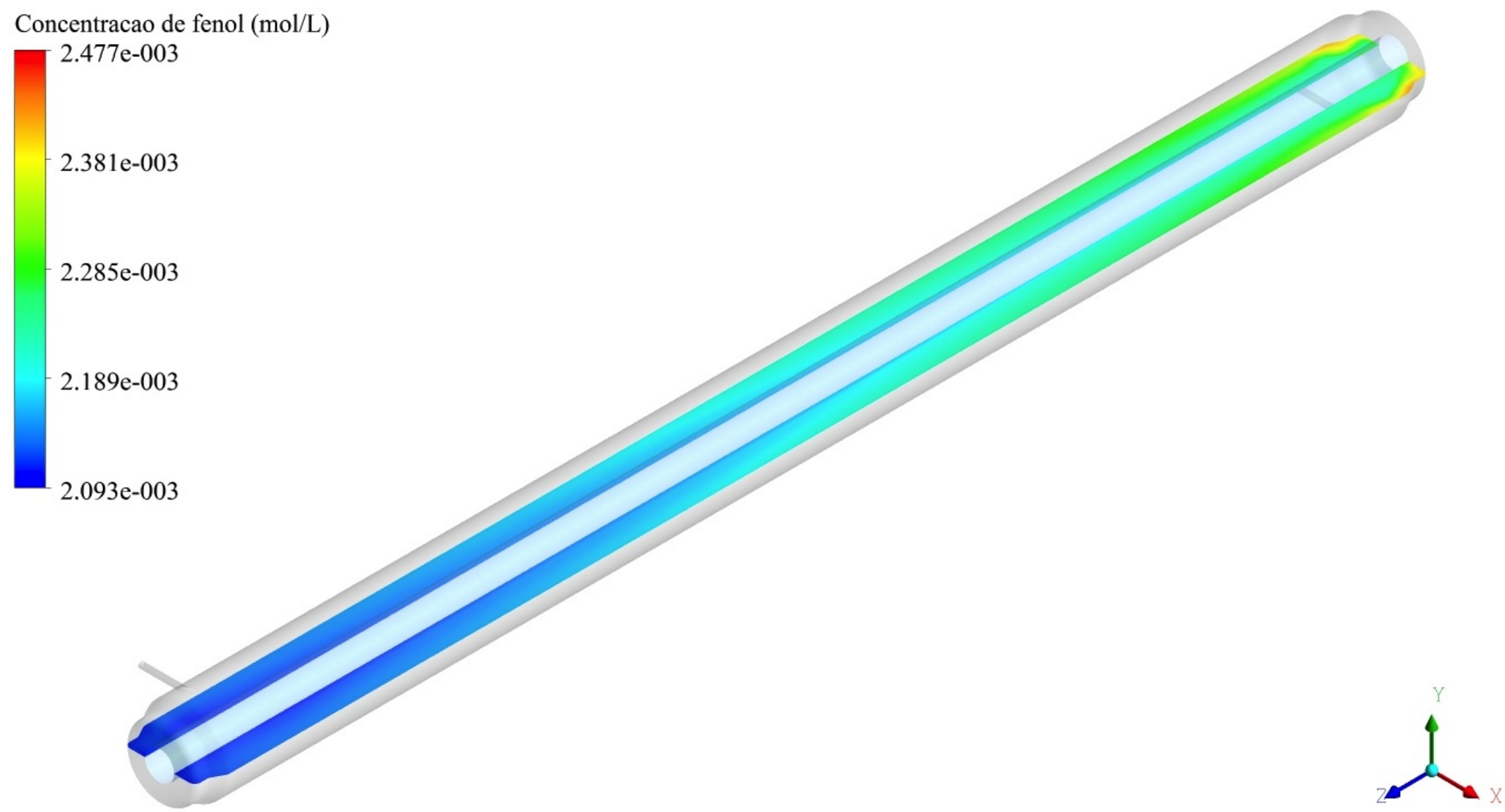

Figura 43. Perfil de concentração de fenol, para o caso de reação 1, com campo de radiação resolvido pelo método discrete transfer. 


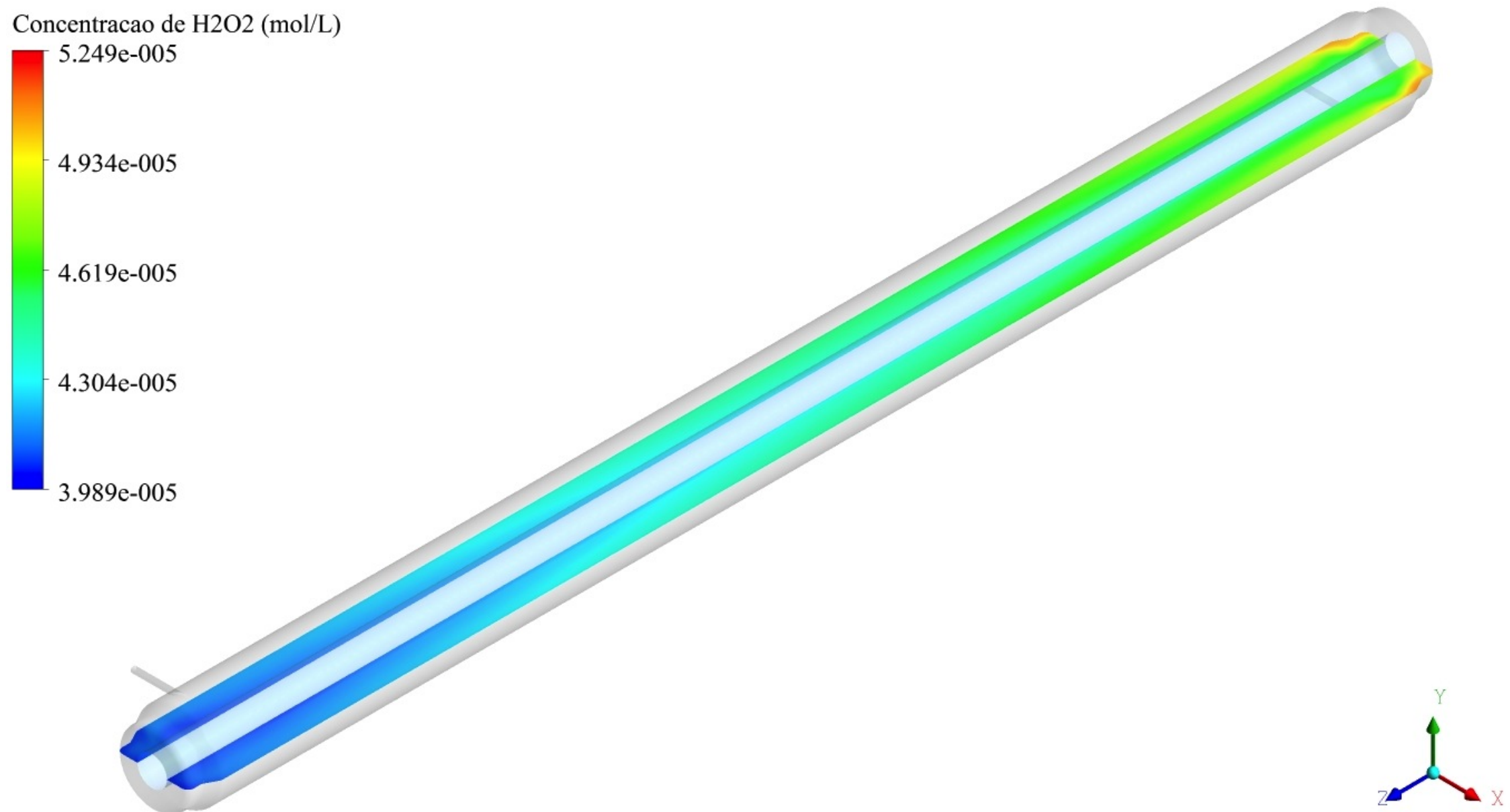

Figura 44. Perfil de concentração de $\mathrm{H}_{2} \mathrm{O}_{2}$ para o caso de reação 1, com campo de radiação resolvido pelo método discrete transfer. 


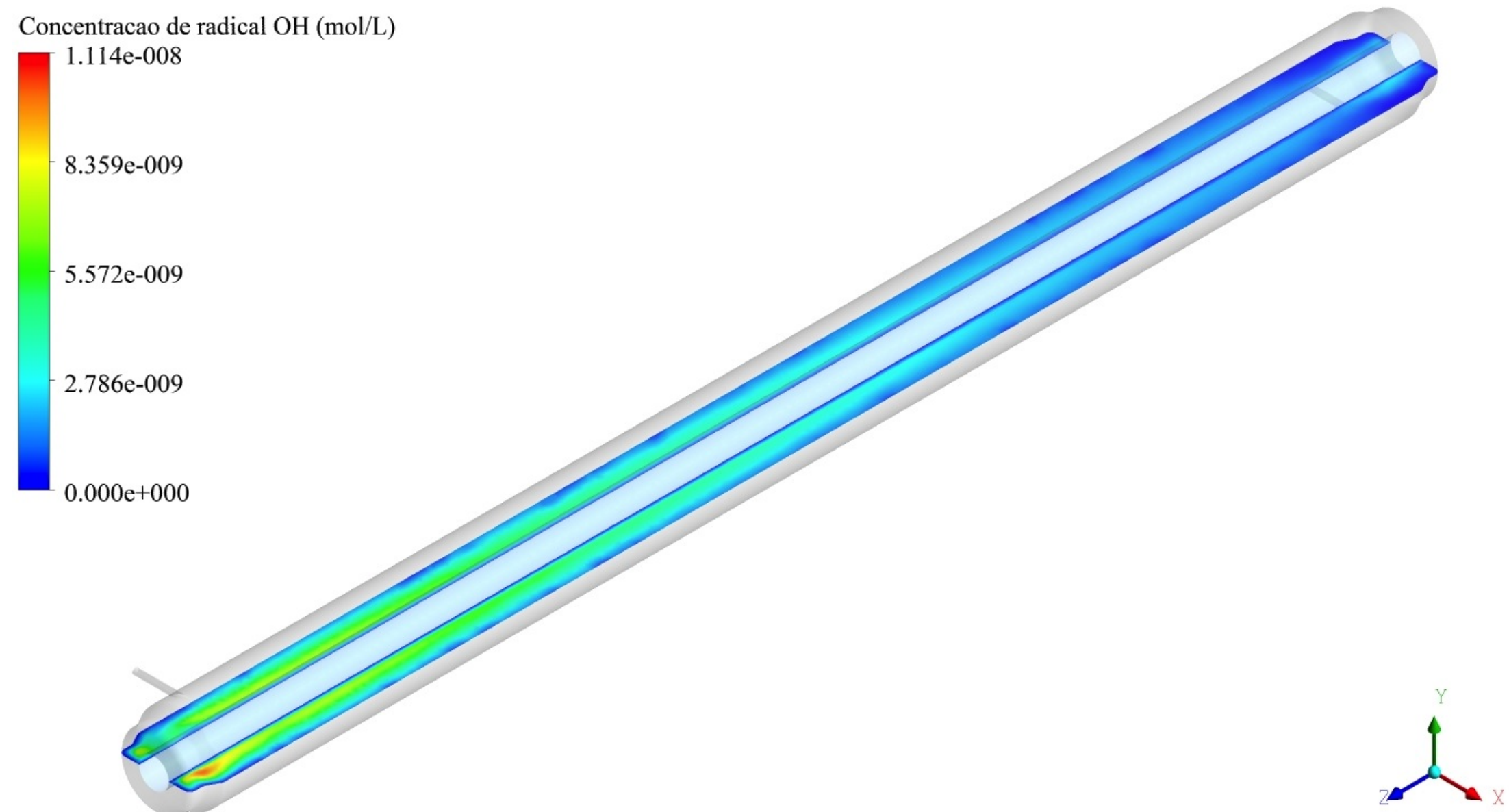

Figura 45. Perfil de concentração do radical hidroxila para o caso de reação 1, com campo de radiação resolvido pelo método discrete transfer. 
Vale ressaltar que as simulações considerando pseudocinética tiveram desvio em relação ao experimental menor que as simulações empregando o mecanismo de Edalatmanesh, Dhib e Mehrvar (2008). Isso se deve em parte ao fato das pseudoconstantes adotadas terem sido calculadas a partir dos próprios cenários simulados. Além disso, não se pode afirmar que é preferível então considerar o modelo de pseudoconstantes como sendo superior aos demais estudados. O grande mérito do trabalho foi reproduzir bem os dados experimentais usando um modelo cinético concebido a partir de experimentos em reatores muito diferentes do analisado e com modelos para o campo de radiação que apresentam aproximações e limitações. Tais modelos são fundamentais para investigar cenários de mudanças no design do reator, aumento de escala e outras situações nas quais não se disponha do sistema experimental construído para levantar pseudoconstantes, e justificam o emprego de CFD como ferramenta para análise e projeto de equipamentos.

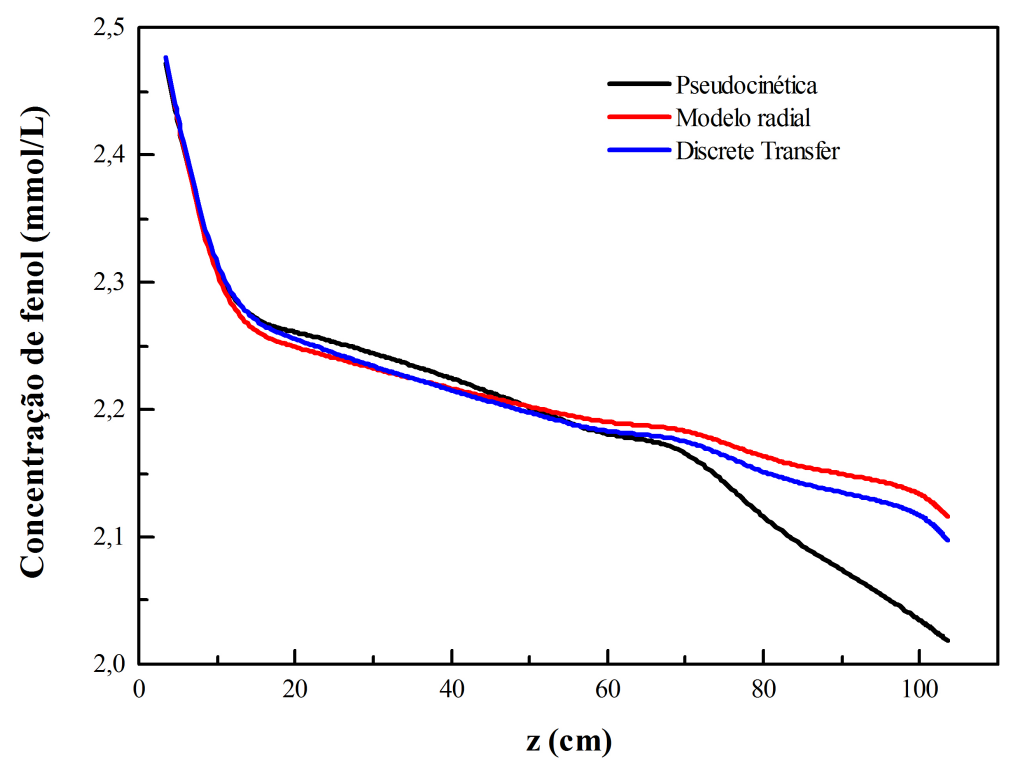

Figura 46. Comparação entre os três modelos cinéticos para degradação de fenol pelo processo $\mathrm{UV} / \mathrm{H}_{2} \mathrm{O}_{2}$, para o caso de reação 1 . 


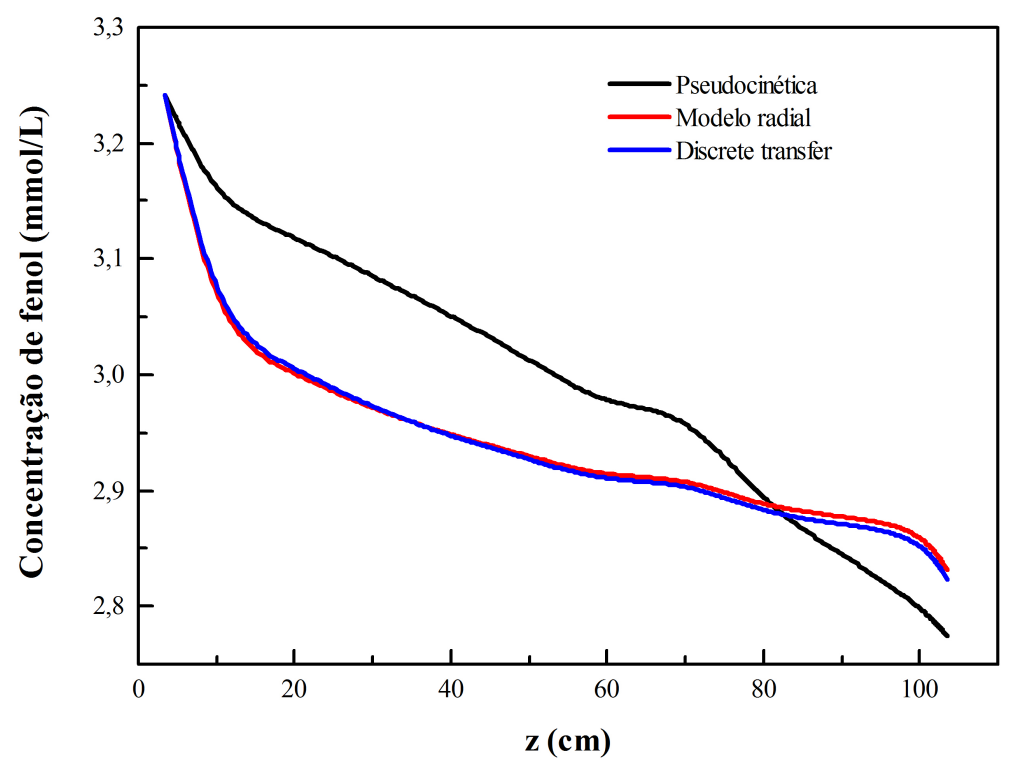

Figura 47. Comparação entre os três modelos cinéticos para degradação de fenol pelo processo $\mathrm{UV} / \mathrm{H}_{2} \mathrm{O}_{2}$, para o caso de reação 6 .

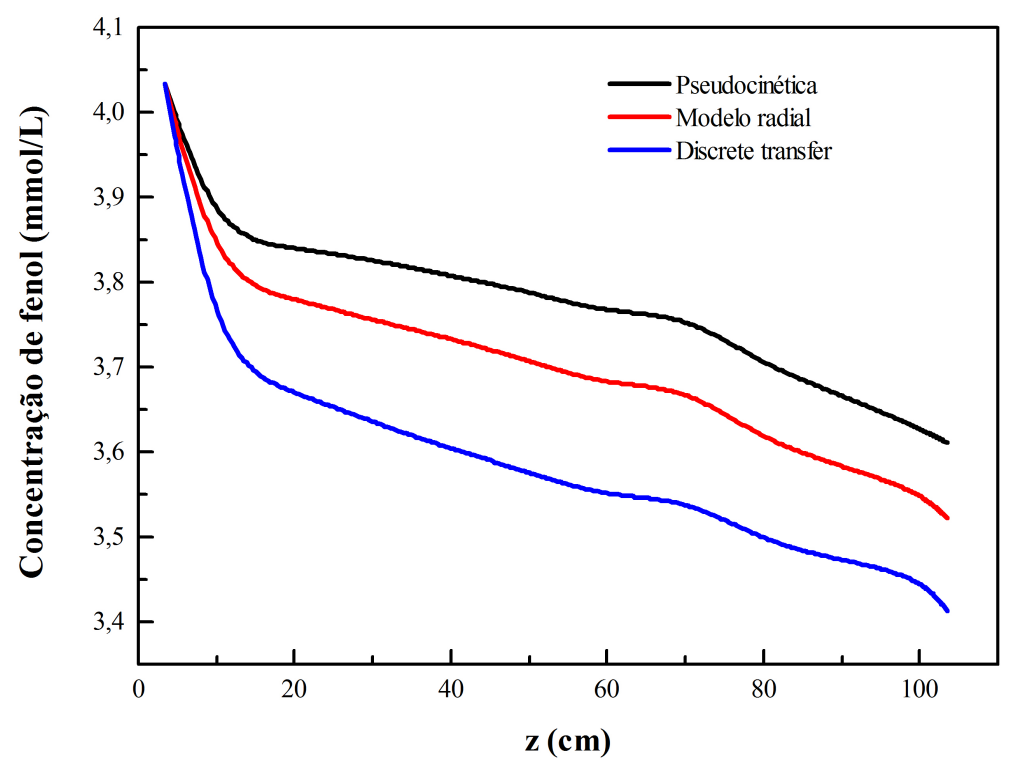

Figura 48. Comparação entre os três modelos cinéticos para degradação de fenol pelo processo $\mathrm{UV} / \mathrm{H}_{2} \mathrm{O}_{2}$, para o caso de reação 7 . 


\section{CONCLUSÕES E RECOMENDAÇÕES}

\subsection{Conclusões do trabalho}

- O modelo computacional do reator reproduziu bem as curvas de distribuição de tempos de residência experimentais, geradas a partir dos campos de velocidade obtidos em estado estacionário;

- O escoamento no reator é dependente da vazão de alimentação. O posicionamento tangencial dos tubos de entrada e saída faz com que o fluido tenha velocidades maiores próximo à parede e atenua os efeitos de turbulência e backmixing em relação à configuração tradicional em U;

- O modelo $k-\omega$ é o mais adequado para descrever o escoamento no reator. O modelo $k-\epsilon$ falha porque o escoamento é rotativo e num espaço anular com distância pequena entre as paredes. Os modelos SST e RSM também representaram bem as curvas de DTR, porém seu custo computacional é maior que o do $k-\omega$

- Utilizar pseudocinética para representar a degradação de fenol levou a resultados próximos das conversões de fenol experimentais. A estratégia é útil quando se dispõe do equipamento real para levantar dados cinéticos;

- O mecanismo de fotodegradação do fenol é composto por um conjunto de equações que possuem altos valores de constantes cinéticas. Isto resulta em um sistema stiff, que deve ser simulado com coeficientes de relaxação de pelo menos 
$10^{12} \mathrm{~kg} \mathrm{~m}^{-3} \mathrm{~s}^{-1}$. O ânion radical superóxido é a espécie que requer maior relaxação. Passo de $10^{-5} \mathrm{~s}$ é suficiente para a simulação, podendo ser menor dependendo do coeficiente de relaxação;

- O formato helicoidal do escoamento para reações simples faz com que os reagentes fiquem concentrados na região da parede e migrem para as vizinhanças da lâmpada ao longo do reator, enquanto os produtos se difundem na direção oposta;

- A elevada intensidade de radiação incidente próxima à lâmpada faz com que a taxa de fotólise do próxido de hidrogênio seja elevada nessa regiao. Os radicais hidroxila resultantes são transportados pelo movimento helicoidal do fluido e causam degradação significativa de fenol na segunda metade do reator;

- O modelo de campo radial e o método discrete transfer, combinados a um mecanismo cinético realista, foram capazes de reproduzir adequadamente a degradação de fenol pelo processo $\mathrm{UV} / \mathrm{H}_{2} \mathrm{O}_{2}$. A intensidade de radiação prevista pelo primeiro é menor que a do segundo, o que se refletiu na diferente ordem de grandeza obtida para o radical hidroxila pelos dois métodos. Não é possível avaliar qual é mais próximo da realidade por falta de recursos experimentais;

- Foi possível aplicar CFD no estudo do escoamento reativo e usar os dados macroscópicos para avaliar o modelo computacional.

\subsection{Recomendações para trabalhos futuros}

A vantagem de realizar um trabalho na área de simulação é que ele permite estabelecer cenários para avaliar fenômenos específicos do sistema estudado. Dessa forma, é possível planejar experimentos que ajudem a compreendê-los. No caso de um reator fotoquímico, os principais pontos a investigar são os campos de velocidades e o de radiação e o treinamento de usuários. 
As plataformas de CFD já se mostraram uma das formas mais eficazes de analisar sistemas fotoquímicos. Para capacitar outros pesquisadores na área, pode-se analisar outros reatores do laboratório no CFX, agora que se tem conhecimento sobre o tratamento de reações fotoquímicas nele. Há também outras plataformas disponíveis no CESQ, como o FLUENT (ANSYS Inc., Canonsburg, Estados Unidos) e o OpenFOAM (OpenCFD Ltd., Bracknell, Inglaterra), cujo uso enriqueceria não só o grupo de fotoquímica, mas também o de usuários de CFD. A recente aquisição de um cluster contribui para a distribuição da carga de processamento, garantindo capacidade computacional para simulações robustas e disponibilidade de licenças para múltiplos usuários.

O campo de velocidades foi validado pela DTR de forma satisfatória. Para obter ainda mais informações sobre a fluidodinâmica do sistema e avaliar melhor os modelos de turbulência poderia ser adquirido um equipamento de PIV. Ele fornece imagens do campo de velocidades experimental do sistema e pode ser empregado em outros equipamentos, diluindo assim seu custo. Seria também um reforço para as atividades dos grupos de CFD e de Fenômenos de Transporte, e um estímulo para que este se aprofundasse ainda mais na cadeira de turbulência.

As reações de degradação de poluentes orgânicos pelo processo $\mathrm{UV} / \mathrm{H}_{2} \mathrm{O}_{2}$ são basicamente as mesmas, variando apenas os intermediários orgânicos formados (i.e., as reações da Tabela 2 independem da espécie oxidada). Seria imediato então adaptar os modelos desenvolvidos neste trabalho para outros poluentes investigados pelo grupo, bastando alterar as reações de ataque do radical hidroxila e os dados experimentais para validação. Outro ponto interessante seria incluir a formação de intermediários no modelo computacional, como o catecol e hidroquinona no caso do fenol. Houve uma tentativa de inclui-los neste trabalho, porém os dados experimentais de Tambani (2011) não foram suficientes para validar adequadamente as concentrações de intermediários: eles só começaram a ser monitorados em períodos superiores a um tempo 
de residência. Recomenda-se então verificar a viabilidade de monitorá-los junto com o poluente em intervalos de tempo inferiores ao tempo de residência para validar as simulações.

Tambani (2011) empregou vazões com variação de $\pm 10 \mathrm{~L} \mathrm{~h}^{-1}$ em torno do ponto central e lâmpadas com potência de emissão no UVC muito próximas entre si, apesar da diferença de potência elétrica. Seria interessante realizar experimentos de degradação com maior variação de vazões, como as adotadas por Silvio et al. (2011), e com lâmpadas com diferença de emissão mais significativa. A influência da entrada tangencial poderia ser verificada construindo novos protótipos do reator com dimensões diferentes das atuais.

Finalmente, o ponto em que mais se pode avançar é na caracterização do campo de radiação. A melhor opção seria instalar sensores para medir a intensidade de radiação em pontos específicos do reator, permitindo validar o modelo do campo de forma independente do modelo cinético de degradação do poluente. Seguindo a linha de investigação baseada em técnicas de estímulo e resposta adotada pelo CESQ, outra opção seria realizar experimentos de DTR com um traçador que sofra fotólise pela radiação UVC e que não seja atacado pelos produtos da reação. É suficiente que a curva de DTR tenha boa resolução, mesmo que a degradação do tracádor seja pequena. A fotólise não é uma reação numericamente stiff, de modo que sua simulação transiente é viável. Caso ocorra alguma reação radicalar após a fotólise, o elevado tempo de processamento praticamente inviabiliza a simulação. É por essa razão que o uso de $\mathrm{H}_{2} \mathrm{O}_{2}$ como traçador não é interessante do ponto de vista computacional. 


\section{REFERÊNCIAS}

ALNAIZY, R.; AKGERMAN, A. Advanced oxidation of phenolic compounds. Advances in Environmental Research, v. 4, p. 233-244, 2000.

ALPERT, S. M.; KNAPE, D. R. U.; DUCOSTE, J. J. Modeling the UV/hydrogen peroxide advanced oxidation process using computational fluid dynamics. Water Research, v. 44, n. 6, p. 1798-1808, 2010.

ANSYS INC. CFX-Solver Theory Guide. Canonsburg, 2010. CD-ROM.

BAGAJEWICZ, M. A review of recent design procedures for water networks in refineries and process plants. Computers $\mathcal{E}$ Chemical Engineering, v. 24, n. 9-10, p. 2093-2113, 2000.

BIRD, R. B.; STEWART, W. E.; LIGHTFOOT, E. N. Fenômenos de Transporte. $2^{\mathrm{a}}$. ed. Rio de Janeiro: LTC - Livros Técnicos e Científicos, 2004.

BRASIL. Agência Nacional de Águas. Conjuntura dos Recursos Hídricos no Brasil: Informe 2011. Brasília, 2011.

BRAUN, A. M.; MAURETTE, M. T.; OLIVEROS, E. Photochemical Technology. Hoboken: John Wiley \& Sons, Inc., 1991.

BRENAN, K. E.; CAMPBELL, S. L.; PETZOLD, L. R. Numerical solution of initial-value problems in differential-algebraic equations. [S.1.]: Elsevier, 1989.

CARVALHO, M. G.; FARIAS, T. L. Modelling of heat transfer in radiating and combusting systems. Transactions of the Institution of Chemical Engineers, v. 76, p. 175-184, 1998.

CASSANO, A. E. et al. Photoreactor analysis and design: Fundamentals and applications. Industrial $\mathcal{E}$ Engineering Chemistry Research, v. 34, n. 7, p. 2155-2201, 1995.

CHUNG, T. J. Computational fluid dynamics. [S.1.]: Cambridge University Press, 2002 .

COELHO, P. J.; CARVALHO, M. G. A conservative formulation of the discrete transfer method. Transactions of the ASME, v. 119, n. ?, p. 118-128, 1997.

CRITTENDEN, J. C. et al. A kinetic model for $\mathrm{H}_{2} \mathrm{O}_{2} / \mathrm{UV}$ process in a completely mixed batch reactor. Water Research, v. 33, n. 10, p. 2315-2328, 1999.

DANCKWERTS, P. V. Continuous flow systems - distribution of residence times. Chemical Engineering Science, v. 2, n. 1, p. 1-18, 1958. 
DE, A. K.; BHATTACHARJEE, S.; DUTTA, B. K. Kinetics of phenol photooxidation by hydrogen peroxide and ultraviolet radiation. Industrial $\mathcal{F}$ Engineering Chemistry Research, v. 36, n. 9, p. 3607-3612, 1997.

EDALATMANESH, M.; DHIB, R.; MEHRVAR, M. Kinetic modeling of aqueous phenol degradation by $\mathrm{UV} / \mathrm{H}_{2} \mathrm{O}_{2}$ process. International Journal of Chemical Kinetics, v. 40, p. 34-43, 2008.

ESPLUGAS, S. et al. Comparison of different advanced oxidation processes for phenol degradation. Water Research, v. 36, n. 4, p. 1034-1042, 2002.

ESTADOS UNIDOS. Environmental Protection Agency. Handbook on Advanced Photochemical Oxidation Processes. Cincinnati, 1998.

FELDHEIM, V.; LYBAERT, P. Solution of radiative heat transfer problems with the discrete transfer method applied to triangular meshes. Journal of Computational and Applied Mathematics, v. 168, p. 179-190, 2004.

FIGAWA. Processos de Oxidação por Via Úmida Ativada para eliminação de substâncias persistentes contidas na água e em efluentes. [S.1.], 1997.

FOGLER, H. S. Elements of Chemical Reaction Engineering. Upper Saddle River: Prentice-Hall PTR, 2006.

GREEN, D. W.; PERRY, R. H. (Ed.). Perry's Chemical Engineers' Handbook. 8th. ed. New York: McGraw-Hill, 2008.

GUPTA, V. K. et al. Removal of rhodamine B, fast green and methylene blue from wastewater using red mud, an aluminum industry waste. Industrial $\mathcal{F}$ Engineering Chemistry Research, v. 43, p. 1740-1747, 2004.

HASSEMER, M. E. N. Oxidação fotoquímica - $U V / \mathrm{H}_{2} \mathrm{O}_{2}$ - para degradação de poluentes em efluentes da indústria têxtil. Tese (Doutorado) - Departamento de Engenharia Sanitária e Ambiental, Universidade Federal de Santa Catarina, Florianópolis, 2006.

HUANG, C.; SHU, H. The reaction kinetics, decomposition pathways and intermediate formations of phenol in ozonation, $\mathrm{UV} / \mathrm{O}_{3}$ and $\mathrm{UV} / \mathrm{H}_{2} \mathrm{O}_{2}$ processes. Journal of Hazxardous Materials, v. 41, p. 45-64, 1995.

HUTCHINSON, B. R.; RAITHBY, G. D. A multigrid method based on the additive correction strategy. Numerical Heat Transfer, v. 9, p. 511-537, 1986.

JACOB, S. M.; DRANOFF, J. S. Light intensity profiles in a perfectly mixed photoreactor. AIChE Journal, v. 16, n. 3, p. 359-363, 1970.

KIM, S.; VOGELPOHL, A. Degradation of organic pollutants by the photo-fenton process. Chemical Engineering E Technology, v. 21, n. 2, p. 187-191, 1998.

KOLMOGOROV, A. N. Equations of turbulent motion of an incompressible fluid. Izvestia Academy of Science, USSR; Physics, v. 6, n. 1-2, p. 56-58, 1942. 
LAAT, J. D. et al. Comparative study of the oxidation of antrazine and acetone by $\mathrm{H}_{2} \mathrm{O}_{2} / \mathrm{UV}, \mathrm{Fe}(\mathrm{III}) / \mathrm{H}_{2} \mathrm{O}_{2} / \mathrm{UV}$ and $\mathrm{Fe}(\mathrm{II})$ or $\mathrm{Fe}(\mathrm{III}) / \mathrm{H}_{2} \mathrm{O}_{2}$. Chemosphere, v. 39, n. 15, p. 2693-2706, 1999.

LAUNDER, B. E.; SPALDING, D. B. Mathematical Models of Turbulence. Londres: Academic Press, 1972.

. The numerical computation of turbulent flows. Computer Methods in Applied Mechanics and Engineering, v. 3, n. 2, p. 269-289, 1974.

LEVENSPIEL, O. The Chemical Reactor Omnibook. Corvallis: OSU Book Stores, Inc.,, 1988.

LIU, D. et al. Evaluation of alternative fluence rate distribution models. Journal of Water Supply: Research and Technology, v. 53, n. 6, p. 391-408, 2004.

. Numerical simutation of UV disinfection reactors: Evaluation of alternative turbulence models. Applied Mathematical Modelling, v. 31, n. 9, p. 1753-1769, 2007.

LOCKWOOD, F. C.; SHAH, N. G. A new radiation solution method for incorporation in general combustion prediction procedures. Eighteenth Symposium (International) on Combustion, v. 1, p. 1405-1414, 1981.

MAJUMDAR, S. A multigrid method based on the additive correction strategy. Numerical Heat Transfer, v. 13, p. 125-132, 1988.

MENTER, F. R. Two-equation eddy viscosity turbulence models for engineering applications. AAIA Journal, v. 32, n. 8, p. 1598-1605, 1994.

MENTER, F. R.; KUNTZ, M.; LANGTRY, R. Ten years of industrial experience with the SST turbulence model. In: HANJALIC, Y. N. K.; TIMMERS, M. (Ed.). Turbulence, Heat and Mass Transfer 4. Redding: Begell House, Inc., 2003.

MOHSENI, M.; TAGHIPOUR, F. Experimental and CFD analysis of photocatalytic gas phase vinyl chloride (VC) oxidation. Chemical Engineering Science, v. 59, p. 1601-1609, 2004.

MOULLEC, Y. L. et al. Flow field and residence time distribution of a cross-flow gas-liquid wastewater treatment reactor using CFD. Chemical Engineering Science, v. 63, n. 9 , p. 2436-2449, 2008.

OPPENLANDER, T. Photochemical Purification of Water and Air - Advanced Oxidation Processes (AOPs): Principles, Reaction Mechanisms, Reactor Concepts. Weinheim: Wiley-VCH, 2003.

PAREEK, V. K. et al. Computational fluid dynamic (CFD) simulation of a pilot-scale annular bubble column photocatalytic reactor. Chemical Engineering Science, v. 58, n. 3-6, p. 859-865, 2003.

PERES, J. C. G.; VIANNA JR., A. S. Simulação de reações em reator anular usando CFD. In: Congresso Brasileiro de Engenharia Química, 19., Búzios. Anais..., Rio de Janeiro: UFRJ, 2012. 1 CD-ROM. 
POULOPOULOS, S. G.; ARVANITAKIS, F.; PHILIPPOPOULOS, C. J.

Photochemical treatment of phenol aqueous solutions using ultraviolet radiation and hydrogen peroxide. Journal of Hazardous Materials, v. 123, n. 1-3, p. 64-68, 2005.

PRIMO, O. et al. Mathematical modelling of phenol photooxidation: Kinetics of the process toxicity. Chemical Engineering Journal, v. 134, p. 23-28, 2007.

QI, N. et al. CFD modelling of hydrodynamics and degradation kinetics in an annular slurry photocatalytic reactor for wastewater treatment. Chemical Engineering Journal, v. 172, n. 1, p. 84-95, 2011.

RANADE, V. V. Computational Flow Modeling for Chemical Reactor Engineering. San Diego: Academic Press, 2002.

SANTORO, D. et al. Modeling hydroxyl radical distribuition and trialkyl phosphates oxidation in $\mathrm{UV}-\mathrm{H}_{2} \mathrm{O}_{2}$ photoreacotrs using computational fluid dynamics.

Environmental Science $\mathcal{E}$ Technology, v. 44, n. 16, p. 6233-6241, 2010.

SHARPLESS, C. M.; LINDEN, K. G. Experimental and model comparison of lowand medium-pressure hg lamps for the direct and $\mathrm{H}_{2} \mathrm{O}_{2}$ assisted UV photodegradation of $N$-nitrosodimethylamine in simulated drinking water. Environmental Science $\mathcal{E}$ Technology, v. 37, n. 9, p. 1933-1940, 2003.

SHIH, T. H. et al. A new $k-\epsilon$ eddy viscosity model for high reynolds number turbulent flows - Model development and validation. Computers $\mathcal{E}$ Fluids, v. 24, n. 3 , p. 227-238, 1995.

SILVIO, U. de et al. Estudo do escoamento e caracterização actinométrica em um reator fotoquímico tubular com escoamento anular e fonte radiante concêntrica. In: Encontro sobre Aplicações Ambientais de Processos Oxidativos Avançados, 6., Rio de Janeiro. Anais..., Rio de Janeiro: UFRJ, 2011. 1 CD-ROM.

SOZZI, D. A.; TAGHIPOUR, F. Computational and experimental study of annular photo-reactor hydrodynamics. International Journal of Heat and Fluid Flow, v. 27, n. 6, p. 1043-1053, 2006.

UV reactor performance modeling by eulerian and lagrangian methods. Environmental Science E Technology, v. 40, p. 1609-1615, 2006.

SPEZIALE, C. G. Analytical methods for the development of Reynolds stress closures in turbulence - ICASE Report No. 90-26. Hampton: NASA, 1990.

SPEZIALE, C. G.; ABID, R.; ANDERSON, E. C. A critical evaluation of two-equation models for near wall turbulence - ICASE Report No. 90-46. Hampton: NASA, 1990.

TAMBANI, P. C. Estudo da degradação de fenol e seus intermediários pelo processo $\mathrm{UV} / \mathrm{H}_{2} \mathrm{O}_{2}$. Dissertação (Mestrado) - Escola Politécnica, Universidade de São Paulo, São Paulo, 2011. 
TEIXEIRA, C. P. de A. B.; JARDIM, W. de F. Processos oxidativos avançados conceitos teóricos. In: Caderno Temático. Campinas: Universidade Estadual de Campinas, 2004. v. 3.

TU, J. Y. Advanced CFD and raditraces techniques - a complementary technology for industrial multiphase applications. In: INTERNATIONAL ATOMIC ENERGY AGENCY (Ed.). Integration of tracing with computational fluid dynamics for industrial process investigation. Vienna: IAEA, 2008.

VERSTEEG, H. K.; MALALASEKERA, W. An Introduction to Computational Fluid Dynamics - The Finite Volume Method. Second edition. London: Prentice-Hall, 2007.

VIANNA JR., A. S. et al. Estimação de constantes cinéticas para poa de fenol. In: Encontro sobre Aplicações Ambientais de Processos Oxidativos Avançados, 6., Rio de Janeiro. Anais..., Rio de Janeiro: UFRJ, 2011. 1 CD-ROM.

WILCOX, D. C. Reassessment of the sclae determining equation for advanced turbulence models. AIAA Journal, v. 26, n. 11, p. 1299-1310, 1988. . Turbulence Modeling for CFD. La Cañada: DCW Industries, 1998.

WILCOX, D. C.; ALBER, I. E. A turbulence model for high speed flows. In: Proceedings of the 1972 Heat Transfer and Fluid Mechanics Institute. Stanford: Stanford University Press, 1972. p. 231-253.

WOLS, B. A. et al. A systematic approach for the design of UV reactors using computational fluid dynamics. AIChE Journal, v. 57, n. 1, p. 193-207, 2011.

WRIGHT, N. G.; HARGREAVES, D. M. The use of CFD in the evaluation of UV treatment systems. Journal of Hydroinformatics, 2001. 


\section{APÊNDICE A - DISTRIBUIÇÃO DE TEMPOS DE RESIDÊNCIA DO MODELO COMPUTACIONAL}

\section{A.1 Algoritmo para levantamento da DTR}

A distribuição de tempos de residência do modelo computacional foi levantada através da criação de um algoritmo em linguagem CEL (CFX Expression Language). Ele abrange a simulação de uma perturbação no tubo de entrada e a captura de seus efeitos na saída do reator.

A primeira parte do algoritmo consiste na criação de uma variável adicional Tracador. Suas propriedades de transporte são as mesmas do traçador usado experimentalmente. Neste trabalho, elas correspondem às do azul de metileno, obtidas de Gupta et al. (2004). É possível também criar um material novo na biblioteca e defini-lo com tais propriedades.

As curvas de DTR são obtidas através de perturbações na entrada do tipo pulso ou degrau. Matematicamente um pulso é definido pela função delta de Dirac, $\delta(t)$, e o degrau é dado por uma função constante transladada no tempo:

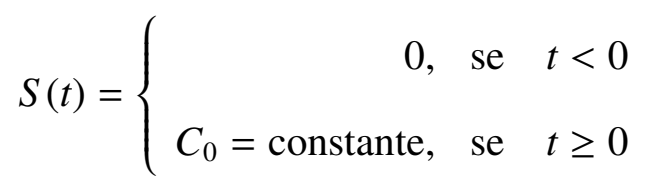


No limite, um pulso pode ser visto como um degrau de largura reduzida. É possível combiná-los na função pulso retangular, dada por

$$
f(t)=\left\{\begin{array}{rll}
0, & \text { se } & t<0 \\
C_{0}=\text { constante, } & \text { se } & 0 \leq t \leq \Delta t_{\text {in }} \\
0, & \text { se } & t>\Delta t_{\text {in }}
\end{array}\right.
$$

O pulso tem altura $C_{0}$ e largura $\Delta t_{i n}$. Esse tipo de sinal é usado para regular a alimentação de traçador no reator: sua vazão mássica é mantida em $C_{0}$ durante $\Delta t_{i n}$ unidades de tempo. A área abaixo da curva de $f(t)$ é a quantidade de traçador injetada ( $\left.=C_{0} \Delta t_{i n}\right)$. Trata-se de uma função versátil porque permite definir experimentos de pulso, tomando $\Delta t_{\text {in }} \rightarrow 0$, ou de degrau, fazendo $\Delta t_{\text {in }}$ maior que o tempo de análise do sistema.

Para introduzir o pulso retangular no CFX, criou-se um ponto de injeção no centro do tubo de entrada pelo comando source point. Na lista de opções de fonte para a variável Tracador no ponto de injeção, foi definida a expressão CEL

$$
\text { InjecaoTracador }=\text { CQ } \operatorname{step}(-t+\text { Tin })
$$

Nela, Tin é o tempo de injeção do traçador e step é a função degrau. Na simulação de um pulso, tal parâmetro é o tempo gasto pelo operador para pressionar o êmbolo da seringa. A vazão mássica de traçador, $C \otimes$, é calculada a partir do tempo de injeção, do volume de traçador adicionado e de sua concentração.

O registro da saída de traçador foi feito por outra expressão CEL, ativada na guia Monitor point da tela Solver control:

$$
\text { SaidaTracador=massAve(Tracador)@Saida }
$$

Ela calcula a vazão mássica média da variável Tracador na seção transversal no extremo do tubo de saída do reator, definida como a condição de contorno Saida. Ela corresponde ao ponto no qual as amostras de efluente do traçador foram tomadas no levantamento experimental da DTR. 


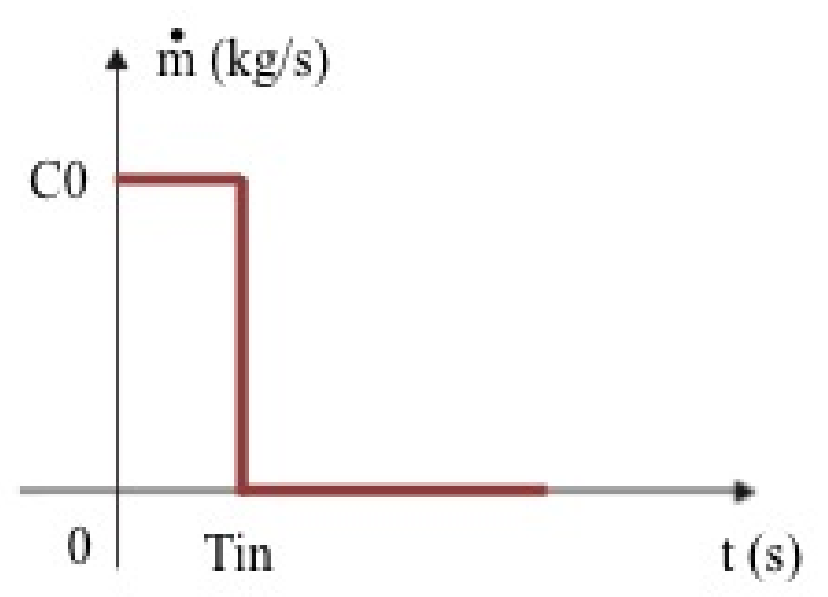

Figura 49. A função pulso retangular implementada para a injeção de traçador.

Para elevar a precisão do algoritmo, verificou-se que a discretização temporal deve dividir o intervalo de tempo de injeção, Tin, em uma certa quantidade de timesteps, ao invés de tomá-lo como o primeiro instante após $t_{0}=0$. Neste trabalho, não houve diferença de resultados entre as curvas obtidas com a discretização adotada na Tabela 14 e o controle automático da escala de tempo, que calcula o passo que mantenha o número de Courant igual a 5. O controle automático empregou passo de aproximadamente $1 \times 10^{-3} \mathrm{~s}$, elevando o tempo de processamento para três dias: o esquema proposto, baseado nos dados experimentais de Silvio et al. (2011), forrnece as curvas em cerca de $2 \mathrm{~h}$ com a mesma precisão.

\section{A.2 Curvas de DTR do modelo computacional}

Abaixo estão apresentadas as demais curvas de DTR levantadas no estudo. 


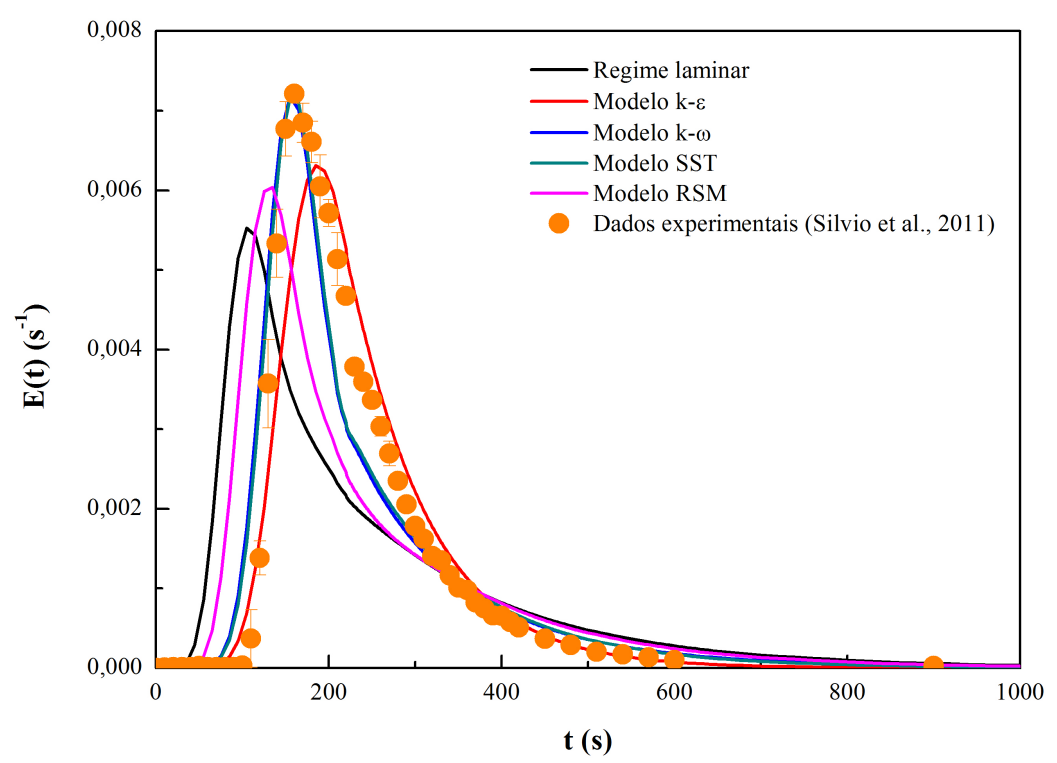

Figura 50. Validação do modelo computacional do escoamento no reator por meio da sua distribuição de tempos de residência, para as configurações A e vazão de $60 \mathrm{Lh}^{-1}$.

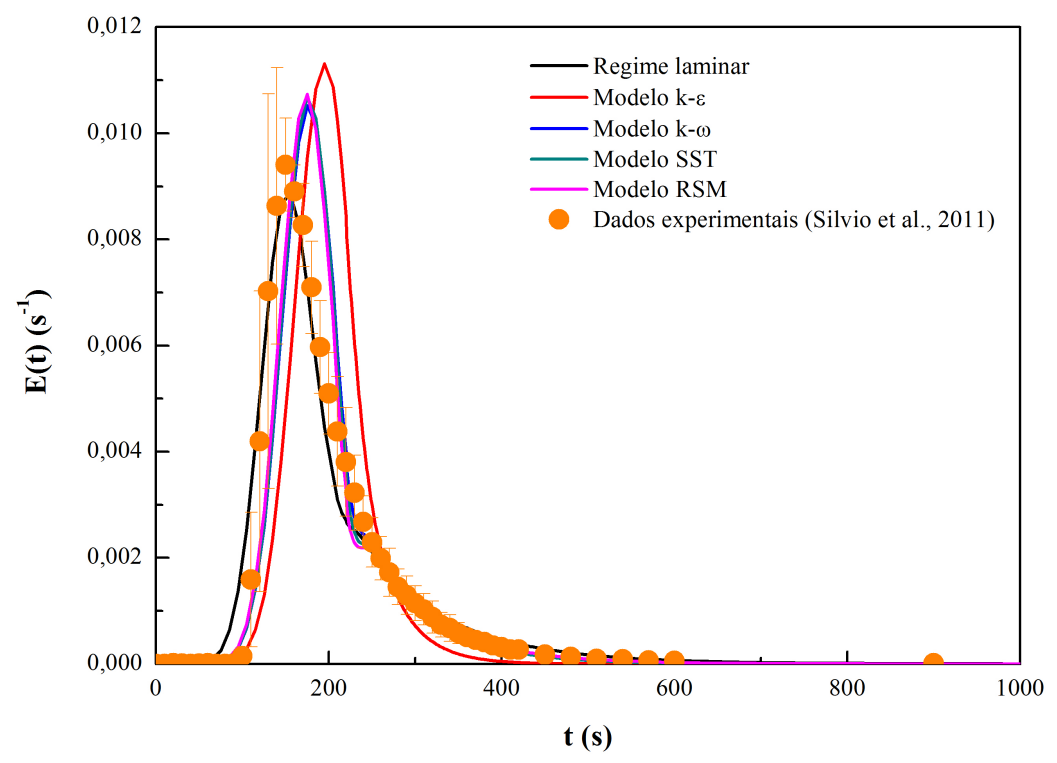

Figura 51. Validação do modelo computacional do escoamento no reator por meio da sua distribuição de tempos de residência, para a configuração $\mathrm{B}$ e vazão de $60 \mathrm{Lh}^{-1}$. 


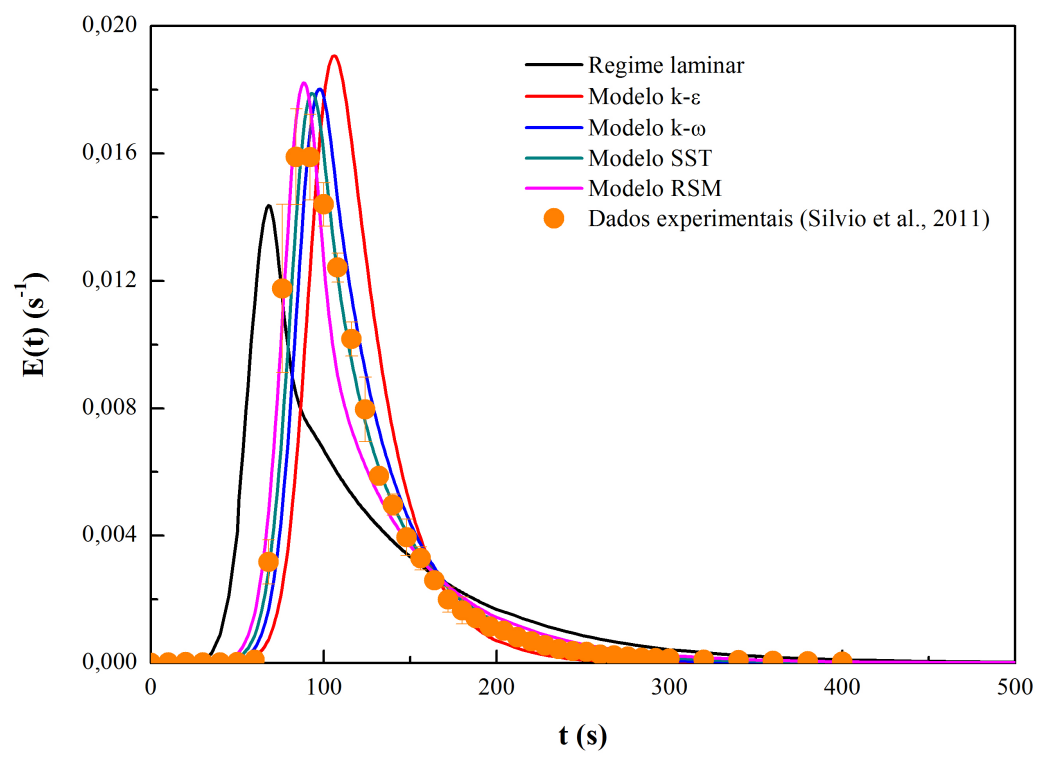

Figura 52. Validação do modelo computacional do escoamento no reator por meio da sua distribuição de tempos de residência, para a configuração B e vazão de $100 \mathrm{Lh}^{-1}$. 